\title{
Investigation of Combustion Phenomena in a Single-Cylinder Spark-Ignited Natural Gas Engine with Optical Access
}

Vishnu Padmanaban

Follow this and additional works at: https://researchrepository.wvu.edu/etd

\section{Recommended Citation}

Padmanaban, Vishnu, "Investigation of Combustion Phenomena in a Single-Cylinder Spark-Ignited Natural Gas Engine with Optical Access" (2016). Graduate Theses, Dissertations, and Problem Reports. 6367. https://researchrepository.wvu.edu/etd/6367

This Thesis is protected by copyright and/or related rights. It has been brought to you by the The Research Repository @ WVU with permission from the rights-holder(s). You are free to use this Thesis in any way that is permitted by the copyright and related rights legislation that applies to your use. For other uses you must obtain permission from the rights-holder(s) directly, unless additional rights are indicated by a Creative Commons license in the record and/ or on the work itself. This Thesis has been accepted for inclusion in WVU Graduate Theses, Dissertations, and Problem Reports collection by an authorized administrator of The Research Repository @ WVU. For more information, please contact researchrepository@mail.wvu.edu. 


\title{
Investigation of Combustion Phenomena in a Single-Cylinder Spark- Ignited Natural Gas Engine with Optical Access
}

\author{
Vishnu Padmanaban \\ Thesis submitted to the \\ Benjamin M. Statler College of Engineering and Mineral Resources \\ at West Virginia University \\ in partial fulfillment of the requirements \\ for the degree of \\ Master of Science \\ in \\ Mechanical Engineering \\ Cosmin Dumitrescu, Ph.D., Chair \\ Arvind Thiruvengadam, Ph.D. \\ V'yacheslav Akkerman, Ph.D. \\ Department of Mechanical and Aerospace Engineering \\ West Virginia University
}

Morgantown, West Virginia

July 2016

Keywords: IC engine, natural gas, spark ignition, optical engine, flame visualization

Copyright 2016 Vishnu Padmanaban 


\title{
ABSTRACT
}

\section{Investigation of Combustion Phenomena in a Single-Cylinder Spark- Ignited Natural Gas Engine with Optical Access \\ Vishnu Padmanaban}

\begin{abstract}
More demanding efficiency and emissions standards for internal combustion (IC) engines require novel combustion strategies, alternative fuels, and improved after-treatment systems. However, their development depends on improved understanding of in-cylinder processes. For example, the lower efficiency of conventional spark-ignited (SI) natural-gas (NG) engines reduces their utilization in the transportation sector. Single-cylinder optical-access research engines allow the use of non-intrusive visualization techniques that study in-cylinder flow, fuel-oxidizer mixing, and combustion and emissions phenomena under conditions representative of production engines. These visualization techniques can provide qualitative and quantitative answers to fundamental combustion-phenomena questions such as the effects of engine design, operating conditions, fuel composition, fuel delivery strategy, and ignition techniques.
\end{abstract}

The thesis is divided in two main parts. The first part focuses on the setup of a single-cylinder research engine with optical access including the design of its control system and the acquisition of in-cylinder pressure data and high-speed combustion images. The second part focuses on measurements of the turbulent flame speed using the high-speed combustion images. Crank-angle-resolved images of methane combustion were taken with a high-speed CMOS camera at a rate of 15,000 Hz. The optical engine was operated in a skip-firing mode (one fired cycle followed by 5 motored cycles) at 900 RPM and a load of 5.93 bar IMEP. The images show that flow turbulence and flame stretch resulted in flame velocities several order of magnitude higher compared to the laminar flame velocity. In addition, both in-cylinder pressure and optical data were used to determine the cycle-to cycle variability of the combustion phenomena. 


\section{Dedication}

This thesis is dedicated to my beloved parents, Dr.Padmanaban, and Beena Padmanaban 


\section{Acknowledgements}

First and foremost, I would like to thank my research advisor Dr. Cosmin Dumitrescu for his support, knowledge and all the friendship he shared with me right from the beginning. Everything he taught me both, in academics and building me as a person will surely stay with me and help me progress in my future career. His perseverance in work have always strongly motivated me to put in a lot of efforts and set an example to my colleagues in the laboratory. I am very grateful to him for teaching me the difference between a scientific and an engineering work, helping me start transforming into a good researcher. On a lighter note, I am very thankful to him for having funded me three long semesters in my master's study.

I would like to express my gratitude to Dan Carder for having initially hired me to the CAFEE, and help me settle down to work with optical engines research project. My heartfelt thanks are due to my committee member Dr. Arvind Thiruvengadam for having been a good friend and a wonderful source of inspiration. With his stature and knowledge, nobody I could think of to have been this modest, helpful and supportive to anybody who approaches him. I thank Dr. Slava Akkerman for having been so kind during my Teaching Assistantship days, and also for his time in reviewing my thesis - a very generous committee member, indeed.

Dr. Ross Ryskamp and Dr. Marc Besch - I thank you affectionately for having taught me immensely at the lab. My special thanks to Jesse Griffins, for developing the engine’s skip-firing controller. Dozens of other CAFEE members helped me to successfully finish up my thesis, and I am thankful to each and every one of them. Extraordinary engineers, inspiring senior students, and my dear graduate student colleagues, I thank you all very much.

Madhuri Vemulapalli, a best friend for my lifetime - I would like to thank her from the bottom of my heart for all the emotional support, comradery, motivation and care she has been providing me with. It was the strong bonding in the friendship that we shared, helped me face difficult times in the US. Nobody could replace your friendship and sisterhood, I believe. Sushmita, Aliya and Charan- these loving friends were like a second family to me. I still fondly cherish the time we spent at Twin Campus. Thanks for sharing all my happiest and troubled moments. My buddies -Satya and Shiva, without you guys the fun would not have been continuing so long. I thank the entire Indian student community and other new friends I made here at WVU for having provided a great companionship.

Last but certainly not least, I would like to thank my family - Padmanaban, Ramesh Vijayrangan, Beena, Madhusudhan, AR Vijayrangan and Vathsala. Without their unconditioned love, warmth and selfless sacrifice, I would not have been enjoying a life like this. More like a father, Ramesh uncle has been beside me throughout my endeavors. 


\section{TABLE OF CONTENTS}

\section{CHAPTER 1 INTRODUCTION .......................................................................................}

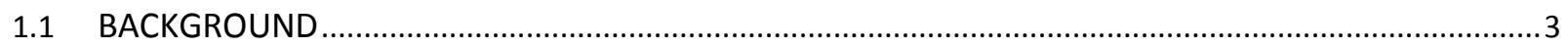

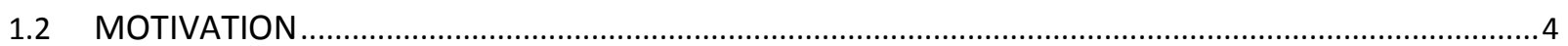

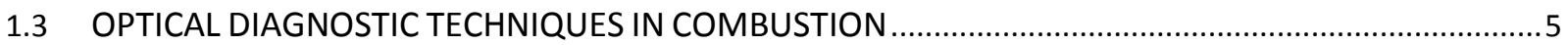

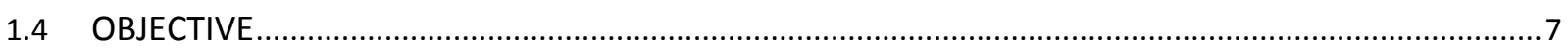

CHAPTER 2 REVIEW OF LITERATURE....................................................................................... 8

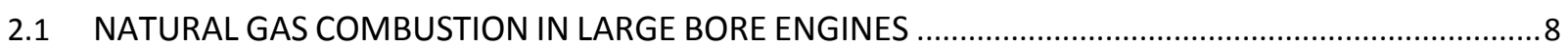

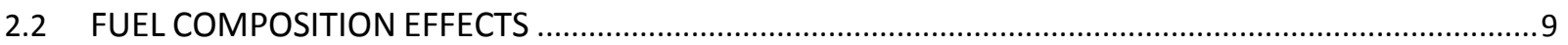

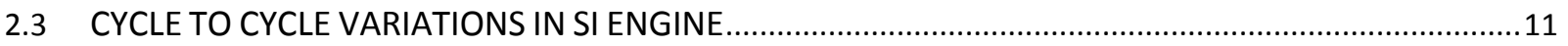

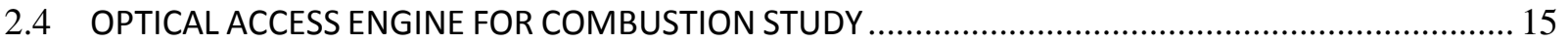

CHAPTER $3 \quad$ EXPERIMENTAL SETUP ................................................................................... 20

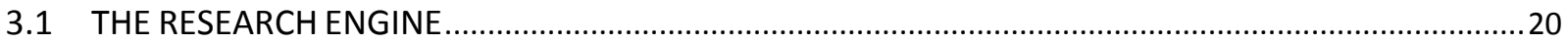

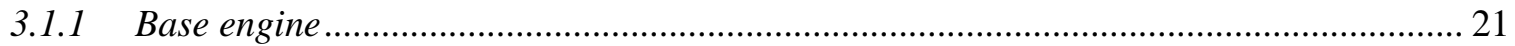

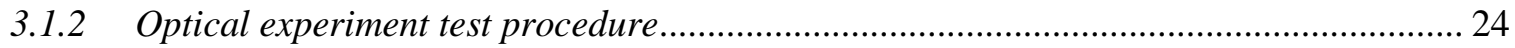

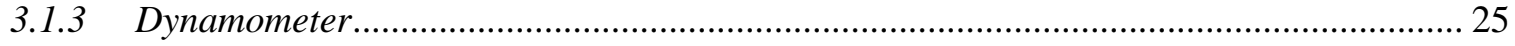

3.1.4 Engine control unit ................................................................................................... 26

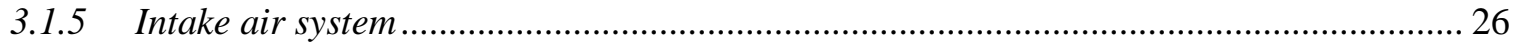

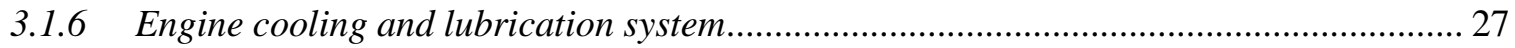

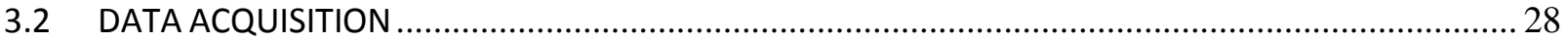

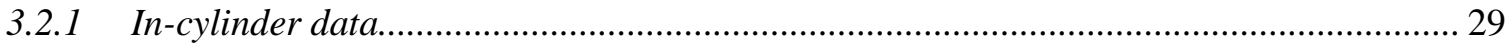

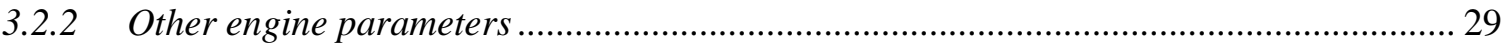

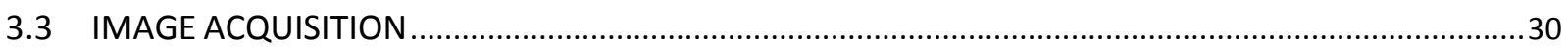

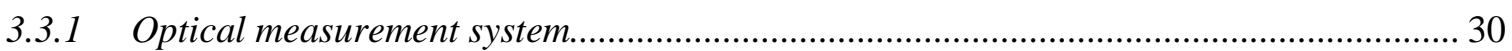

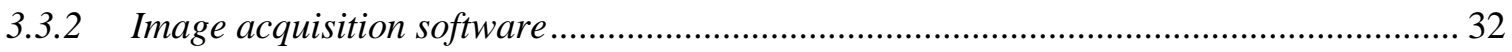

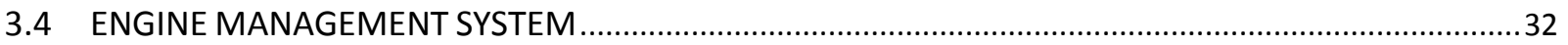

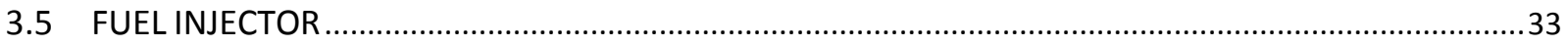

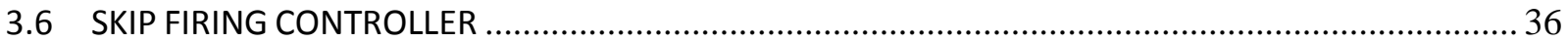




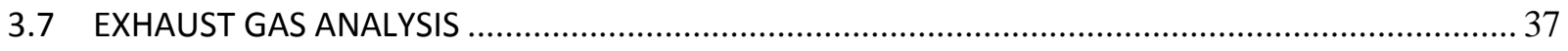

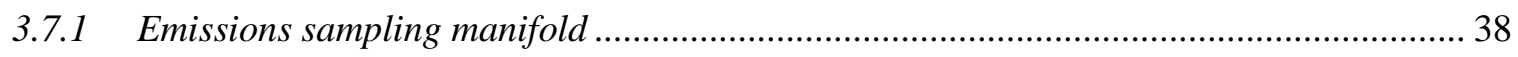

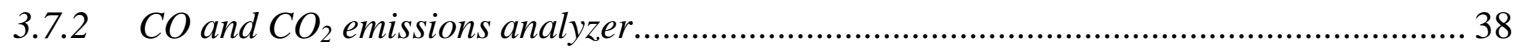

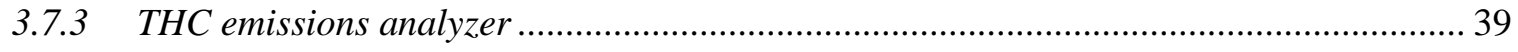

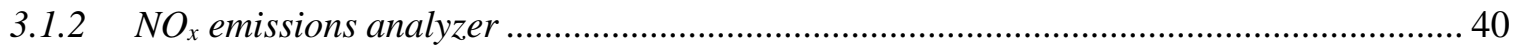

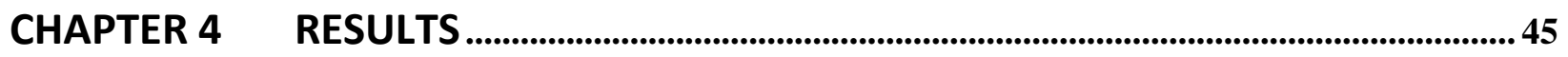

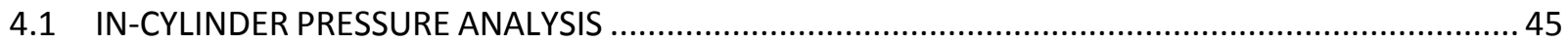

4.1.1 Correlation of combustion with optical data ................................................................ 57

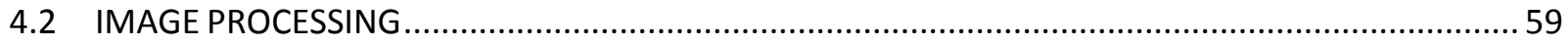

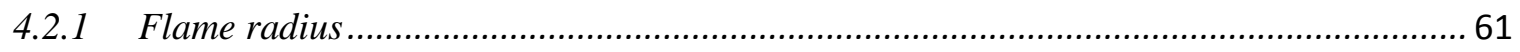

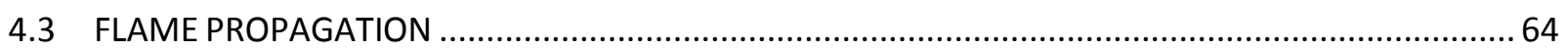

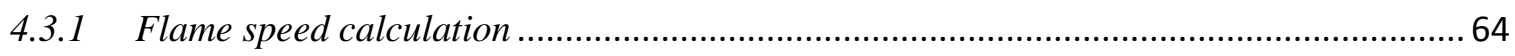

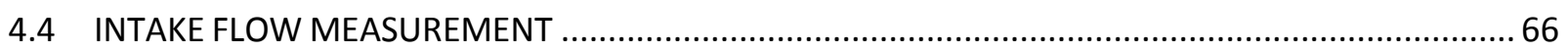

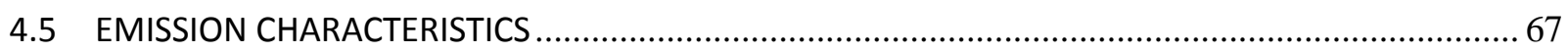

CHAPTER 5 CONCLUSIONS......................................................................................................69

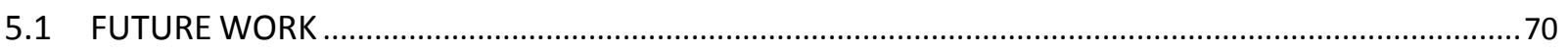

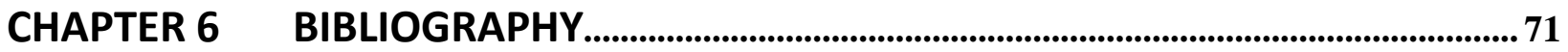




\section{LIST OF FIGURES}

FIGURE 1.1 CONSUMPTION OF NATURAL GAS IN THE US . 1

FIGURE 1.2 ESTIMATED CONSUMPTION OF ALTERNATIVE FUEL BY AFVS IN THE U.S. .................................. FIGURE 1.3 TYPICAL (A) OPTICAL ENGINE CONFIGURATION, (B) STANDARD METAL ENGINE CONFIGURATION (SINGLE CYLINDER GDI ENGINE), AND (C) A 3D-CAD VIEW OF AN ELONGATED PISTON WITH OPTICAL ACCESS 4

FIGURE 1.4 ENDOSCOPE INSERTION IN THE CYLINDER HEAD OF A DIESEL ENGINE ...........................................

FIGURE 2.1 SCHEMATIC DIAGRAM OF BOWDITCH'S SLOTTED, EXTENDED PISTON DESIGN... 16

FIGURE 2.2 HIGH-SPEED OPTICAL ENGINE DEVELOPED BY LOTUS ENGINEERING LIMITED AND LOUGHBOROUGH UNIVERSITY. 19

FIGURE 3.1 FIGURE 3.2 FIGURE 3.3 FIGURE 3.4 FIGURE 3.5 FIGURE 3.6 FIGURE 3.7 FIGURE 3.8 FIGURE 3.9

FIGURE 3.10 FIGURE 3.11 FIGURE 3.12 FIGURE 3.13 FIGURE 3.14 FIGURE 3.15 FIGURE 3.16 FIGURE 3.17

FIGURE 4.1 FIGURE 4.2 FIGURE 4.3 FIGURE 4.4 FIGURE 4.5 FIGURE 4.6 FIGURE 4.7 FIGURE 4.8 FIGURE 4.9 FIGURE 4.10

FIGURE 4.11

FIGURE 4.12 FIGURE 4.13

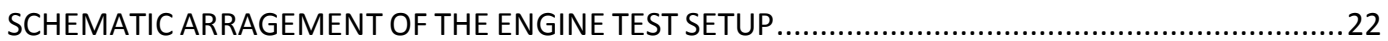

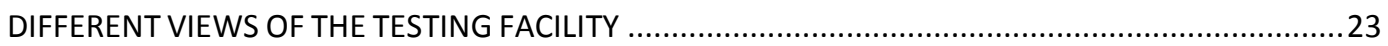

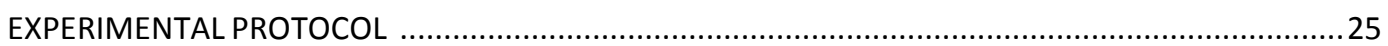

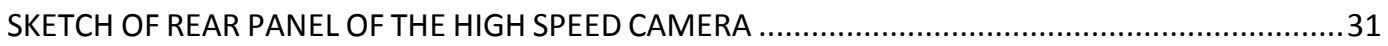

SCHEMATIC SHOWING THE OPTICAL MEASUREMENT SYSTEM …...................................................... 31

MANUFACTURER CALIBRATION FLOW CURVES FOR THE INJECTOR IG7 WITH 4 SEATS WORKING . 33 INJECTOR FLOW CURVE PLOTTED FROM BENCH TESTING AT LAB ……....................................... SCHEMATIC WAVEFORM OF INJECTOR EVENTS PER CYCLE BASIS ............................................... 34 LINEARITY REGION IN THE FLOW CALIBRATED INJECTOR PERFORMANCE

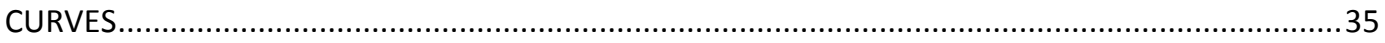

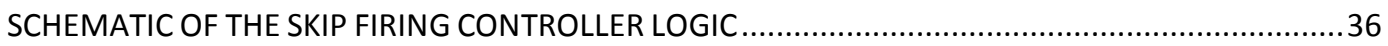

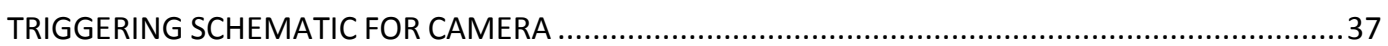

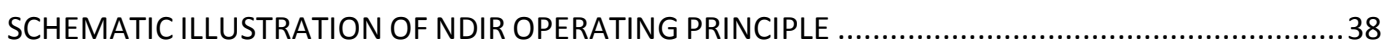

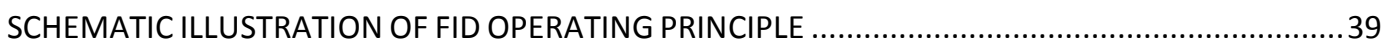

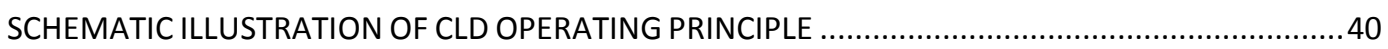

FLOW SCHEMATIC FOR CO 2 ANALYZER BOX

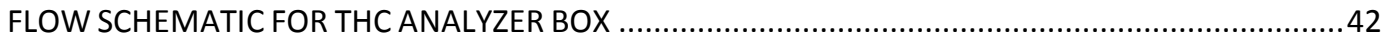

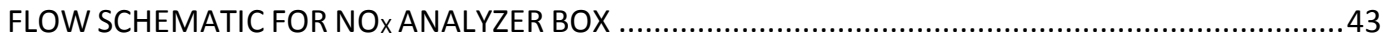

MOTORING TRACE AFTER PEGGING FOR COMPRESSION RATIO CALCULATION ….......................45

EXAMPLE OF A COMBUSTION PRESSURE TRACE FOR A FIRED CYCLE …..........................................46

IN-CYLINDER PRESSURE RAW DATA (WITHOUT FILTER) FOR COMBUSTION TRACE OF 97 CYCLES.. 46

ZERO PHASE DIGITAL FILTER FOR COMBUSTION TRACES OF 97 CYCLES..........................................47

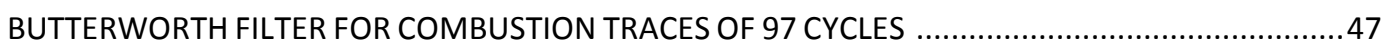

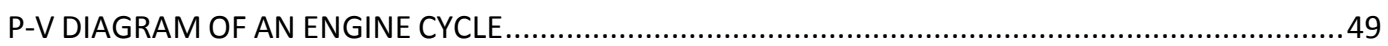

IN-CYLINDER CUT OFF VIEW OF A TYPICAL SINGLE CYLINDER OPTICALLY ACCESIBLE ENGINE ........49

LOG P VS LOG V, PLOT OF A COMBUSTION CYCLE ……............................................................. 50

THE NET HEAT RELEASE RATE FOR A REPRESENTATIVE COMBUSTING CYCLE ................................51

MASS FRACTION BURNED FROM -5 DEG TO 50 DEG COMBUSTION DURATION OF A

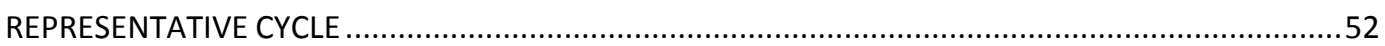

MASS FRACTION BURNED PROFILE BASED ON RASSWIELER \& WITHROW METHOD FOR A

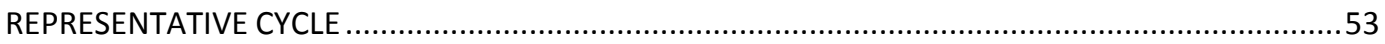

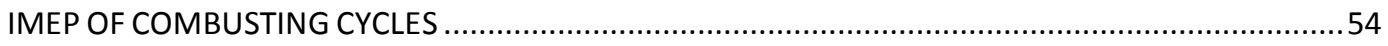

ENGINE LOAD PROFILE FOR ONE SET OF SKIP FIRED OPERATION N..............................................5 
FIGURE 4.14 IMAGED REGION RELATIVE TO THE TOTAL CYLINDER HEAD AREA, SPARK LOCATION AND ENGINE

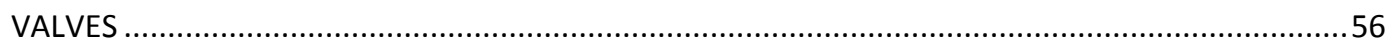

FIGURE 4.15 RAW FLAME IMAGES REPRESENTATIVE OF COMBUSTION EVENTS FROM CAD -10 TO CAD $50 \ldots . . . .57$

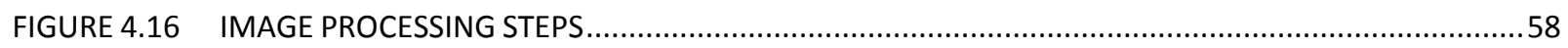

FIGURE 4.17 CHARACTERISTIC PLOT OF WRINKLING RATIO WITH THE FLAME GROWTH ..................................60

FIGURE 4.18 EXAMPLE OF FLAME IMAGES USED TO DETERMINE BURN RATE PARAMETERS ...........................61

FIGURE 4.19 THE FLAME RADIUS INCREASE WITH CAD FOR A REPRESENTATIVE COMBUSTING CYCLE..............62

FIGURE 4.20 EVOLUTION OF FLAME GROWTH STUDIED EXPERIMENTALLY USING PLIF BY [105] .....................62

FIGURE 4.21 FLAME VELOCITY FOR A REPRESENTATIVE FLAME IMAGES SET ..........................................64

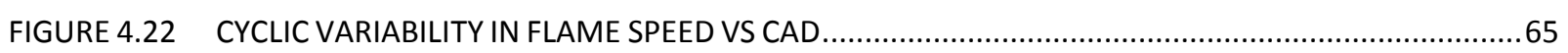

FIGURE 4.23 EFFECT OF SURGE TANK ON INTAKE FLOW FLUCTUATIONS WITH 0.01" ORIFICE SNUBBERS..........65

FIGURE 4.24 MEASURED EMISSION LEVEL FROM NDIR GAS ANALYZER FOR ONE SET OF SKIP FIRED OPERATION

FIGURE 4.25 MEASURED EMISSIONS LEVEL FROM FID GAS ANALYZER FOR ONE SET OF SKIP FIRED OPERATION 


\section{LIST OF TABLES}

TABLE 1.1 ANALYSIS TECHNIQUES IN TRANSPARENT RESEARCH ENGINES AND STANDARD ENGINES ..............5

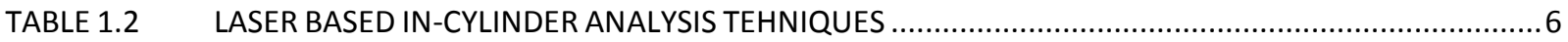

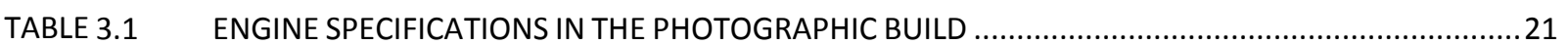

TABLE 3.2 COMPOSITION SPECIFICATION OF CHEMICALLY-PURE-GRADE METHANE .....................................28

TABLE 3.3 TECHNICAL SPECIFICATIONS OF THE SENSORS USED FOR DATA ACQUISITON ................................

TABLE 3.5 TECHNICAL SPECIFICATIONS OF THE IG7 NAVAJO CNG INJECTOR

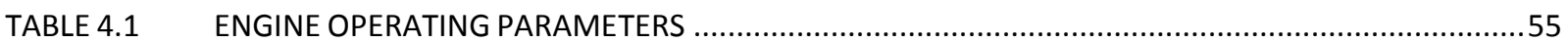




\section{LIST OF ABBREVIATIONS}

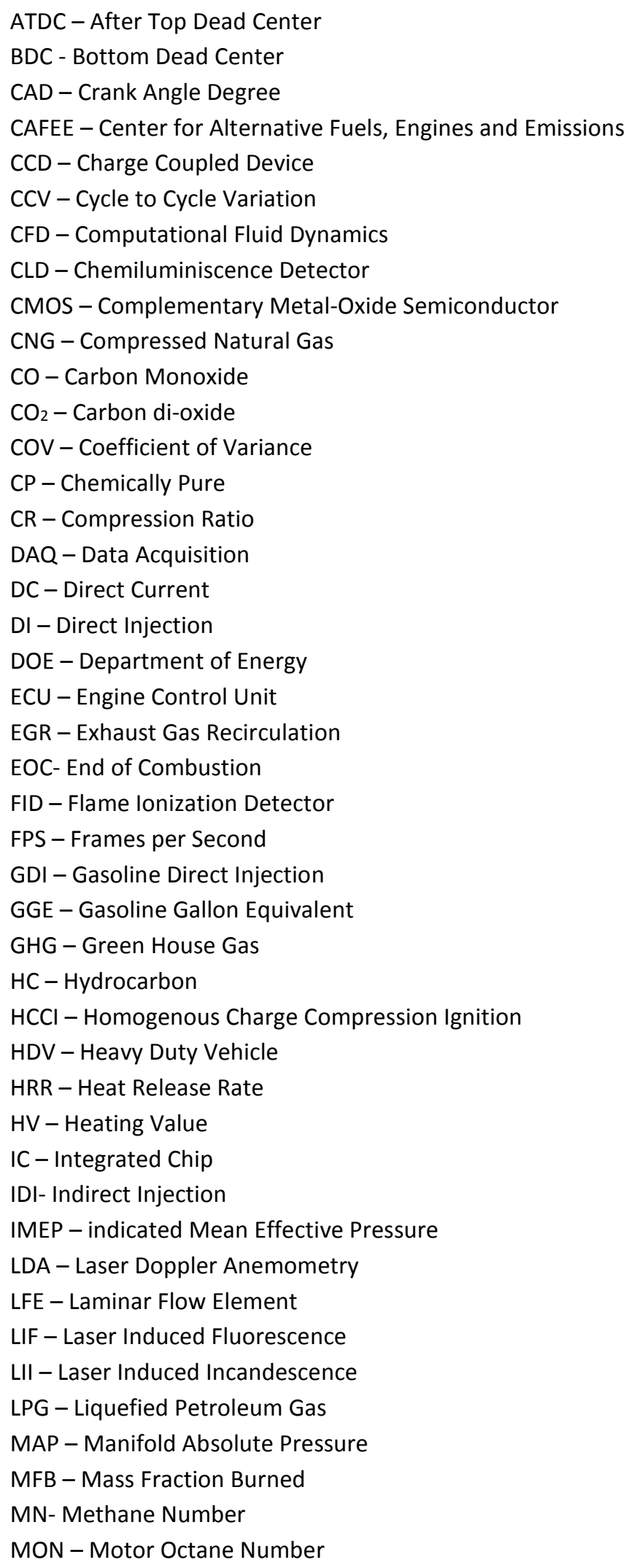




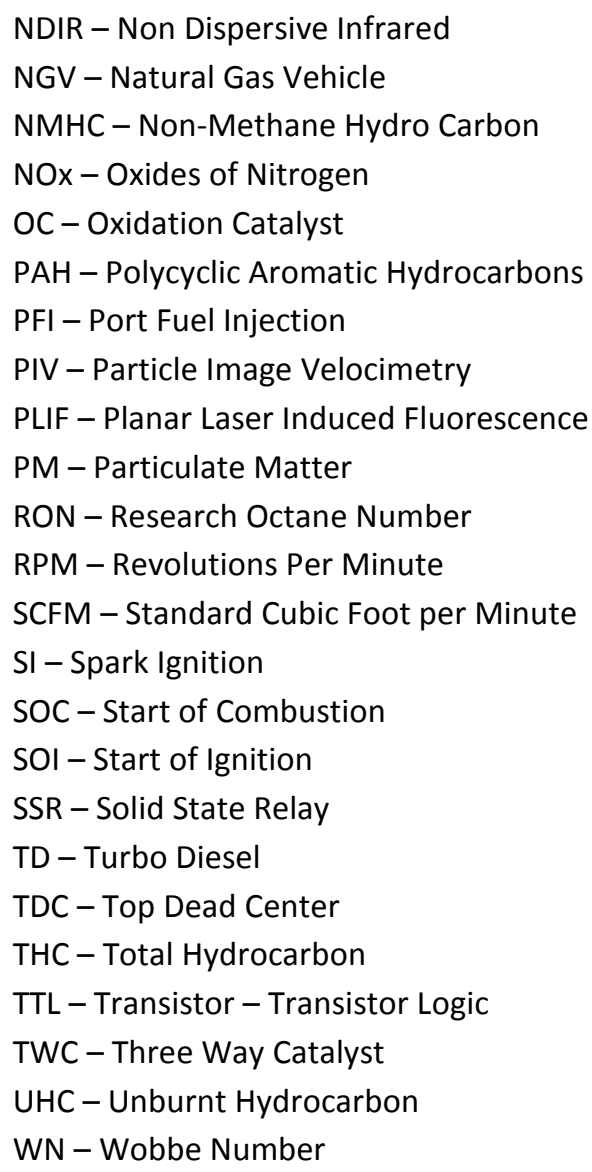




\section{Chapter 1}

\section{Introduction}

The use of natural gas in the transportation sector is well established with over 17 million natural gas vehicle (NGVs) worldwide and about 150,000 vehicles in the United States (U.S.) alone [1]. There are some 24,000 natural gas (NG) refueling stations worldwide and global demand in 2013 accounted for around $2 \%$ of total energy use in on-road transportation. Approximately one million heavy-duty vehicles (HDVs) are sold in the United States every year, but less than 1 percent are powered by natural gas. However, NG became suddenly abundant in U.S. due to the booming shale gas industry, which reduced its price to as low as one-third of diesel fuel. U.S. Department of Energy (DOE) website indicates that only $0.12 \%$ of the NG consumed in the country in 2014 was used to power vehicles [2]. This shows that the compressed natural gas (CNG) and liquefied petroleum gas (LPG) motor fuels market has a very little sway over the NG specifications, operations and market.

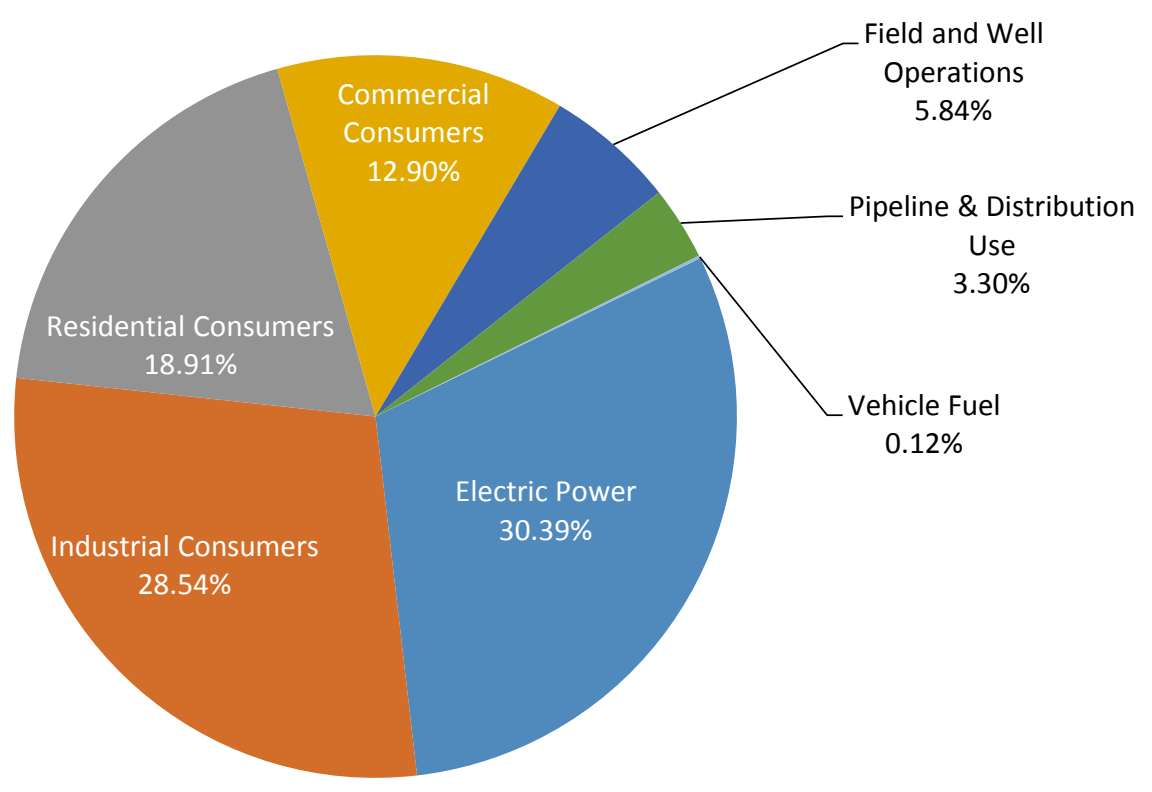

Source: http://afdc.energy.gov/data

Figure 1.1 Consumption of natural gas in the U.S. [3]

It is expected that the low price and large availability of NG in U.S. will prompt the commercial trucking industry to invest in new NG-powered trucks over the coming decades. A recent assessment by the U.S. DOE. indicates that NG vehicles could constitute up to 20 percent of the new 2025 heavy duty vehicle market [2], potentially displacing a significant amount of diesel fuel combusting vehicles. Also, the 
U.S. Energy Information Administration's Annual Energy Outlook 2015 projects that natural gas will be the fastest-growing fuel in the transportation sector, with an average annual demand increase of 10 percent from 2012 to 2040 [4]. Heavy-duty vehicles are the leading edge of this projected expansion, with a projected average annual growth rate for natural gas of 14 percent [2].

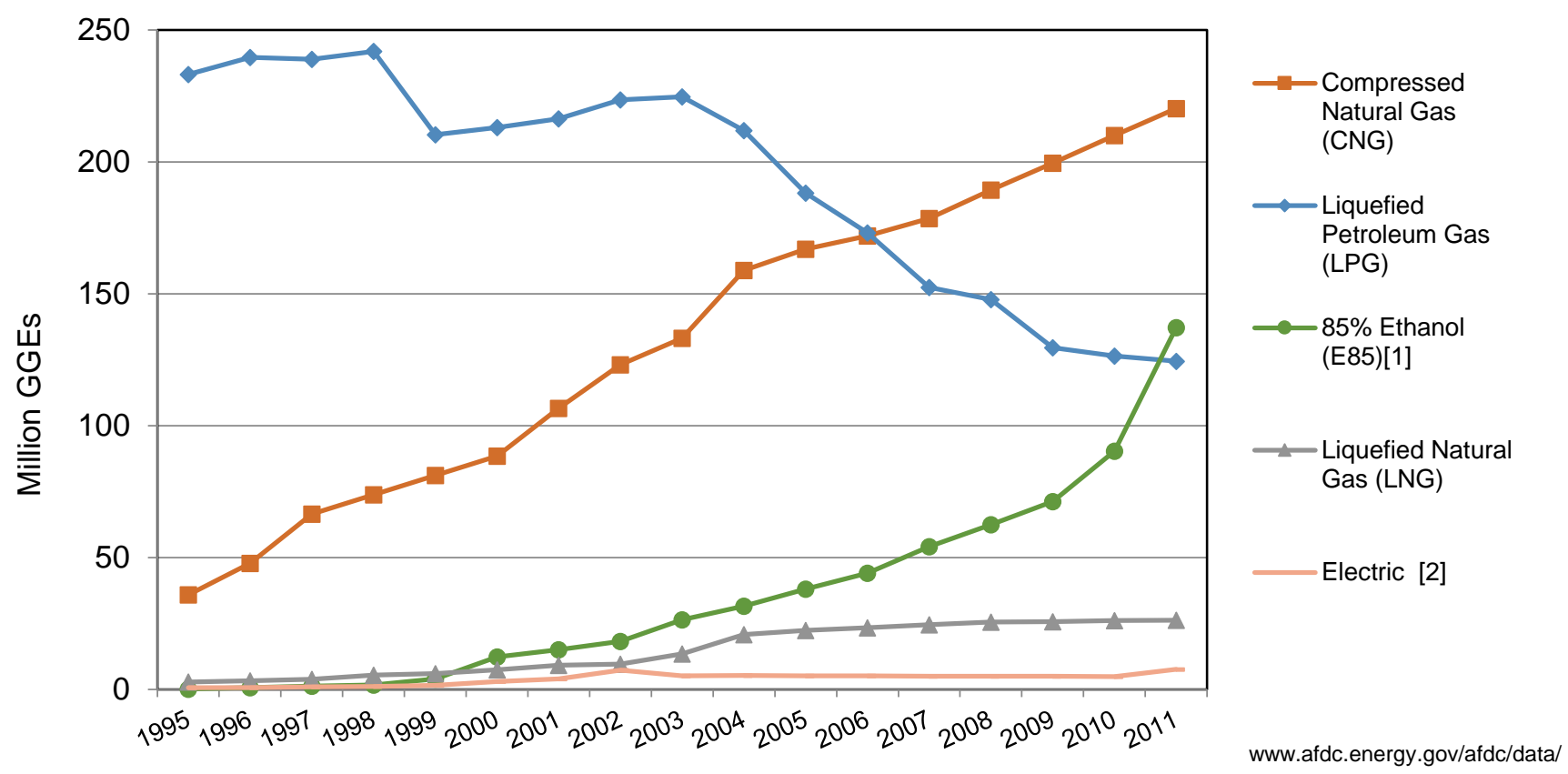

Figure 1.2 Consumption of alternative fuel by AFVs in the U.S. [5]

Figure 1.2 presents the consumption of alternative fuel and electricity by the alternative fuel vehicles (AFVs) in U.S. from 1995 to 2011, in millions of gasoline gallon equivalent (GGE). This figure shows that CNG-powered vehicles dominated the alternative-fuel fleet, suggesting them as an economically viable alternative for the commercial vehicle manufacturers. Greater use of alternative fuels in public transportation vehicles would yield environmental benefits such as reduced tailpipe emissions of air pollutants that were shown to affect public health, reduced risk of soil and water contamination from diesel fuel spills, and quieter operation, while also reducing the diesel fuel consumption. For example, engines operating with alternative fuels generally emit lower levels of non-methane hydrocarbons (NMHC), oxides of nitrogen $\left(\mathrm{NO}_{\mathrm{x}}\right)$, and particulate matter $(\mathrm{PM})$ than current diesel engines. This is especially true for alternative fuel comparisons involving ferryboats and locomotives, which typically have reduced (if any) diesel emission controls installed on their engines. 


\subsection{Background}

More stringent IC engine emissions regulations, the depletion of fossil-fuel reserves and climate-effects considerations continue to stimulate the spark engine development. These stringent efficiency and emission regulations require novel combustion strategies and improved after treatment systems. Single cylinder optically-accessible engines can help the development of such novel strategies by improving the fundamental understanding of in-cylinder processes. Such engines allow the use of non-intrusive visualization techniques that study in-cylinder flow, fuel-oxidizer mixing, and combustion and emissions phenomena under conditions representative of production engines. The experimental data obtained from engines with extended optical access (“optical engines”) is used for both the validation of engine computational models that accelerate engine development and the development of new combustion strategies as they provide a detailed insight into the physical processes occurring inside the combustion chamber. However, the operation of optical engines presents numerous challenges as compared to production (metal) engines. In addition, there are a few design differences between an optical engine and a production engine. First, optical research engines have simplified chamber geometries to facilitate optical access while minimizing image distortion issues. Further, the optical components (i.e., glass windows) cannot resist the thermal stress accumulated during continuous engine operation. As a result, optical engines can run only for a few minutes and usually in a skip-firing mode (one fired engine cycle followed by $n$ motored cycles, where $n \geq 1$ ). Furthermore, the location of the piston ring pack on an optical engine usually differs from that on an all-metal engine, due to the use of dry lubrication methods in the extended portion of the optical piston. In addition to these design aspects, the use of materials such as quartz, sapphire and titanium in optical engines has a significant impact on engine combustion characteristics. The reason for this is that the thermal conductivity of the aforementioned materials is significantly lower than the thermal conductivity of steel or aluminum. Therefore, it is very important that an adequate control of intake temperature, fueling and ignition systems is established in the test setup to ensure the longevity of optical and metal components, repeatable experimental results, and also that the optical engine experiments are representative of the metal engine and hence could provide us with deep a meaningful insight on a physical phenomenon taking place inside the combustion chamber. Figure 1.3 shows the difference between an optical (Figure 1.3a) and standard metal configuration of the same type of engine (Figure 1.3b) to give the readers an idea about the major differences in build and component types in either of the configurations. 


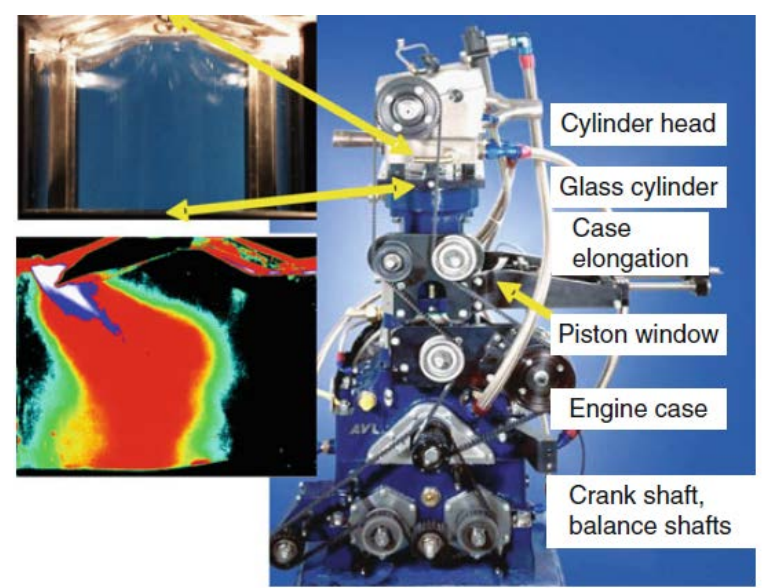

a

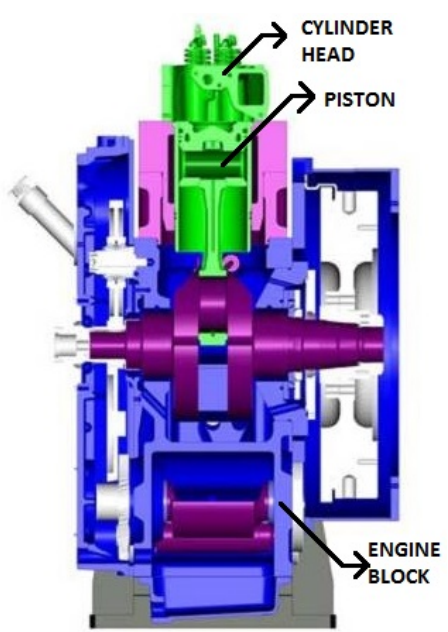

b

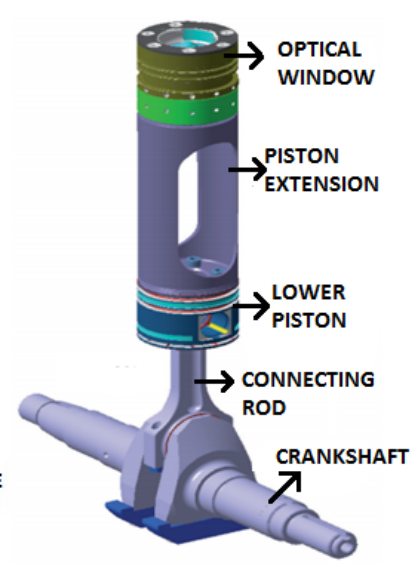

C

Figure 1.3 Typical (a) optical engine configuration, (b) standard metal engine configuration (single cylinder GDI engine [6]), and (c) a 3D-CAD view of an elongated piston with optical access [7]

\subsection{Motivation}

While computational fluid dynamics (CFD) simulations are becoming ubiquitous and can dramatically reduce engine development time and cost, engine manufacturers cannot achieve their targets on engine efficiency and emissions without spending a large amount of time on extensive engine testing and calibration. The reason is the lack of fundamental combustion knowledge with respect to the complex physical and chemical processes that are taking place inside the engine combustion chamber. For example, two combustion strategies with similar initial conditions can achieve the same power output, but have completely different efficiency and emissions. Engines with optical access and visualization techniques such as the one discussed in this thesis help improving the fundamental knowledge by providing essential qualitative and quantitative insight into the combustion process.

In addition, recent energy shortages and a larger concern with respect to the environmental protection increased the interest in alternative fuels f. The use of alternative fuels in IC engines showed promising results compared to gasoline or diesel fuel. For example, alternative-fuel combustion is generally soot-free compared to conventional petroleum fuels. NG is one of the alternative fuels of interest. NG is a mixture with methane is its major constituent (75-98\% of methane; $0.5-13 \%$ of ethane; and 0-2.6\% of propane [6]. NG combustion produces less soot emissions than diesel fuel due to a simpler molecular structure, and no need for fuel evaporation [7]. NG completely mix with air, which eliminates potential regions with local rich mixture and reduces $\mathrm{CO}$ emissions. Also, NG produces less $\mathrm{CO}_{2}$ emissions than gasoline for the same power output, due to its higher hydrogen to carbon ratio [8]. The high octane number of NG (average of the Research Octane Number (RON) and the Motor Octane Number (MON) is between 120 and 130) greatly reduces the knocking potential, allowing a spark ignition engine to be operated with a higher 
compression ratio than an equivalent gasoline engine. This increases engine thermal efficiency and lowers fuel consumption. The RON for a particular fuel composition is determined from laboratory tests performed with a special research engine with a variable compression ratio. Motor Octane Number (MON) also uses a similar test engine, but with a preheated fuel mixture, a higher engine speed and variable ignition timing. Additionally, NG has a lower lean limit than gasoline, which can further reduce CO and HC emissions and increase the thermal efficiency. However, the number of fundamental studies in the literature that explain these observation and can be used to predict engine efficiency and emissions is limited compared to those dedicated to gasoline or diesel fuel. This motivates the present study of investigating the combustion phenomena occurring inside a spark-ignition NG engine with extended optical access.

\subsection{Optical diagnostic techniques in combustion}

This section gives an overview of optical methods and their application to various aspects of combustion analysis. These optical visualization techniques were deemed helpful in gaining a fundamental insight of the physio-chemical processes taking place inside the combustion chamber and hence, have aided in developing advanced combustion chamber for production type engines. There are numerous methods applied in engine and combustion research, however, just a few of them have the potential of being applied in practical engine development. The decision for application of a specific optical technique is based on information one needs to study and hence the efforts and chances to gain the required results with a given method. The following table lists the common optical diagnostic techniques adopted by combustion researchers across the globe.

\begin{tabular}{|c|c|c|}
\hline Method & Physical information & Device \\
\hline $\begin{array}{c}\text { Single-cylinder with } \\
\text { extended optical access }\end{array}$ & $\begin{array}{c}\text { Mixture formation, combustion process } \\
\text { Spray characteristics, flame characteristics, } \\
\text { emissions formation }\end{array}$ & $\begin{array}{c}\text { High-speed cameras, } \\
\text { lasers }\end{array}$ \\
\hline $\begin{array}{c}\text { Endoscopic imaging in } \\
\text { metal engine }\end{array}$ & $\begin{array}{c}\text { Spray-combustion chamber interaction } \\
\text { Local flow velocity, temperature field, soot } \\
\text { concentration }\end{array}$ & $\begin{array}{c}\text { Lasers, high-speed } \\
\text { cameras, endoscopes }\end{array}$ \\
\hline
\end{tabular}

Table 1.1 Analysis techniques in transparent research engines and standard engines [6]

\begin{tabular}{|c|c|c|c|}
\hline Method & Particles & Physical information & Device \\
\hline $\begin{array}{c}\text { Particle Image Velocimetry } \\
\text { (PIV) }\end{array}$ & Fuel droplets & Flow field & Camera \\
\hline
\end{tabular}




\begin{tabular}{|c|c|c|c|}
\hline $\begin{array}{c}\text { Laser Doppler } \\
\text { Anemometry (LDA) }\end{array}$ & Particles, droplets & Local flow velocity & Photodiode, multiplier \\
\hline $\begin{array}{c}\text { Laser Induced Fluorescence } \\
\text { (LIF) }\end{array}$ & $\begin{array}{c}\text { Fluorescent } \\
\text { molecules }\end{array}$ & Species concentration & CMOS/CCD camera \\
\hline $\begin{array}{c}\text { Laser Induced } \\
\text { Incandescence (LII) }\end{array}$ & Soot particles & Soot distribution & $\begin{array}{c}\text { Solid state laser with } \\
\text { CMOS camera }\end{array}$ \\
\hline
\end{tabular}

Table 1.2 Laser-based in-cylinder analysis techniques [6]

The most common way of visualizing the combustion chamber is through the use of a see-through piston. For example, a large piston window allows the simultaneous inspection of the fuel sprays as well as observation of the entire flame field. Spray-t- spray and flame-to-flame uniformity are especially of interest in Diesel combustion studies. In case of SI engines, the optical analysis supports the following research areas:

1. Emissions formation

2. Stability: flame kernel formation, flame front propagation under the influence of turbulent incylinder flow

3. Efficiency: knock initiation site analysis

4. Abnormal combustion: engines with high power density combustion systems are under risk of uncontrolled self-ignition events. Such irregular ignition and combustion is identified with optical diagnostic procedures

Endoscopes (Figure 1.4) are optical instruments for image transfer by means of long, rod-shaped lenses or by coherent optical fiber bundles, used mainly for combustion studies in standard metal engines. Such combustion chamber windows are designed to withstand the pressure and temperature conditions of usual engine operating modes. With adequate design and material selection, window applications include full load operation in both Diesel and gasoline engines. 


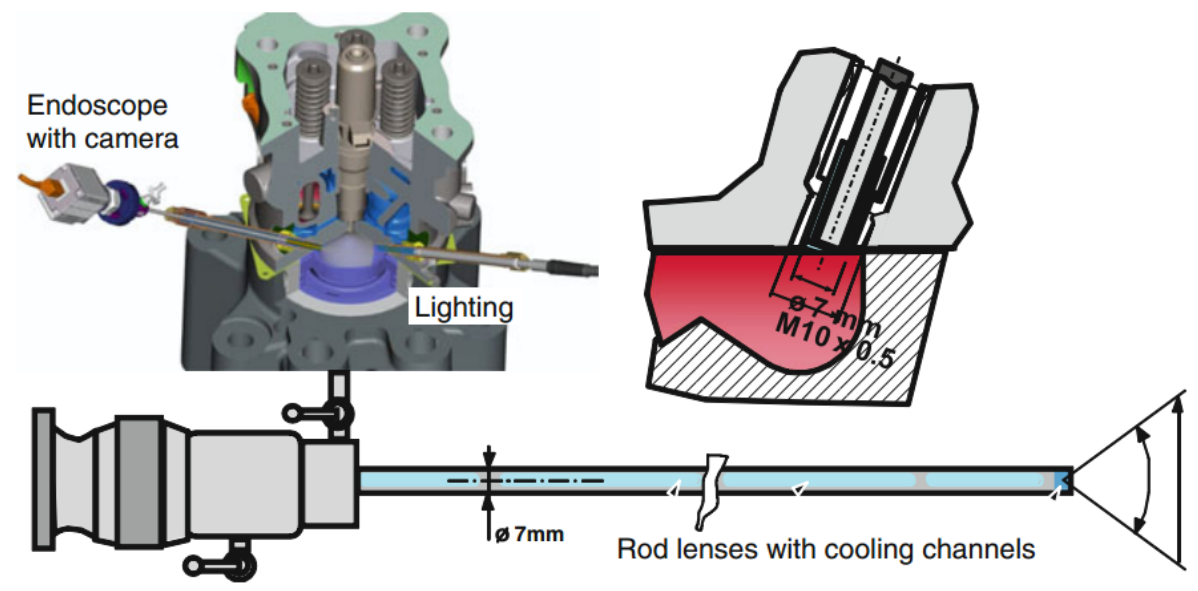

Figure 1.4 Endoscope insertion in the cylinder head of a diesel engine [6]

\subsection{Objective}

The global objective of this research is to develop an experimental platform that can be used to study engine fundamental combustion phenomena. The specific goal in this study is to test this experimental platform against similar flame speed measurements using natural gas as fuel. This study is divided in two main parts. The first part focuses on the setup of a single-cylinder research engine with optical access including the design of its control system and the acquisition of in-cylinder pressure data and high-speed combustion images. The second part focuses on measurements of the turbulent flame speed using the highspeed combustion images. Accurate interpretations of the combustion phenomena using combustion visualization can help engine designers accelerate the introduction of NG engines in the heavy-duty vehicle market. 


\section{Chapter 2}

\section{Review of Literature}

\subsection{Natural gas combustion in large bore engines}

Natural gas consumption is forecasted to be doubled between 2001 and 2025, with the most robust growth in demand expected among the developing nations [9]. Similarly, natural gas vehicles (NGVs) have been implemented in a variety of applications as part of efforts to improve urban air quality in the United States, particularly within California [10-12]. Two technologies have been widely being used for NG heavy duty engines, namely lean-burn combustion and stoichiometric combustion. Older technology NGVs are equipped with lean-burn engines and oxidation catalysts to effectively control CO and formaldehyde emissions. Current heavy-duty NGVs are equipped with spark-ignited stoichiometric combustion engines, with water cooled exhaust gas recirculation (EGR) technology, and three-way catalysts (TWC) in order to meet the more stringent 2010 NOx emission standards from the US Environmental Protection Agency (USEPA). Stoichiometric combustion engines with TWC are superior to lean-burn combustion engines with oxidation catalysts for reducing $\mathrm{NO}_{\mathrm{x}}$ emissions $[13,14]$. However, stoichiometric engines with TWCs produce higher CO emissions than lean-burn engines [14]. Particulate Matter (PM) emissions from both stoichiometric and lean-burn combustion NG engines are very low due to the almost homogeneous combustion of the air-gas mixture, and the absence of large hydrocarbon chains and aromatics in the fuel [15]. For NGVs, one issue that has been shown to be important with respect to emissions is the effect of changing the composition of the fuel. This is part of a broader range of issues which are classified under the term interchangeability, which is the ability to substitute one gaseous fuel for another in a combustion application without materially changing operational safety, efficiency, performance or materially increasing air pollutant emissions. Changes in the NG composition used in NGVs can affect the reliability, efficiency, and exhaust emissions. Studies conducted with small stationary source engines, heavy-duty engines/vehicles, and light-duty vehicles have shown that NG composition can have an impact on emissions [16-19]. Karavalakis et al. [20] showed higher NOx emissions when they tested a 2002 lean-burn NG waste hauler on lower methane number/higher Wobbe number fuels. Hajbabaei et al. [21] reported $\mathrm{NO}_{\mathrm{x}}$ and nonmethane hydrocarbon (NMHC) emission increases for fuels with low methane contents when they tested two transit buses equipped with lean-burn NG engines. However, they did not find any fuel effect on $\mathrm{NO}_{\mathrm{x}}$ emissions when they tested a bus with a stoichiometric combustion engine and a TWC. The effect of NG 
composition on exhaust emissions was also confirmed by Feist et al. [22] where they found NOx and total hydrocarbon (THC) emissions increases with higher Wobbe number fuels under lean-burn engine combustion, while the stoichiometric engines showed no clear trends for $\mathrm{NO}_{\mathrm{x}}$ and $\mathrm{THC}$ emissions with different fuels $[23,24]$.

\subsection{Fuel composition effects}

Natural gas is considered to be a promising alternative fuel for passenger cars, truck transportation and stationary engines providing positive effects both on the environment and energy security. The US government is continually pushing the use of natural gas engines in order to reduce foreign oil dependence and achieve lower greenhouse gas (GHG) emissions. The most important GHGs are carbon dioxide $\left(\mathrm{CO}_{2}\right)$, methane $\left(\mathrm{CH}_{4}\right)$, and nitrous oxide $\left(\mathrm{N}_{2} \mathrm{O}\right)$, with the transportation sector being the main contributor of the overall GHG emissions in the US [25]. Therefore, the introduction of natural gas as a potential alternative to conventional liquid fuels in the heavy-duty vehicle segment (viz., vehicles with gross vehicle weight ratings ranging from 3.9 to 15 tons and over), which consumes a large amount of fuel, is a fast growing market. Currently, California supplies $85-90 \%$ of its needs with NG imported domestically from the Rockies, from southwest states, such as Texas, and from Canada [26]. Natural gas is a mixture of various hydrocarbon molecules such as methane $\left(\mathrm{CH}_{4}\right)$, ethane $\left(\mathrm{C}_{2} \mathrm{H}_{6}\right)$, propane $\left(\mathrm{C}_{3} \mathrm{H}_{8}\right)$, and butane $\left(\mathrm{C}_{4} \mathrm{H}_{10}\right)$, and inert diluents such as molecular nitrogen $\left(\mathrm{N}_{2}\right)$ and carbon dioxide $\left(\mathrm{CO}_{2}\right)$. Several parameters affect the natural gas composition such as demographic location, season, and treatments applied during production or transportation [26-30]. Moreover, additional mixing of different gases occurs during pipeline transmission [31, 32]. Therefore, its thermodynamic properties are dependent on the composition of the gas [33]. To obtain the thermodynamics properties accurately, the effect of the gas compositions must be also considered. Many researchers working on the natural gas engines demonstrated that natural gas composition significantly affects engine performance and emissions. It was also reported that the heating value (HV), thermal efficiency, and concentration of un-burnt hydrocarbon (UHC) and other emission particles would highly depend on the source of supply of natural gas as the main fuel [34, 35]. The most important compositional parameters that affect the quality of natural gas include methane number (MN) and Wobbe number (WN). A $100 \%$ methane composition is given 100 as $\mathrm{MN}$ and as the higher hydrocarbons percentage increases, the MN decreases. Methane is a dominant component in the natural gas and hence is an important parameter for consideration. The MN of the mixture is defined as the percentage of methane in a methane hydrogen mixture. The $\mathrm{WN}$ is a measure of the fuel energy flow rate through a fixed orifice under given inlet conditions. It is calculated as the ratio of the heating value divided by the square root of the specific gravity. Generally, the WN is a good criterion for natural gas because it correlates well with the ability of an internal combustion engine to use a particular gas. [36-38]. The earliest research on 
implication of natural gas composition in SI engines should be traced back to the middle of 1980s, when natural gas was employed as the secondary fuel in gasoline engine. Elder et al. [39] carried out experimental and theoretical investigations at the University of Auckland to determine the effects of varying fuel compositions on vehicle fuel consumption, power output and pollutant emissions. King [40] analyzed the impact of natural gas fuel composition on fuel metering and engine operational characteristics. He developed a fuel metering model to analyze the impact of fuel composition on carbureted, premixed, and direct-injected engine configurations. The change in physical properties of the fuel was found to have a profound effect on fuel metering characteristics. He found that fuel composition affects fuel metering configurations. However, these variations were minor compared to the fuel property effects. Moreover, he reported that fuel composition also affects the lean- flammability-limit of the mixture which, when combined with fuel metering variations, can cause a lean-burn engine to misfire. Also, fuel temperature variations affected fuel metering and must also be considered. The results indicated that closed-loop mixture control is essential for stoichiometric engines and very beneficial for lean-burn engines. Thiagarajan et al. [41] experimentally investigated effect of varying gas composition on the performance and emissions of a SI engine. The pipeline natural gas composition was varied by adding volumes of propane (up to 20\%) or nitrogen (up to 15\%). They found that brake power, fuel conversion efficiency and before catalyst emissions of $\mathrm{CO}, \mathrm{NO}_{\mathrm{x}}$ and hydrocarbons were not affected by propane addition as long as stoichiometric combustion was maintained. In addition, nitrogen addition at the stoichiometric condition significantly reduced before catalyst $\mathrm{NO}_{\mathrm{x}}$ emissions and increased after catalyst $\mathrm{CO}$ emissions. Limited information is available on the unregulated emissions from NGVs, including gaseous toxic pollutants and PAHs (polycyclic aromatic hydrocarbons). Kado et al. [42] found that the carbonyl emissions from CNG (compressed natural gas) buses were primarily formaldehyde. Formaldehyde emissions from these buses were much greater than those of diesel buses fitted with OCs, and CRTs (continuously regenerating traps). Ayala et al. [43] also found that formaldehyde emissions were reduced by OCs on CNG buses by over 95\% over the CBD (Central Business District) cycle. Okamoto et al. [44] and Kado et al. [42] performed mutagenic tests on the exhaust from transit buses operating on CNG. They both reported lower mutagenic activity for CNG buses equipped with OCs, compared to buses without OCs. Kado et al. [42] also found that mutagenic activity using the TA98NR test strain decreased, indicating the possible presence of nitro-PAH in the PM emissions. Turrio-Baldassarri et al. [45] showed that a spark ignition heavy-duty urban bus NG engine with a TWC produced 20 times lower formaldehyde, more than 30 times lower PM emissions, and 50 times lower PAH emissions, compared to a diesel engine without after treatment. 


\subsection{Cycle to cycle variations in SI engine}

Today, engine designers are seeking every kind of solution aimed at the reduction of fuel consumption and emission levels. The cycle to cycle variation (CCV) in combustion significantly influences the performance of spark-ignition engines. The process variables such as pressure and heat release in an internal combustion engine undergo cycle-to-cycle variations. SI engines superficially operating under steady-state conditions do not maintain perfectly stable operation i.e. a comparison between one cycle and another reveals random variations in. In general, combustion in spark-ignition engines varies considerably from cycle to cycle. Many studies have been carried out in order to find the main causes of this effect. These variations are associated with considerable variations in flame speed and combustion duration. Very early in the combustion event taking place within the cylinder, cyclic variation in peak cylinder pressure, the rate of pressure rise and the work done by the gas are observed by the researchers [46]. The CCV may become severe under lean-burn conditions, and for highly dilute mixtures with exhaust gas recirculation [47]. Cycleto-cycle variations have been observed in spark ignition, compression ignition, and HCCI engines. The CCV may reduce the power output of the engine, lead to operational instabilities, and result in undesirable engine vibrations and noise. Cyclic variation of automobile engine combustion is a fundamental characteristic of the power plant that is the primary means of transportation in this country. The extremes of this variation reduce drivability and gas mileage, and can be responsible for significant air pollutant emissions from the engine. There have been many studies of cyclic variation from various perspectives.

Several sources of CCV in a spark ignition engine have been identified. They include (a) turbulence intensity of the flow field in the cylinder, (b) variations in the fuel air ratio, (c) amount of residual or recirculated exhaust gases in the cylinder, (d) spatial inhomogeneity of the mixture composition especially near the spark plug, and (e) spark discharge characteristics and flame kernel development. It has been estimated that elimination of the CCV may lead to about $10 \%$ increase in power output for the same fuel consumption in a gasoline engine [48]. There have been many studies on the analysis of CCV in internal combustion engines. Some of these studies have revealed that any process that increases the burning velocity of the combustible mixture will result in a reduction of the CCV. Stone et al. [49] highlight that total elimination of cyclic variation is not desirable for engine management systems that retard the ignition when incipient knock is detected. If there were no cyclic variation, there would be no foresight for the engine management system to detect when the onset of knock will occur. Galloni [50] studied the different parameters that could affect the cyclic variation in a SI engine. The engine under consideration used three different shapes of combustion chamber, featuring four cylinders with two vertical valves per cylinder. The fuel was introduced upstream the inlet valves by means of plate four hole injectors capable of producing droplets with a Sauter mean-diameter of about $130 \mathrm{~nm}$. The author proposed that laminar flame speed, turbulence intensity and velocity magnitude have been considered among the factors that affect the extent 
of the engine cyclic variation. The influence of these parameters was investigated. Correlating these features of the charge with the measured coefficient of variation in the indicated mean effective pressure, a mathematical relationship was obtained by means of a multiple regression, by the author [50]. Further Reyes et al. [51] evaluated the relative influence of the equivalence fuel/air ratio and the engine rotational speed on the cycle-to-cycle variations produced in a single-cylinder spark ignition engine fueled with natural gas, through a thermodynamic combustion diagnostic model that includes genetic algorithms for parameter adjusting. The single cylinder air cooled engine under study had a flat piston bowl arrangement. A traditional estimator of the cycle-to-cycle variation is the Coefficient of Variation in Indicated Mean

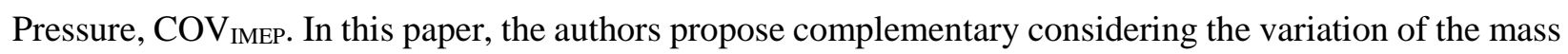
fraction burning rate of each individual cycle to characterize cyclic variation, The authors propose that standard deviation of mass fraction burned could be used as an indicator of cyclic dispersion of combustion events [51]. Kaleli et al. [52] used the approach controlling spark timing for consecutive cycles to reduce the cyclic variations of SI engines. A stochastic model was performed between spark timing and in cylinder maximum pressure by using the system identification techniques. The combustion process begins before the end of the compression stroke with spark event. Then, this process continues through the early part of the expansion stroke and, ends after the point in the cycle at which the peak cylinder pressure occurs. If the choice of ignition point versus crank angle is too late, then although the work done by the piston during the compression stroke is reduced, so is the work done on the piston during the expansion stroke, since all pressures during the cycles will be reduced. If the spark timing is controlled for consecutive cycles instead of the open loop system by predicting the pressure related parameters of the one step ahead cycle, it will be possible to reduce the cyclic variations. For the faster cycles, the ignition timing should be retarded and it should be advanced for slower cycles. The experiments for this study were performed on a FORD MVH418 spark ignition engine with electronically controlled fuel injectors [52]. Finally Ji et al. [53] studied the cyclic variation of large-bore multi point injection engine fueled by natural gas with different types of injection systems. The studied engine was a 12-cylinder natural gas engine mainly used for power generation. The quality of mixture formation was correlated closely with cycle-to-cycle combustion variation (COV), so COV was used to evaluate the influence of the shape and location of the injection nozzle as well as end of ignition (EOI) timing on mixture formation. According to the structural characteristics of the studied engine, four types of injection system with different shapes and locations were proposed to measure and analyze cylinder pressure in the same working conditions. The influence of the shape and location of the injection nozzle as well as EOI timing on mixture formation and combustion process was studied in the research. Experimental results showed that the mixture formation quality of high power gas engine which has weak airflow in the cylinder could be improved by optimizing the shape and 
position of the nozzle as well as EOI timing. Improvement of mixture formation can promote combustion process finally.

Methane which is the main composition of natural gas has unique tetrahedral molecular structure with larger $\mathrm{C}-\mathrm{H}$ bond energies, thus demonstrates some unique combustion characteristics such as high ignition temperature and low flame propagation speed, leading to the poor lean-burn ability and slow burning velocity. These may lead to the incomplete combustion, high misfire ratio and large cycle-by-cycle variations when utilizing natural gas in the spark ignition engine especially under lean mixture operating condition. One effective way to solve this problem is to mix the natural gas with a fuel that possesses the high burning velocity. Hydrogen is an excellent additive to improve the combustion of natural gas due to its low ignition energy and high burning velocity. Ma et al. conducted a work in a turbocharged lean burn natural gas S.I. engine with hydrogen enrichment, to investigate the effects of hydrogen addition on the combustion behavior and cycle by-cycle variations in a turbocharged lean burn natural gas spark ignition engine. They found that hydrogen addition contributes to reducing the duration of flame development, which has highly positive effects on reducing cycle-by-cycle variations [54]. Wang et al. studied the effect of hydrogen addition on cycle-by-cycle variations of the natural gas engine. Their results showed that the peak cylinder pressure, the maximum rate of pressure rise and the indicated mean effective pressure increased and their corresponding cycle-by-cycle variations decreased with the increase of hydrogen fraction at lean mixture operation [55]. Huang et al. [56] analyzed the cycle-by-cycle variations in a spark ignition engine fueled with natural gas hydrogen blends combined with EGR. The authors show that the cylinder peak pressure, the maximum rate of pressure rise and the indicated mean effective pressure decrease and cycle-by-cycle variations increase with the increase of EGR ratio. Interdependency between the above parameters and their corresponding crank angles of cylinder peak pressure is decreased with the increase of EGR ratio. For a given EGR ratio, combustion stability is promoted and cycle-by-cycle variations are decreased with the increase of hydrogen fraction in the fuel blends. Recently, Reyes et al. [51] characterized mixtures of natural gas and hydrogen (in different propositions) in a single-cylinder spark ignition engine by means of a zero dimensional thermodynamic model. A thermodynamic combustion diagnostic model based on genetic algorithms is used to evaluate the combustion chamber pressure data experimentally obtained in the mentioned engine. The model is used to make the pressure diagnosis of series of 830 consecutive engine cycles automatically, with a high grade of objectivity of the combustion analysis, since the relevant adjustment parameters (i.e. pressure offset, effective compression ratio, top dead center angular position, heat transfer coefficients) are calculated by the genetic algorithm. Results indicate that the combustion process is dominated by the turbulence inside the combustion chamber (generated during intake and compression), showing little dependency of combustion variation on the mixture 
composition. This becomes more evident when relevant combustion variables are plotted versus the mass fraction burned (MFB) of each mixture.

The formation of the flame kernel and the following flame growth through a laminar like phase depend on: the local air fuel ratio, the mixture motion and the exhaust gas concentrations in the spark-plug gap at the time of ignition and in the spark-plug region immediately after ignition. Cyclic variations occur because the bulk flow, turbulence, residual amounts and gasoline supplied to each cylinder vary from cycle to cycle. Moreover, within the cylinder, the mixing of air fuel and exhaust gas residuals is not complete, therefore the mixture is not homogeneous at the spark time. The turbulent nature of the flow in the cylinder causes random spatial and time-dependent fluctuations in the variables characterizing the mixture and its flow field. These fluctuations cause a random value of the mixture concentration in the spark-plug region, a random convection of the spark kernel away from the electrodes, a random heat transfer from the burning kernel, etc. [57-59]. In particular, the random displacement of the flame kernel during the early stages of combustion seems to play a major role in the origination of cycle variation in combustion.

Ozdor et.al. commented that despite many years of experimentation and research a full understanding of cyclic variation was still lacking, back then. They also mentioned previous studies which have shown that it may be possible to achieve a $10 \%$ increase in power for the same fuel consumption if cyclic variations could be eliminated. However, the elimination of cyclic variation may not be truly desirable even if it were possible, which still remains true till date [60]. According to Ozdor [61], Matekunas [62] and Heywood [47], the cyclic variations can be characterized by the parameters in four main categories; pressure related parameters, combustion related parameters, flame front related parameters and exhaust gas related parameters. Pressure related parameters are the in-cylinder maximum pressure $\left(\mathrm{P}_{\max }\right)$, the crank angle at which the in-cylinder maximum pressure occurs $\left(\mathrm{qP}_{\max }\right)$, the maximum rate of pressure rise $(\mathrm{dP} / \mathrm{dq}) \max$, the crank angle at which the maximum rate of pressure rise occurs $q(\mathrm{dP} / \mathrm{dq})$ max, indicated mean effective pressure (IMEP) of individual cycles. Combustion related parameters are about the heat release, burnt mass fraction and combustion duration characteristics. Flame front related parameters are about the formation, progression and the speed of the flame. The last category is on the subject of the concentration of exhaust gases in the exhaust. Moreover, even if many factors do not cause cyclic variation, they determine the sensitivity of the engine to the factors which give origin to the phenomenon. For example, the overall weakness of the mixture [63], the spark-plug and the spark-timing and the in cylinder mixture motion do not cause cyclic dispersion in combustion themselves but affect the extent of cyclic variation caused by other factors [64-66]. The conclusion seems to be that anything that tends to slow down the flame propagation process, especially in its development stage, tends to increase the cyclic dispersion in combustion. In a completely different perspective, Pischinger and Heywoood investigated how heat losses to the spark plug electrodes affect the flame kernel development in an SI engine [67]. A conventional spark 
plug and a spark plug with smaller electrodes were studied in M.I.T.'s transparent square piston engine. The purpose was to learn more about how the electrode geometry affects the heat losses to the electrodes and the electrical performance of the ignition system, and how this affects the flame development process in an engine. The spark plug with the smaller electrodes was shown to reduce the heat losses to the electrodes, and thereby extend the stable operating regime of the engine. At conditions close to the stable operating limit, cycle-by-cycle variations in heat losses cause significant cyclic variations in flame development. Cyclic variations in heat loss are due to cyclic variations in the contact area between flame and electrodes. The contact area is largely controlled by the local flow field in the spark plug vicinity: cycles in which the flame is convected away from the electrodes have a smaller contact area than cycles in which the flame remains centered in the spark gap.

The cyclic variations are due to the variations in combustion process. Although the engine runs under steady state conditions, there are variations in the pressure traces during the combustion process especially due to the variations in the rate of flame development and the combustion duration for consecutive cycles. While the combustion for some cycles occurs at optimum conditions, it may occur faster for some cycles and slower for others. The faster combustion cycles have higher in cylinder maximum pressure values $\left(\mathrm{P}_{\max }\right)$ than slower cycles, and the crank angle at which the in cylinder peak pressure $\mathrm{qP}_{\max }$ occurs closer to TDC. Conversely, as the rate of combustion decreases, the $\mathrm{P}_{\max }$ decreases and the $\mathrm{qP}_{\max }$ increases.

\subsection{Optical-access engines for combustion studies}

The visualization of in-cylinder mixing processes and combustion characterization remain a challenge from the very beginning of the IC engine. A particular interest is in the evolution of the combustion process of alternative fuels used pure or in blends with fossil fuels, in engines adopting more or less conventional configurations or new ignition systems, which could help to make possible further steps in the development of systems characterized by ever-lower emissions and fuel consumption levels. Visualization studies today still serve this purpose - after over a century of application, studies in optically accessible engines continue to provide new perspectives in engine research [68]. 


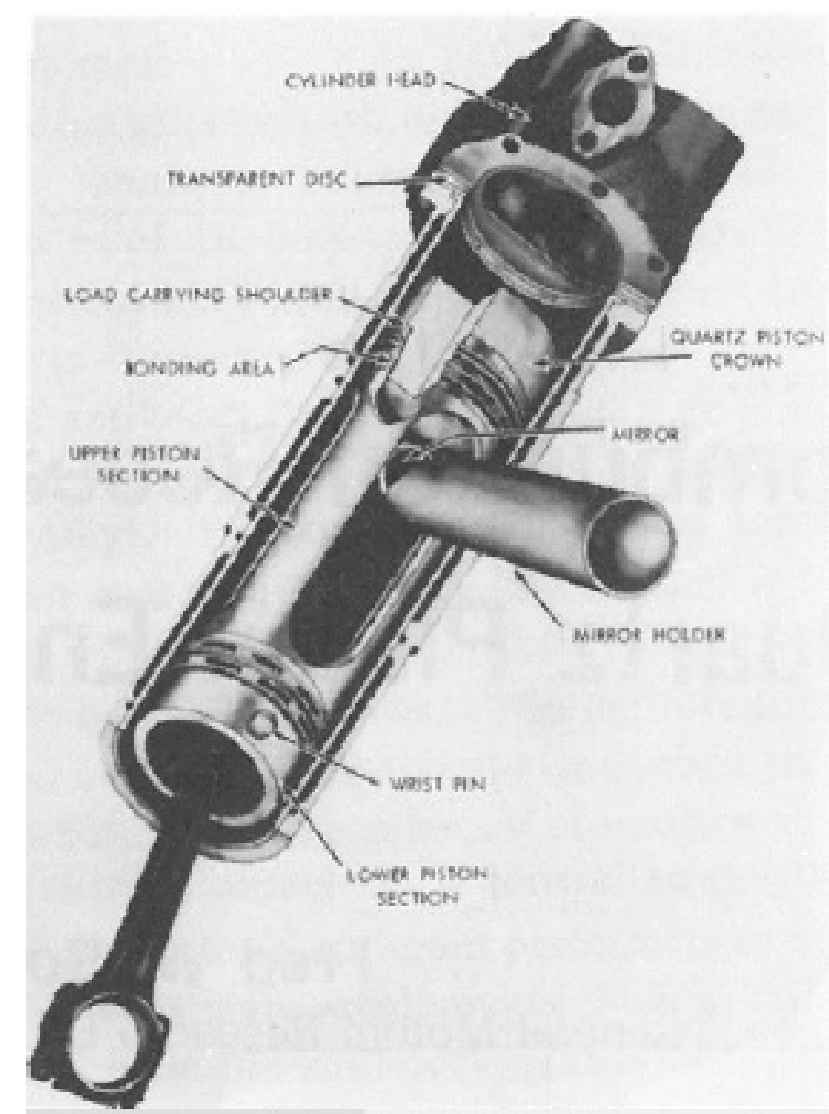

Figure 2.1 Schematic diagram of Bowditch’s slotted, extended piston design [69, 70]

With regards to experimental engine research, single-cylinder, optical-access engines have been widely used as they allow the application of both qualitative and quantitative, non-intrusive, optical diagnostic techniques to gain a detailed insight of the mixing, combustion and emissions formation processes occurring in-cylinder. Although earlier work performed on optical engines provided useful experimental data enabling an improved understanding of fundamental in-cylinder physical phenomena and for the validation of CFD models, the value of optical engine data was often deemed to be rather limited from the engine developer's point of view since optical engines were not considered to be fully representative of standard all-metal engines. In particular, certain compromises are often made such as the use of simplified piston bowl geometries in order to maximize engine optical access. Furthermore, single-component fuels rather than standard commercial fuels are often employed due to laser diagnostic constraints. Non-standard piston rings manufactured from specialist materials are also used on optical engines due to the need to dry-run these engines (i.e. the upper cylinder liner on the optical engine is not lubricated) and as a result, it is often claimed that engine blow-by is more significant in optical engines compared to standard engines. 
In this section of the review of optically accessible engines, the unique characteristics of these special research engines and how these characteristics evolved to enable measurement of the desired quantities in a SI engine will be discussed. The basic architecture of the modern day optical accessible piston assembly was designed in 1958 by F.W. Bowditch of the General Motor Corporation, shown in Figure. Bowditch's essential innovation involved slotting the piston extension to allow the combustion chamber to be viewed from below via a $45^{\circ}$ mirror and a quartz piston top. In this way, a large degree of optical access could be obtained in overhead valve designs without significant modifications to the combustion chamber geometry. Bowditch reports successfully operating this engine at compression ratio up to 10.7:1 at engine speeds of $1200 \mathrm{rpm}$. In developing this engine, Bowditch addressed many of the design challenges that optical designer will struggle with today. The shape and size of the quartz piston top, was selected considering mechanical, thermal and optical stress requirements. The operational difficulties that Bowditch encountered with this engine are likewise familiar to modern researchers. Excessive oil leakage past the valve guides was found to eventually foul the mirror, a problem that was resolved with special valve stem seals. Likewise, oil coming up from the crankcase was problematic, and required a special ring pack to resolve.

Post 1945 work on SI engines, an engine design incorporating a large quartz head window similar to that used by Rassweiler and Withrow [71] was employed by Nakanishi, et.al [72]. Few decades later, researchers from MIT's Sloan Automotive Laboratory [73] studied the combustion process in SI engine using flame photographs. In a SI engine, the combustion is initiated with the assistance of spark discharge and propagating a turbulent flame through a premixed air-fuel mixture. The researchers believed that the details of the flame propagation process influence the efficiency of energy conversion and engine performance, as well as pollutant formation. They studied the structure of flame development and its propagation, with the use of a square cross section engine [74] where two of the cylinder walls were quartz windows to permit full optical access to the cylinder volume throughout the entire engine cycle. The engine had a CR of 4.8:1, was run at a speed of $1380 \mathrm{rpm}$ and was fired in short bursts of approximately 16 cycles. After approximately 3 fired cycles, the combustion was reasonably stable. Similar 'burst' firing strategies to obtain stable operation or desired surface temperatures in optical engines have been subsequently employed by others [75-77]. From the study, it was summarized that, from the set of photographs illustrating important aspects of flame development in a SI engine, both bulk gas motion and smaller scale turbulence were seen to have an influence on the flame kernel within a few degrees after ignition. The flame kernel can be convected away from the spark gap, the direction and extent of motion varying cycle by cycle. Around the same year, Richman and Reynolds developed the transparent cylinder research engine having a compression ratio which could be varied from 6.25 to 11, and a speed up to $3000 \mathrm{rpm}$. The innovative features of this engine were the use of electro hydraulic valve actuators and thin walled transparent cylinder fabricated from single crystal sapphire. Further after, due largely to the expense of full transparent liners, a 
number of researchers chose instead to employ a transparent ring of limited height for the upper portion of the liner. In parallel the drawback to the transparent liner designs with the lack of optical access into the combustion chamber of pent roof design, was rectified by placing optical windows in to the gables of engine head.

A quickly removable liner concept is now an integral part of such modern optically accessible engines. With excellent optical access to the entire combustion chamber, and the ability to rapidly clean the optical windows, the next step towards making the most realistic engine measurements involved adopting piston shapes matching prototype engines. More recently, the optical engines developed by Lotus Engineering Ltd., in conjunction with Loghborough University and another one developed by Toyota Central R\&D Labs has features incorporated to take measurements similar to production engines. The first engine features the hydraulically actuated Lotus Active Valve Train system such that there is no obstruction from a timing belt assembly. Additionally, the transparent liner and gable windows are incorporated into a single piece, providing seamless access to the combustion chamber. The design targets for this engine were a maximum cylinder pressure of $60 \mathrm{bar}$ and a maximum speed of $5000 \mathrm{rpm}$. To achieve this speed, the developers used both primary and secondary balancing shafts for the crankcase [78]. To enable still higher speeds, the Toyota design abandoned the usual balancing approach, and implemented a system based on twin, vertically opposed pistons [79], minimizing the bending forces on crankshaft. 


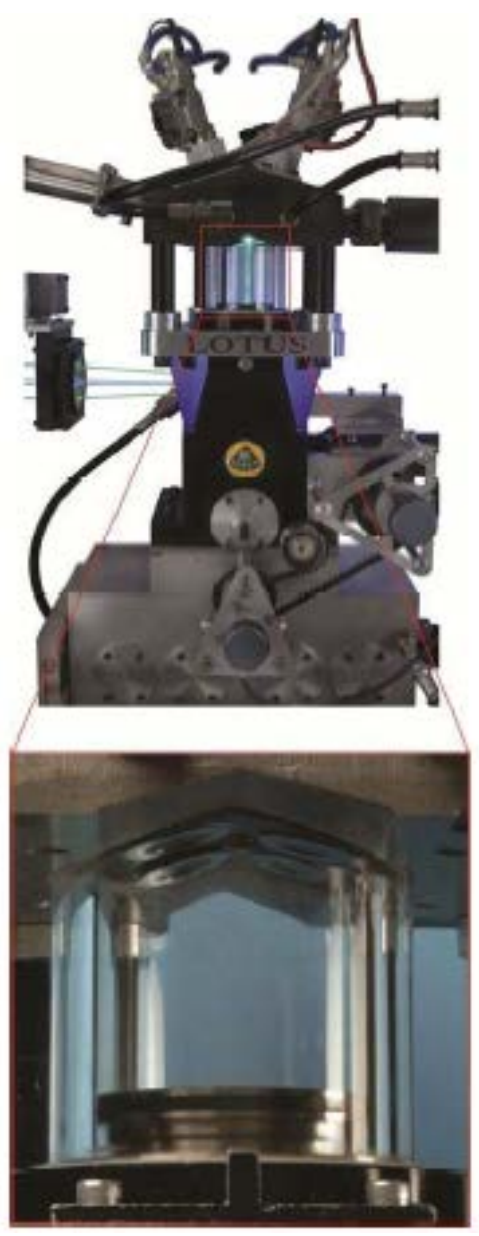

Figure 2.2 High-speed optical engine developed by Lotus Engineering Limited and Loughborough University ([79]) 


\section{Chapter 3}

\section{Experimental Setup}

This chapter describes the engine setup and explains the testing procedure. This study was performed in one of the engine laboratories in the WVU Evansdale campus. Figure 3.1 shows a schematic of the experimental setup, which consists of a single-cylinder research engine, dynamometer, control and instrumentation hardware for measuring and modifying the operational conditions of the engine.

A 75-kW dynamometer (McClure 4999 Trunnion type) maintains a constant engine speed regardless of the engine load. The test setup includes an air flow measurement device, temperature measurement devices, fuel delivery equipment, different engine sensors (for e.g., cam sensor, crank sensor, etc.), and a central engine controller unit. A laminar flow element (LFE) measures intake flow rate, K-type thermocouples measure the temperatures of engine coolant, engine oil, intake air, and exhaust gas. A 100kg load cell with a strain gauge arrangement (TEDEA-Huntleigh 104H Coated) measures the engine torque. Further, an emissions bench with different types of gas analyzers for measuring the constituent species concentration in the exhaust gas is present. An aftermarket engine management system (Megasquirt Model $3 \mathrm{X})$, containing the pre-programed engine maps with desired operating parameters, is synced with all the essential engine sensors to monitor/control the engine operation.

An in-house build skip firing controller (based on Arduino Nano prototyping platform) receives input from the engine encoder and the engine management system to allow the fuel injector to skip certain number of engine cycles. Additionally the skip firing controller provides burst of signals for triggering the camera for image acquisition during the fired engine cycles. These controls are vital for experiments conducted in an optical engine.

\subsection{The research engine}

The single cylinder research engine (Ricardo/Cussons, Model Proteus) was built to meet the need for a robust single cylinder machine in the 100-150 mm bore and 120-165 mm stroke range. Such an engine enables a wide variety of research areas to be investigated and in particular to replicate commercial multicylinder engines without incurring the problems and costs of adapting a multi cylinder engine for research purposes. The engine, which is based on a Volvo TD 120 engine, has a classic toroidal bowl in piston combustion chamber in conjunction with a helical swirl. In addition, the same engine could be adapted for 
both DI/IDI operations as well as photographic build for in cylinder flame observations. The engine is mounted on an integral base frame with separate oil and cooling modules. The control instrumentation is provided in a remote console. The original diesel configuration was modified to a high-compression spark ignition (SI) engine. As a result, the original diesel pump and injector were removed from the engine and the intake system has been modified to accommodate a port fuel injector. In addition, the original diesel injector mount was modified to fit a NG spark plug.

\subsubsection{Base engine}

The base engine can be modified for direct injection (DI), in-direct injection (IDI) and photographic investigations by replacing the cylinder head, piston and combustion chamber components. Table 3.1 lists the general specifications of the base engine. The reported maximum intermittent power of the engine is $55 \mathrm{~kW}$, obtained on a load range curve at $36.7 \mathrm{rev} / \mathrm{sec}$ at a boost ratio of 3.0 and inlet air temperature $65^{\circ} \mathrm{C}$. Figure 3.2 shows images of the test facility.

\begin{tabular}{|c|c|}
\hline Bore & $130.2 \mathrm{~mm}$ \\
\hline Stroke & $150 \mathrm{~mm}$ \\
\hline Swept Volume & 1.997 liters \\
\hline Connecting Rod Length & $275 \mathrm{~mm}$ between centers \\
\hline Valve timings & Inlet opens 12 BTDC \\
& Inlet closes 40 BTDC \\
& Exhaust opens 54 BTDC \\
& Exhaust closes 10 ATDC \\
\hline Rated speed & 1,200 rpm \\
\hline Compression Ratio & $10: 1$ \\
\hline Combustion chamber & Flat piston \\
\hline
\end{tabular}

Table 3.1 Engine specifications in the photographic build 


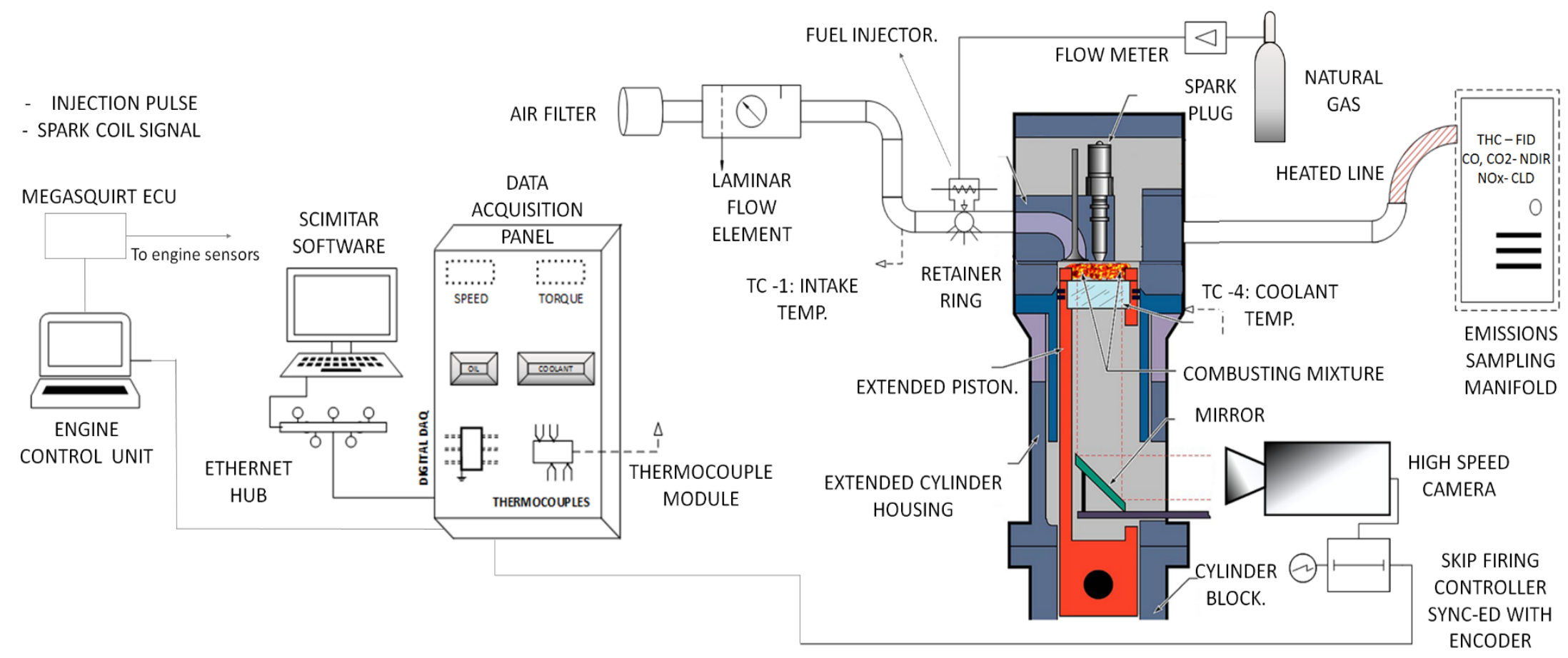

Figure 3.1 Schematic arrangement of the engine test setup 


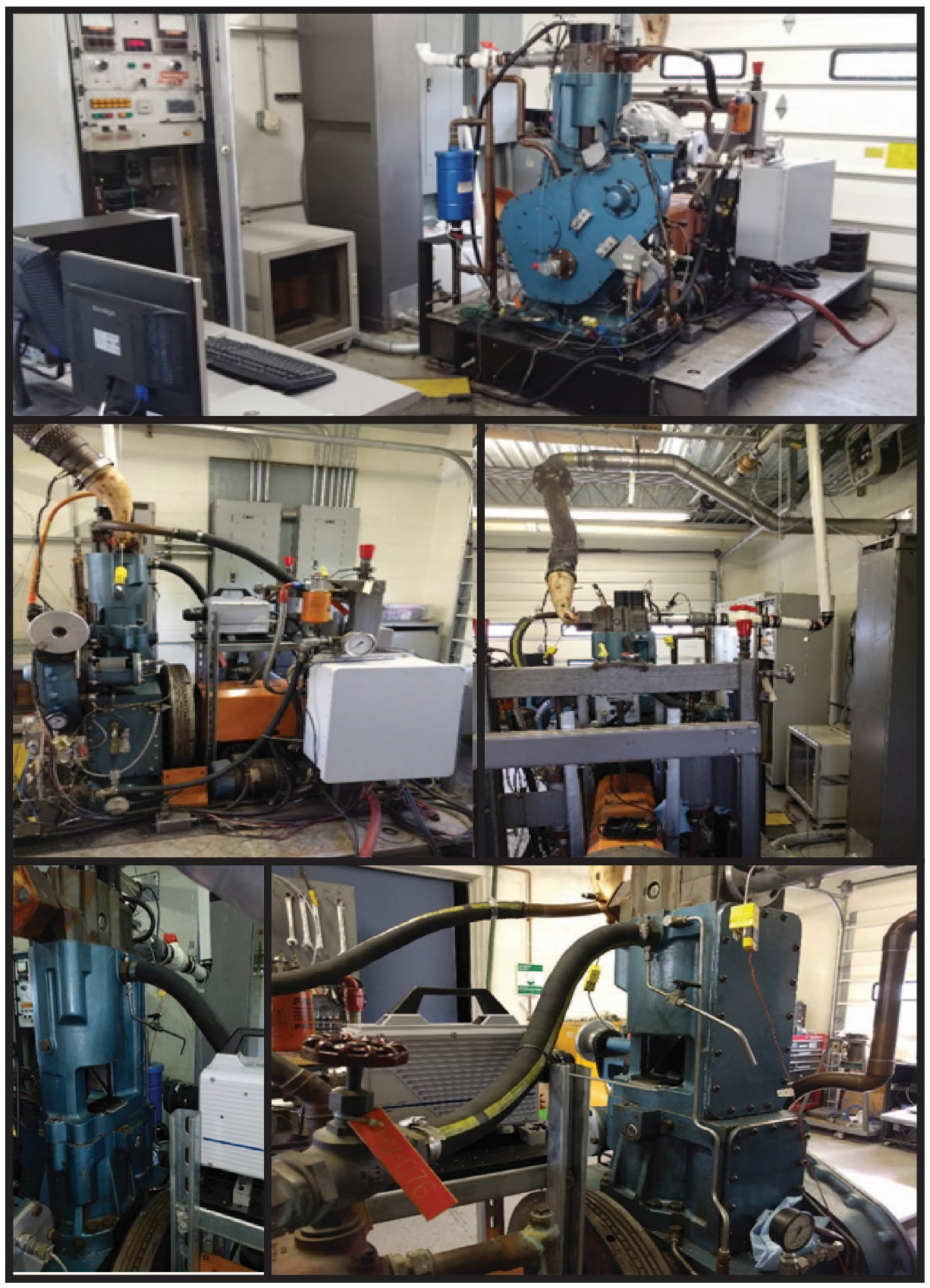

Figure 3.2 Different views of the testing facility 


\subsubsection{Optical experiment test procedure}

A Bowditch extended piston mounted inside a special engine extension "sandwiched" between the crankcase base and the cylinder head provides the optical access to the engine combustion chamber from below. However, this special arrangement of photographic piston and its corresponding liner does not contain the regular oil-feed channels. Hence, it is recommended by the manufacturer that the photographic engine build be run for just the minimum time necessary to obtain the conditions required for combustion imaging. The only method of lubrication for the extended piston assembly is the application of a small amount of molybdenum disulphide anti-scuffing paste to the walls of the upper liner. This provides enough lubrication for a few minutes of operation and hence need to be re-applied every run of the engine. However, this also means that the cylinder head needs to be removed any time a new application of anti-scuffing paste is needed. In addition, the application of a larger volume of the lubricating paste would lead to fouling of the optical windows and hence would distort the quality of the images recorded with the high speed camera.

There are significant differences between the optical engine configuration and the DI/IDI engine configurations. These differences mainly arise from the design of the Bowditch piston. The Bowditch piston produces a lower compression ratio than the conventional piston; 10:1 compared to 13.3:1. In addition, the flat quartz piston creates a cylindrical bowl, compared to the original toroidal bowl. Further, the thermal conductivity of quartz is much lower than the one of the original aluminum piston, which can promote the formation of hot spots. Finally, the optical liner used with the Bowditch piston has a greater clearance than the stock thermodynamic liner, which results in greater blow-by. The Bowditch piston uses two of the three stock (thermodynamic) piston rings, which necessitate manual lubrication of the liner and piston rings at very frequent intervals during testing. Because of these numerous differences between the optical and thermodynamic engine configurations, a different operating protocol is required when performing optical engine measurements. To keep the quartz window from over-heating, the engine must be operated in a skipfired mode, where a fired cycle is followed by $n$ motored cycles (with $n \geq 1$ ) to reduce the heat transferred to the window and allow the window to cool between the fired cycles. Because of the numerous mechanical and instrument-related limitations, a specific optical testing protocol was followed to maximize the number of optical measurements, which is presented in figure 3.3. 


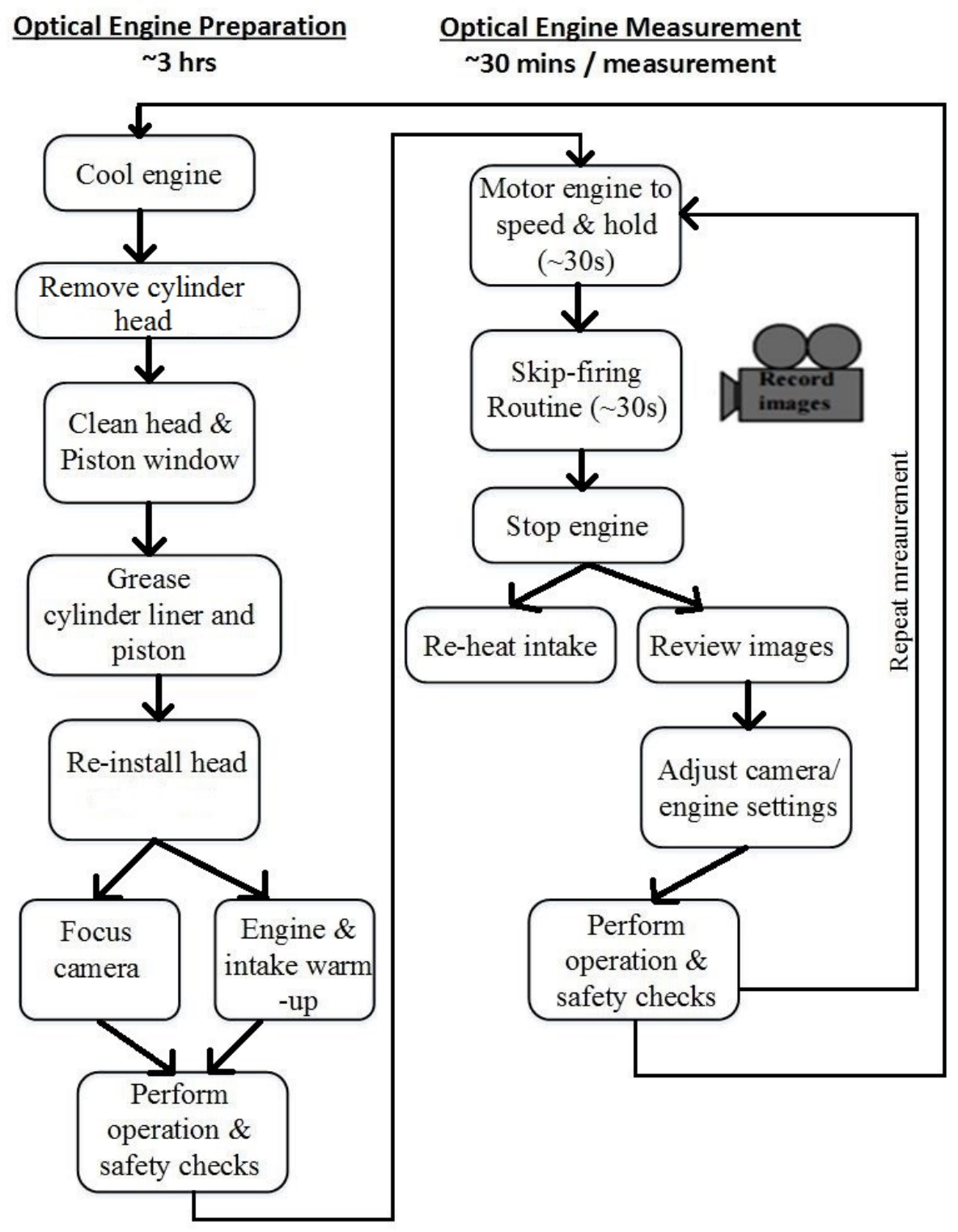

Figure 3.3 Experimental protocol

\subsubsection{Dynamometer}

The 75kW DC dynamometer is mounted on trunnion bearings supported by pedestals. The unit is force ventilated by an electrically driven fan mounted on the base frame adjacent to the dynamometer. The dyno carries two torque arms each of which has a weight which can be adjusted in its slotted mounting hole to achieve static balance. The right hand torque arm is connected through a load limiting device to a 100-kg load cell that provides a continuous display of torque $(\mathrm{Nm})$ at the control unit. The dynamometer was calibrated through a 10-point calibration ranging from $10 \mathrm{~kg}$ to $100 \mathrm{~kg}$. The effective torque arm radius was 
fixed at 407.8mm during the calibration. An arrangement of thyristor bank (KTK Model PS4O) powers up and drives the dynamometer, so that it can act as DC motor to drive the engine while it is motoring, or as a DC generator when the engine is fired (the DC power from the dynamometer is converted to 3 phase A.C. mode by the converter unit and fed back into the mains supply). A tach generator mounted on the dynamometer shaft provides a speed signal to the closed loop speed control system so that the speed selected at the control console is maintained by automatic adjustments to the motoring or loading torque.

\subsubsection{Engine control unit}

The engine control unit is a racked panel consisting of three main sub systems: the safety shutdown unit (SSU), the dynamometer control unit and the speed/torque control unit.

SSU is a safety trip system designed to protect the equipment based on the feedback of a certain fault conditions, such as dyno fault, under speed, over speed, oil pressure, or coolant temperature. In the event of any of these conditions being unsatisfactory, the appropriate warning light will start pulsing.

The dynamometer control unit consists of start/auto, absorb and motor controls to facilitate the dyno operation. In the start/auto mode, the dynamometer automatically changes from motor to load and vice versa to maintain speed setting. In absorb mode, the dynamometer absorbs the power generated by the engine. The set speed is not maintained if engine power is below pumping and friction losses. Further, in the motor mode, dynamometer motors only. To start the dynamometer the SSU must be reset and coolant pump should be kept on.

The torque-and-speed rack consists of digital and analogue displays reading the engine load (Nm) and speed (rev/sec).The signal received from the engine is conditioned and amplified through a dedicated signal conditioning system, whose detailed functionality is listed in the operating manual [80].

\subsubsection{Intake air system}

The engine is naturally aspirated through a 2"-diameter pipe system. A 2"-diameter laminar flow element (LFE; Meriam, Model 50MC2-2) ensures high accuracy, fast response time, and good repeatability of the intake air flow measurements (max 100 SCFM at a differential pressure of 5 inches of water). The intake air is filtered before passing through the LFE. As higher intake flow pulsations are expected from a single cylinder engine, pressure snubbers and orifices are placed downstream the LFE to dampen the pulsation effects produced by the intake valve motion. The LFE operation is detailed next. In addition to multiple internal flow straighteners to eliminate any turbulent flow, the LFE consists of an absolute pressure transducer positioned before and differential pressure transducer positioned across the flow straightening mechanism to calculate the volume flow of air flowing through. Included with the LFE is a NIST traceable calibration curve that provides the volumetric flow rate of air as function of the measured pressure. The 
volumetric flow rate (Q) at standard conditions is determined from the differential pressure across the LFE using equation 3.1:

$$
Q_{\text {actual }}=\left(B^{*} D P\right)+\left(C^{*} D P^{2}\right)
$$

where $B$ and $C$ are unique constants specified by the manufacturer after the LFE calibration. The flow rate calculated with equation 3.1 is then corrected for the difference in fluid viscosity relative to the viscosity at standard conditions:

$$
Q=\left(B^{*} D P\right)+\left(C * D P^{2}\right) * \frac{\mu_{s t d}}{\mu f}
$$

where $\mu_{\text {std }}$ is the viscosity of the viscosity of flowing gas at $70 \mathrm{~F}$ in micro-poise and $\mu_{f}$ is the viscosity of the flowing gas at the flowing temperature. Further, for the calculation of actual volumetric flow rate in standard conditions, the pressure and temperature correction factors are applied to the steps described above, to yield the final equation.

$$
Q_{\text {corrected }}=\left(B^{*} D P\right)+\left(C^{*} D P^{2}\right) * \frac{\mu_{s t d}}{\mu f} * \frac{T_{s t d}}{T_{f}} * \frac{P_{f}}{P_{\text {std }}}
$$

A 30 gallon air tank is mounted 30" downstream of the LFE and 6” upstream of the intake to dampen the pressure fluctuations in the air intake system due to the cyclic opening and closing of inlet valve.

\subsubsection{Engine cooling and lubrication system}

Engine cooling is realized through a closed pressurized coolant system filled with a 50/50 mixture by volume of demineralized water and commercial anti-freeze. The pressurized header tank is a structure formed from rectangular steel tube constructed as an H-frame; when viewed from the engine the left hand leg and top section only form the engine coolant tank. The coolant is drawn from the bottom of the header tank and is pumped by an electrically-driven pump through the heat exchanger before passing out to the engine cylinder jacket. Out of the heating arrangement, the $6 \mathrm{~kW}$ heater is used for the photographic build to achieve operating temperature before firing the engine. Temperature control of the coolant is achieved by a sensor in the vertical leg of the header tank, which is connected by a capillary actuator to an in-line valve controlling the raw water flow through the heat exchanger.

Engine oil lubrication is realized through a separate temperature and pressure control loop. The lubricating oil is drawn from the engine oil sump by an electrically-driven pump and pumped through the heat exchanger, oil filter and temperature sensor pocket before delivery to the oil distribution manifold at 
the engine. The oil temperature is controlled by a sensor which is connected by a capillary actuator to an inline valve controlling the raw water flow through the heat exchanger. A relief valve at the oil distribution manifold, maintains the oil pressure to 4 bar thereby delivering the excess oil back to the engine sump. The minimum oil pressure of 2 bar is monitored by a pressure switch also at the distribution manifold, which provides a signal to the SSU if the pressure fails. The engine oil sump also contains two $1.5 \mathrm{~kW}$ electrical heaters which are used to warm up the oil to working temperature prior to the start of the optical experiments.

The fuel system consists of a chemically-pure methane gas bottle (Airgas CP Methane- 99.5\% purity, Size 300) connected to the intake manifold through barbed connections and a hydrocarbon-fuel-resistant Buna-N rubber hose. The custom injection system uses 2 NG port fuel injectors (IG7 Navajo) that deliver the fuel to the intake manifold $55 \mathrm{~mm}$ from the intake valve. The injection duration is determined according to fuel maps set for a given operating conditions. Table 3.2 lists the detailed composition of the fuel used for this study.

\begin{tabular}{|c|c|}
\hline Fuel composition and characteristics & Value \\
\hline Methane & $99.5 \mathrm{vol} \%$ \\
\hline $\mathrm{O}_{2}$ & $<50 \mathrm{ppm}$ \\
\hline $\mathrm{H}_{2} \mathrm{O}$ & $<10 \mathrm{ppm}$ \\
\hline $\mathrm{C}_{2} \mathrm{H}_{6}$ & $<1000 \mathrm{ppm}$ \\
\hline $\mathrm{N}_{2}$ & $<4000 \mathrm{ppm}$ \\
\hline Molecular weight & $16.0425 \mathrm{~g} / \mathrm{mol}$ \\
\hline Specific volume & $24.11 \mathrm{ft}^{3} / \mathrm{lb} @ 70^{\circ} \mathrm{F} \& 1 \mathrm{~atm}$ \\
\hline
\end{tabular}

Table 3.2 Composition specification of chemically pure grade methane gas

\subsection{Data acquisition}

There are two data acquisition systems in the setup- high speed crank angle resolved in-cylinder data acquisition system and a $10 \mathrm{~Hz}$ sampling frequency, python based software to acquire and log other essential engine parameters such as temperature profiles, intake flow, engine load and emissions concentration.

\subsubsection{In-cylinder data}

Piezoelectric sensors (Kistler, Model 6011) are used for in-cylinder pressure measurement. A charge in sensor capacity (37 pC/bar) corresponding to a pressure change is output from the pressure transducers 
to a Kistler charge amplifier type 5010. The signal is amplified and related to a voltage, which is then output to a DAQ card (National Instruments, Model SCB-68). A rotary optical incremental type shaft encoder (BEI, Model H25D) coupled to the crankshaft pulley measures engine speed and transmits the digital information (1800 clock pulses per rotation and 1 Z-pulse every rotation of the encoder) to the DAQ card. Additional inputs acquired by the DAQ card for combustion analysis are intake and exhaust gas temperature from K-type thermocouples. A high-speed multifunction M Series data DAQ board optimized for superior accuracy at fast sampling rates (National Instruments, Model PCI-6250) conveys the analog signals to a PC for analysis. In-house built software analyzes the data to provide preliminary combustion information. The Z-pulse mark provided from the shaft encoder helps identify the TDC offset of the engine. The accuracy of TDC offset is very important for the IMEP calculation and heat release calculation. From the acquired pressure data, suitable post processing code is executed in MATLAB to calculate the combustion related parameters such as apparent heat release rate, mass fraction burned, and indicated mean effective pressure (IMEP) variability.

\subsubsection{Other engine parameters}

An in-house data acquisition software (SCIMITAR) that was developed by Center for Alternative Fuels, Engines and Emissions (CAFEE) engineers on a Python software platform is installed on a Windows PC and used for the monitoring and time series logging of the essential engine parameters. Devices such as transducers, thermocouples and strain gauges transmits a suitable current or voltage signal which is proportional to the magnitude of the physical quantity measured. Over-the-shelf DAQ systems (Labjack, Model UE9 and ICPCON, Model 7010Z) are used as the hardware interface that receive the signals from the various engine and dynamometer sensors and send them to the PC. Module blocks programmed in the SCIMITAR software allow calibration and data logging of the engine sensors used for various measurements. The DAQ devices communicate with the PC through Ethernet-based routers. The model and technical specifications of the different data acquiring equipment are tabulated below in Table 3.3.

\begin{tabular}{|c|l|}
\hline \multicolumn{1}{|c|}{ Parameter } & \multicolumn{1}{c|}{ Specification } \\
\hline $\begin{array}{c}\text { Engine Temperatures - coolant, oil, } \\
\text { intake manifold, exhaust manifold }\end{array}$ & $\begin{array}{l}\text { Model: Omega K type, ungrounded } \\
\text { Output: 0 - 25mV }\end{array}$ \\
\hline Absolute pressure & $\begin{array}{l}\text { Model: Viatran 0-15 psi } \\
\text { Output: 0-5 V }\end{array}$ \\
\hline Differential pressure & $\begin{array}{l}\text { Model: Ashcroft XLdp 5” WC } \\
\text { Output: 4- 20 mA }\end{array}$ \\
\hline
\end{tabular}




\begin{tabular}{|l|l|}
\hline Engine load & $\begin{array}{l}\text { Model: TEDEA 301-23, } 100 \mathrm{~kg} \\
\text { Output: 0-10V DC }\end{array}$ \\
\hline
\end{tabular}

Table 3.3 Technical specifications of the sensors used for data acquisition

\subsection{Image acquisition}

A high-speed camera (Photron, Model Fastcam SA5) acquires images of the combustion events through an f/1.4D 50-mm Nikon lens. The system is composed of the camera body, AC power supply, and the PFV controls software. The camera is mounted on a bridge shown in figure 3.2 and secured in place to minimize the effect of vibration during engine operation. A linear slider mechanism helps focusing the camera on the area of interest inside the combustion chamber.

\subsubsection{Optical measurement system}

The high-speed camera captures the combustion process from the SOI to the EOC. The camera was operated at 15,000 frame-per second (fps), which corresponds to 2.77 frames per crank-angle degree (CAD) at an engine speed of $900 \mathrm{rpm}$. The maximum image resolution at this framing rate was 512 x 512 pixels, which resulted in a $113 \mathrm{~mm}$ x $113 \mathrm{~mm}$ area. The camera exposure times was set to $58.82 \mu \mathrm{s}(1 / 17,000 \mathrm{~s})$. The camera body contains integrated chip (IC) based memory for image recording, equipped with a Gigabit Ethernet interface, as shown in figure 3.4. The interface permits full camera control and data download is possible via fast Ethernet connection to a PC. The external synchronization/trigger signals, input/output connector are also housed at the back of the camera. For all cases no additional filters were used. A circular window in the center of a Bowditch piston allows camera access from below via a mirror placed at a $45^{\circ}$ angle. Figure 3.5 shows a schematic diagram of the photography system setup. 


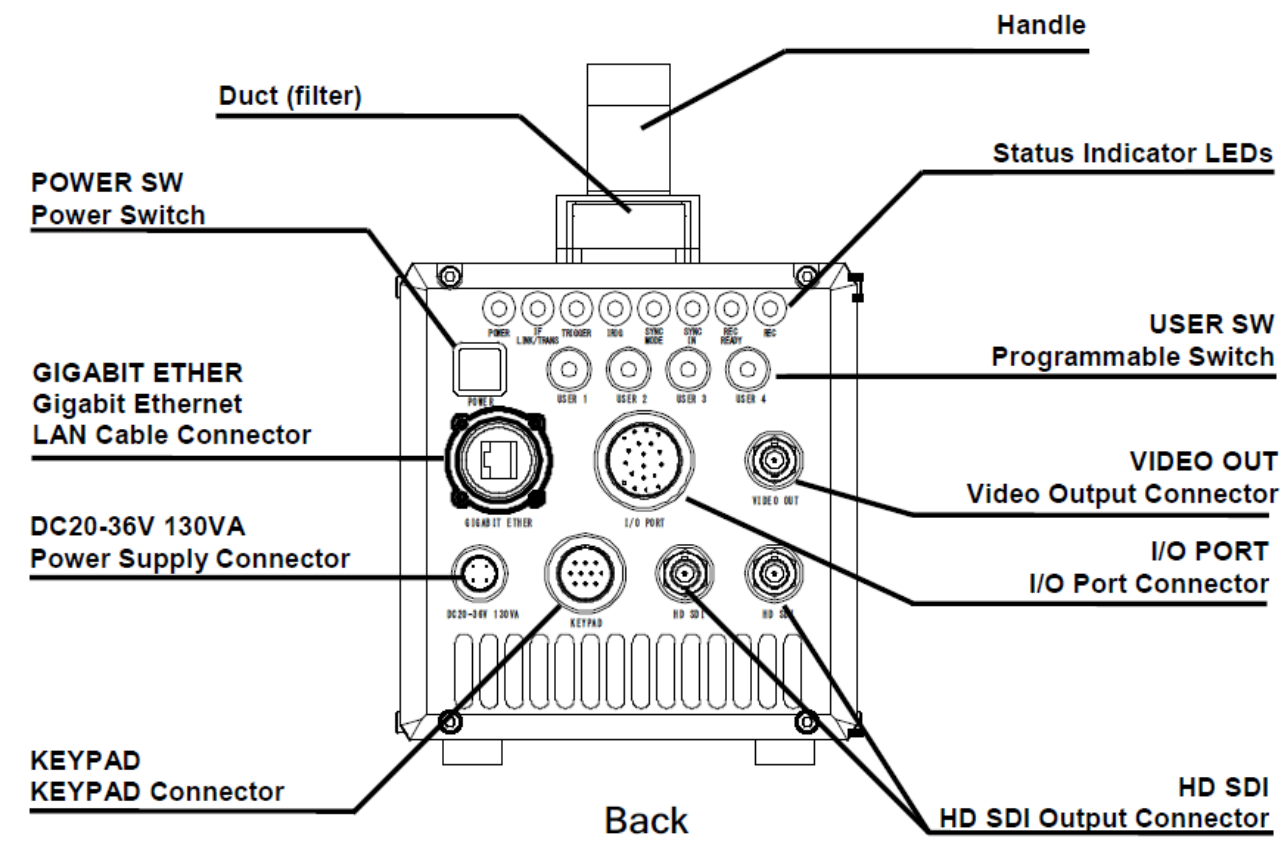

Figure 3.4 Sketch of rear panel of the Photron SA5 high speed camera [81]

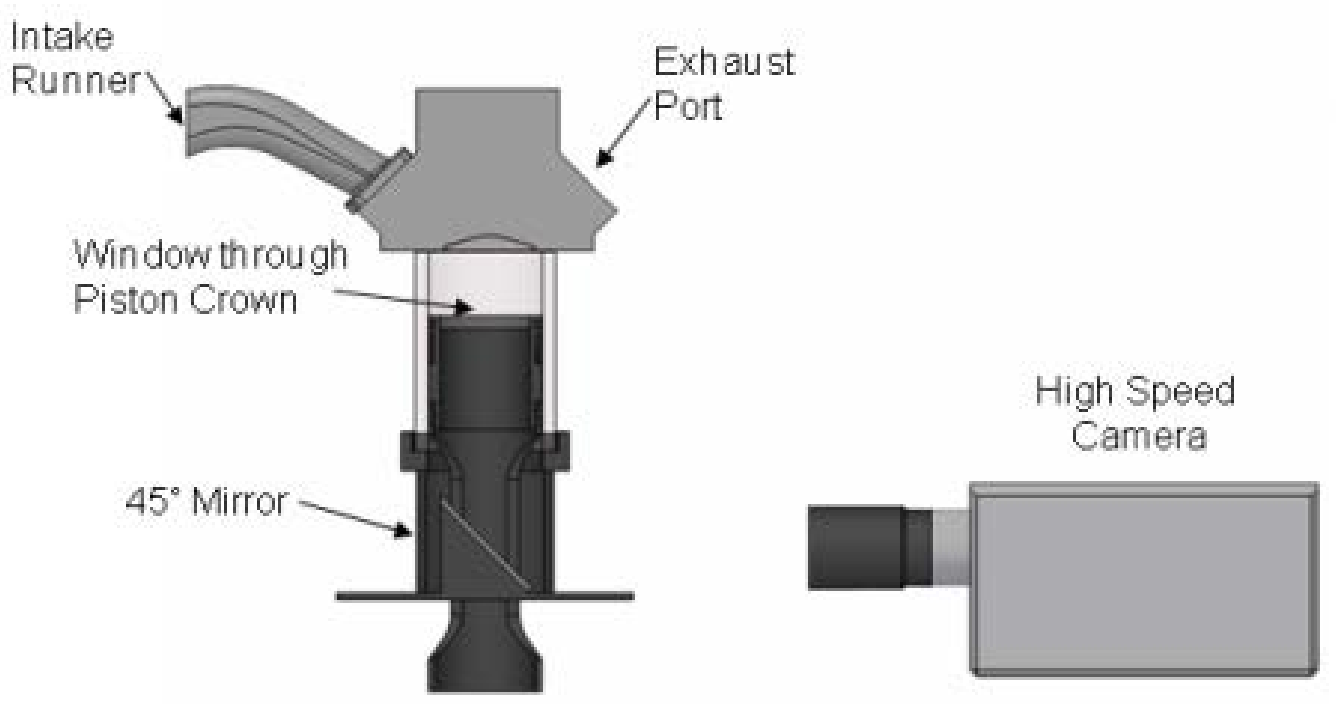

Figure 3.5 Schematic showing the optical measurement system [82]

\subsubsection{Image acquisition software}

Photron PFV Version 3.6.4 software controls camera operation (i.e., frame rate, active pixel array size, shutter speed, and camera triggering). The flame front propagation was recorded after SOC. The images were exported as .raw or .avi movies and subsequently compiled into a series of still images (*.tiff) for image processing using Matlab Image Processing toolbox. 


\subsection{Engine management system}

An aftermarket electronic engine control unit (ECU; Megasquirt, Model V3.0X/3.5.7) was used to control and monitor the optical engine operation in the SI configuration. The ECU was used only for controlling the fuel injection rate and spark ignition timing based on the set operating conditions. These two parameters are determined by the software program supplied with the Megasquirt- known as Tuner Studio. Since the mixture entering the chamber is homogeneous, fuel injection duration is based on a mass per cycle setting, calculated from a desired equivalence ratio value. Calibration of the injector flow rate is included in Section 3.5. The ECU allows the adjustment of fuel through volumetric efficiency tables and adjustment of ignition timing (spark advance) as functions of engine speed (RPM) and engine load (manifold pressure, MAP). A higher volumetric efficiency value increases the amount of fuel being injected during the intake stroke and a lower volumetric efficiency decreases the amount of fuel. The Tuner Studio program lets us choose between different options of control algorithms for the calculations of pulse-width for the injectors. In the present study, Alpha-N algorithm was chosen. Alpha-N uses throttle position (alpha) and RPM (N) to calculate the amount of fuel to inject as opposed to using MAP sensors or other control algorithms. At each of the mapped operating condition of the engine, the ECU looks up in to the VE table, AFR table and thus places its correction, deciding upon how much fuel to be injected and what would be the pulse-width for that particular injection event. Similarly, ignition map specifies the spark advance (in $\mathrm{CA}{ }^{\circ} \mathrm{BTDC}$ ) to be commanded to the spark plug, for each cell in the operating map.

Tuner Studio requires two signals from the engine to determine timing for engine and peripheral system events relative to piston position and stroke. A 6 tooth crankshaft encoder and a Hall-effect half-shaft encoder are the two signals generated for the ECU software. The toothed wheel is marked along the flywheel of the engine. The Hall Effect sensor, used for CAM timing is mounted on to the existing fuel pump setup in the DI diesel configuration of the Proteus.

\subsection{Fuel Injector}

The methane fuel is transported from the pressure regulator to the intake manifold through a CNG rubber hose. The natural gas injectors deliver a precise volume of gas to the intake manifold during the intake stroke, where methane is mixed with the incoming air. Figure 3.9 represents a schematic waveform containing injection characteristic parameters such as duty cycle, pulse width, opening/closing time, etc.

\begin{tabular}{|c|c|c|}
\hline Characteristic & Unit & Value \\
\hline Pressure & bar (psi) & 0.5 to 3 ( 7 to 43 ) \\
\hline Rated voltage (at coil) & volt & 10.8 to 14.4 \\
\hline
\end{tabular}




\begin{tabular}{|c|c|c|}
\hline Resistance & ohm & 2 \\
\hline Suggested peak current time & $\mathrm{ms}$ & 3.0 \\
\hline Suggested holding current & $\mathrm{A}$ & 1.6 \\
\hline Minimum injection pulse & $\mathrm{ms}$ & 2.6 \\
\hline Opening / Closing response time & $\mathrm{ms}$ & $1.9 / 1.4$ \\
@14V & & 120 @ 1 bar inlet P \\
\hline Static flow rate with max nozzle & SLPM & 240 @ 3 bar inlet P \\
diameter & & 9.8 @ 1 bar inlet P \\
\hline Calculated max flow rate with max & & 13 @ bar inlet P \\
nozzle diameter & $\mathrm{kg} / \mathrm{h}$ & $<=15$ \\
\hline Leakage (with air) & & $\mathrm{cc} / \mathrm{h}$ \\
\hline
\end{tabular}

Table 3.4 Technical Specifications of IG7 Navajo CNG injector used for the study

The important technical specifications of the fuel injector used in the study is given in Table 3.4. In order to verify this precision accuracy, a bench test was conducted to measure the amount of flow variation when injected from a known command of pulse-width from the ECU. The flow was measured through a NIST standard 2" LFE with a sampling frequency of $10 \mathrm{~Hz}$ through SCIMITAR. Figure 3.7 shows the calibration plot provided for the injector with 4 seats working. In this setup, only two injectors were used. The results of injector flow, thus yielded from bench testing were similar to the manufacturer's calibration trend in terms of flow (Fig. 3.6) and linearity of the plotted region (Fig. 3.9).

\section{$\emptyset 3,5$ mm nozzle @ 2 bar}

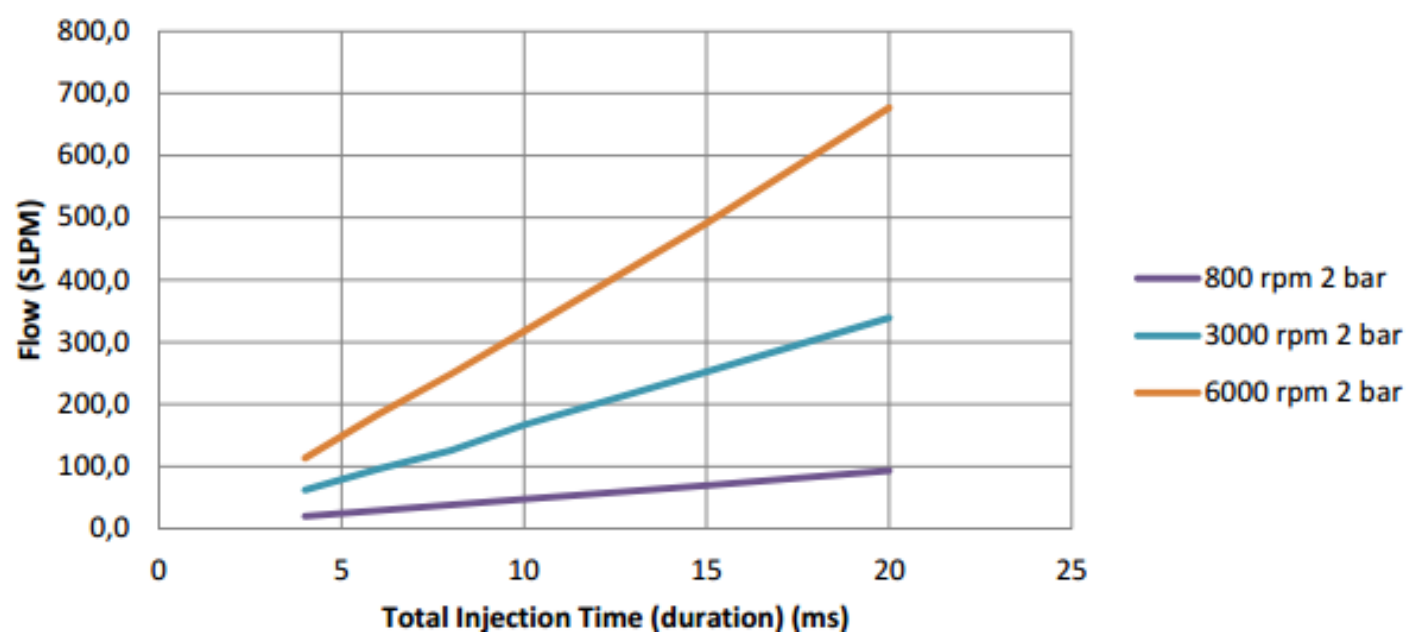

Figure 3.6 Manufacturer calibration flow curves for the injector IG7 with 4 seats working 


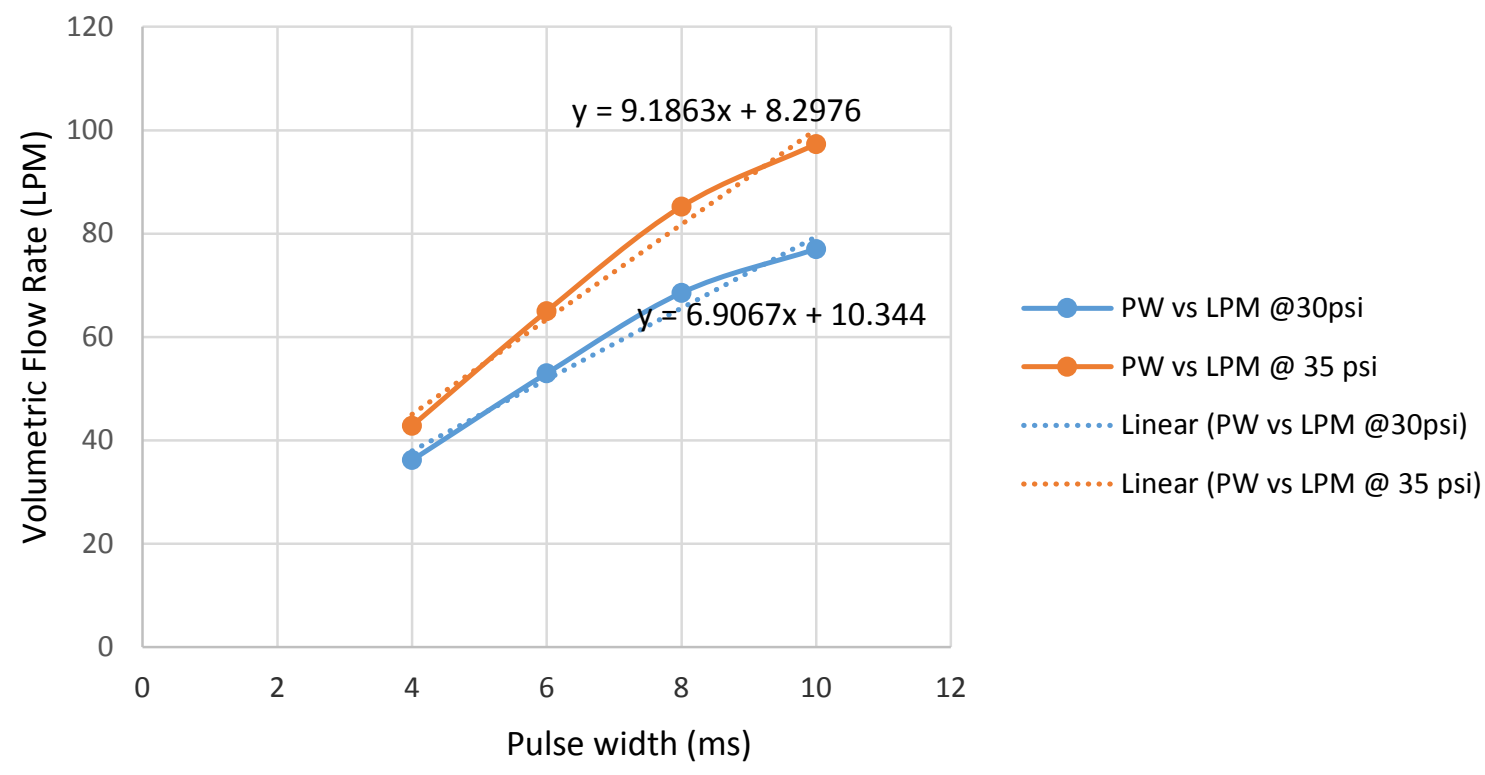

Figure 3.7 Injector flow curve plotted from bench testing at lab

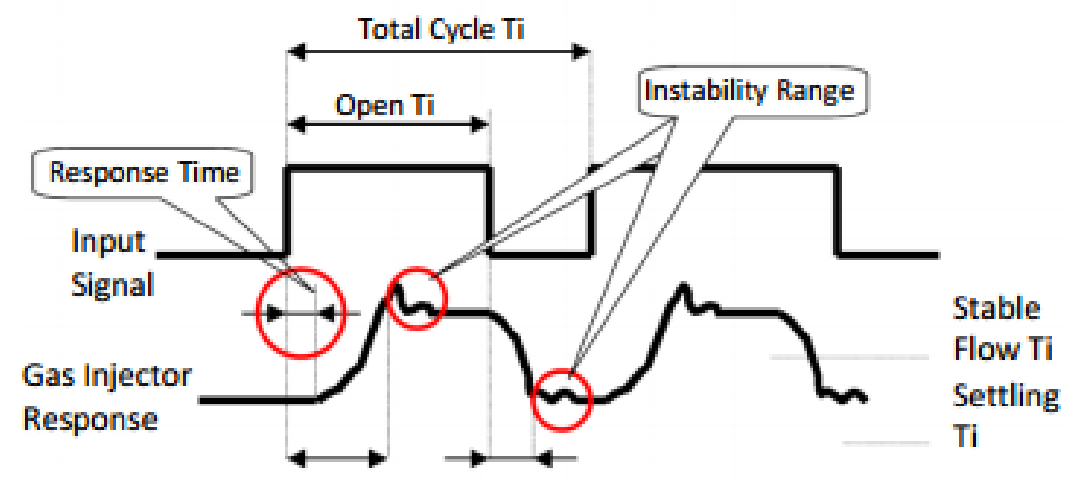

Figure 3.8 Schematic waveform of injector events per cycle basis 


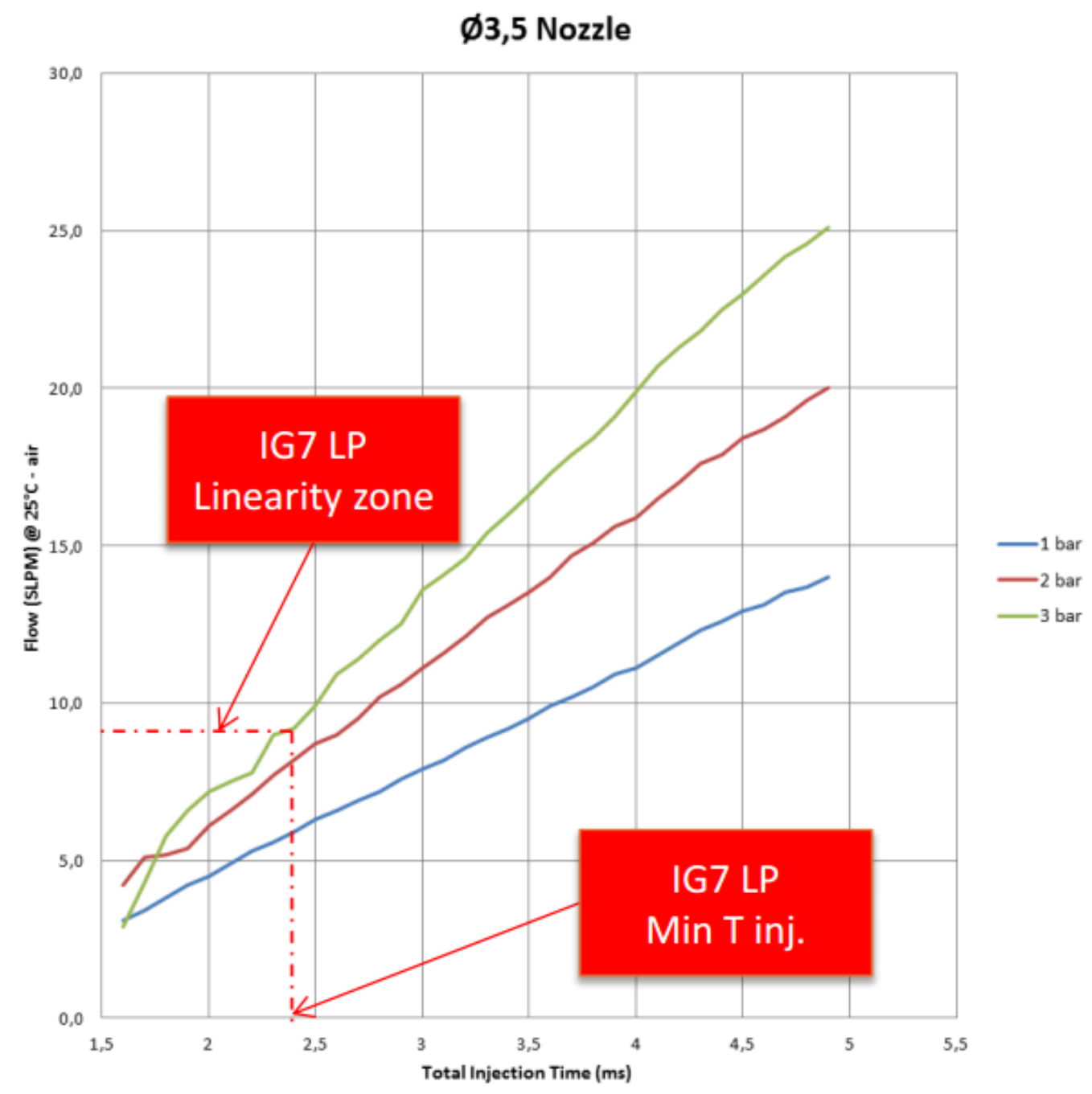

Figure 3.9 Linearity region in the flow calibrated injector performance curves

\subsection{Skip firing controller}

A skip-firing controller is required to protect the optical engine such that the upper extension of the piston assembly does not get overheated and to reduce the effect of fouling on the optical components due to repetitive firing every engine cycle (no applicable for this study as methane premixed combustion do not produce soot). In the present study, an electronically-operated skip-firing controller based on the Arduino platform was developed in-house. The controller intercepts the fuel injector command sent by the ECU, then allows the injector command pulse to pass through a solid state relay only once every ' $n$ ' cycles. Using the cam sensor as a reference, the controller starts the skip functionality by counting the number of pulses to from the instance it receives the first cam signal pulse. In addition, the controller monitors the engine encoder signal to trigger and synchronize the camera with the combustion events taking place inside the cylinder, on a scale of $0.1^{\circ}$ crank angle resolution. In addition to skipping the injector pulse, the controller 
also provides the TTL signals required for triggering the high speed camera. Specifically, the controller provides a pulse enough for the camera to remain exposed for the entire duration of the combustion event and subsequently provides bursts of multiple trigger pulses which would remain cascaded inside the long pulse. Each pulse inside the signal burst is synchronized with the engine encoder and allows the camera to capture one frame per pulse. A diagrammatic schematic of the skip firing controller logic and the triggering schematic for the camera is depicted in Fig. 3.10 and Fig.3.11 respectively.

The camera memory-gate function can be employed to ensure the synchronization of the data acquisition system with the main cycle events and maximize the available camera memory space. However, this feature was not used in the present study, although the skip firing controller was designed to operate in conjunction with the memory gate function. The memory gate option prevents recording images continuously, which at the current frame acquisition rate would fill the camera memory in approximately 50 engine cycles. Instead, image acquisition was triggered only for the fired portion of the engine operation. This also permitted increasing the number of cycles over which images are recorded by an order of magnitude.

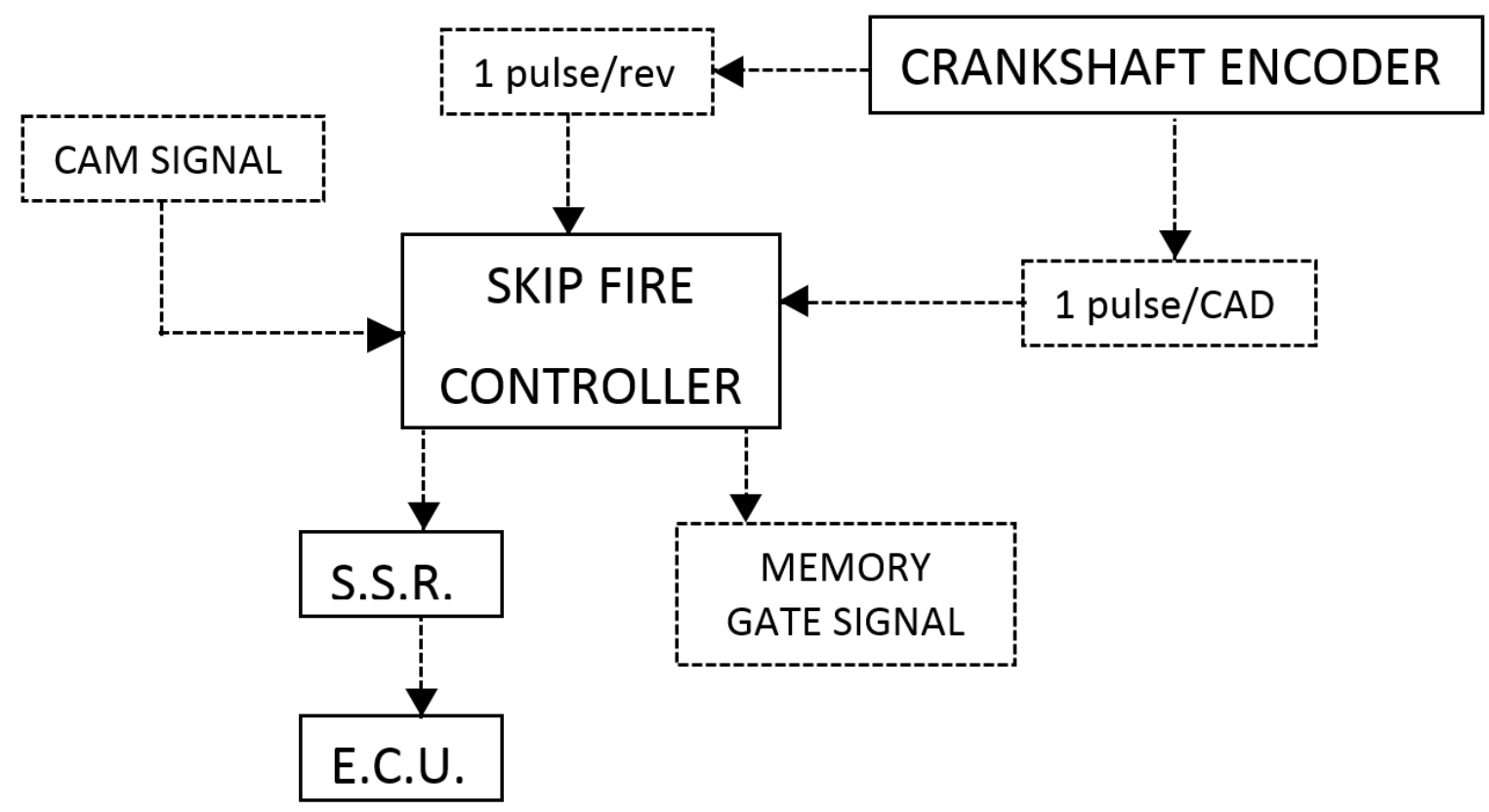

Figure 3.10 Schematic of the skip firing controller logic 


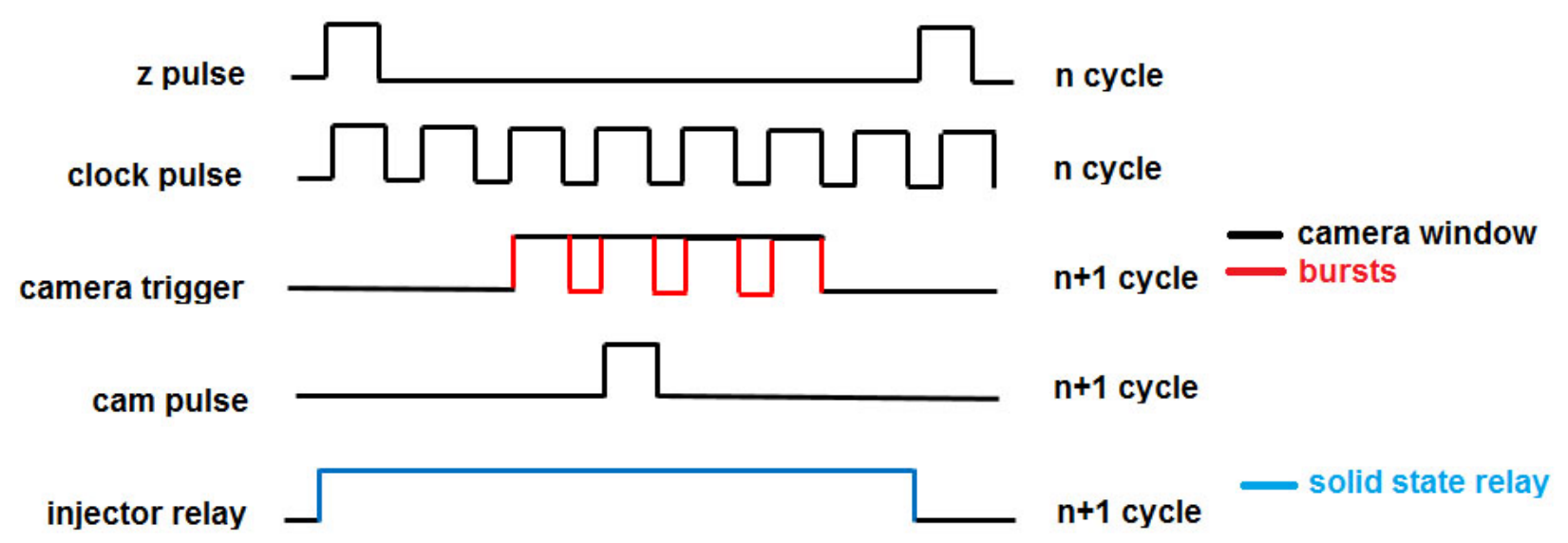

Figure 3.11 Triggering schematic for camera

\subsection{Exhaust Gas Analysis}

A gas analysis system consisting of heated probes, heated transfer lines, temperature control units, and gas analyzers was used to measure the concentration of gaseous components in the exhaust gas stream. These raw-gas analyzers are setup in accordance with the CFR Title 40 regulations. A basic schematic diagram of the raw box analyzers is shown in figs. $3.15-3.17$. The heated probes are flooded probe type for supplying exhaust gases to the analyzer, at heated temperatures. The probes are fitted at the sampling plane according to the $10 \mathrm{x}$ diameter rule from the mixing region. Total hydrocarbons (THC), NOx, $\mathrm{CO}_{2}$ and CO concentrations were measured in the raw exhaust. These probes were connected to heated lines which transfer the sampled exhaust to the gas analyzers. The hydrocarbon line and probe were kept at a wall temperature of $375^{\circ} \mathrm{F} \pm 10^{\circ} \mathrm{F}\left(191^{\circ} \mathrm{C} \pm 5.5^{\circ} \mathrm{C}\right)$ while the other probes and lines were heated to $175^{\circ} \mathrm{F} \pm 10^{\circ} \mathrm{F}\left(79^{\circ} \mathrm{C} \pm 5.5^{\circ} \mathrm{C}\right)$. The temperatures were kept high to prevent condensation of water or volatile organic compounds in the sample lines for the $\mathrm{NO}_{\mathrm{x}}$ and $\mathrm{CO}$ samples and hydrocarbon compounds for the THC sample. All data were recorded at a sampling frequency of $10 \mathrm{~Hz}$. $\mathrm{CO}$ and $\mathrm{CO}_{2}$ emissions were measured using a non-dispersive infrared (NDIR) analyzer (Horiba, Model AIA-210). $\mathrm{NO}_{\mathrm{x}}$ emissions were measured using a chemiluminescence-based detector (Eco Physics, Model CLD 844 CM). THC emissions were measured using a flame ionization detector (FID; Horiba, Model FIA 236). Dedicated temperature control modules (Omega, Model CNI-32) were used to control in a closed-loop system the temperatures of the various probes and transfer lines as per CFR 40 regulations [83]. Individual temperature controllers were assigned set points and when the temperature feedback from the transfer line and probes fell below this set point value the controllers send a signal to a solid state relay. The relay switches power to the respective heating unit to bring the temperature up to the set point and the controller disconnects the power through the relay once temperature set point has reached. 


\subsubsection{Emissions sampling manifold}

The emissions from the exhaust manifold is routed to individual component gas analyzers via a sampling manifold. The sampling manifold receives the gas sample through heated lines maintained at a temperature of $375 \mathrm{~F}$ and distributes them to specific gas analyzers, comprising an arrangement similar to that of the inside of raw analyzer boxes, as discussed in the forthcoming sections.

\subsection{2 $\mathrm{CO}$ and $\mathrm{CO}_{2}$ emissions analyzer}

The operating principle of the $\mathrm{CO} / \mathrm{CO}_{2}$ analyzer is based upon the infrared wavelength being capable of absorbed by $\mathrm{CO} / \mathrm{CO}_{2}$ gases. Two equal infra-red energy beams are sent through corresponding optical chambers. One chamber is filled with a reference gas and sealed and the other chamber consists of the continuously-flowing sample gas. The IR beam is interrupted by a chopper at a given frequency. As the beam passes through the gas filled chambers it gets absorbed by the flowing gases and the detector placed on the far end of the chamber reads the reduced intensity of the beam. The quantity of the IR beam thus absorbed would be proportional to the concentration of the flowing gas. The detector measures the intensity of radiation from the reference cell as well the sample cell and converts the difference in radiation as change in capacitance, which in turn is converted to sample concentration. A schematic illustration of the $\mathrm{CO} / \mathrm{CO}_{2}$ gas analyzer operating principle is illustrated in fig. 3.12.

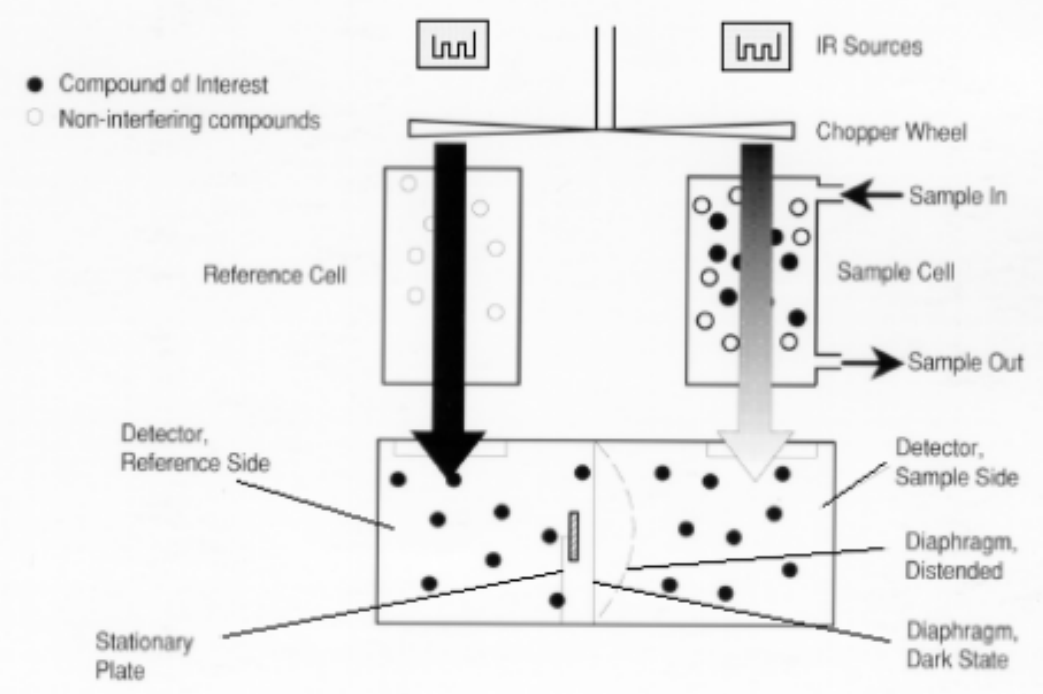

Figure 3.12 Schematic illustration of NDIR operating principle [84] 
Upon entering the $\mathrm{CO}_{2}$ sampling system, the sample is drawn through a heated filter by a heated pump. A rotameter regulates the sampled gas flow through the NDIR analyzer at the required values (2" of water).

\subsubsection{THC emissions analyzer}

The hydrocarbon sample is drawn from heated probes through the sampling manifold and stainless steel transfer lines maintained at $375 \mathrm{~F}\left(190.5^{\circ} \mathrm{C}\right)$ to prevent condensation of hydrocarbons in the transfer tubes. The analyzer consists of a burner which is supplied with fuel (60\% hydrogen and $40 \%$ helium) and air. The sample gas passes through the burning flame and undergoes an ionization process producing electrons and positive ions. These electrons are collected by an electrode, which causes a current to flow through the external circuit. The ionization current produced is proportional to the number of carbon atoms entering the burner which is a measure of the hydrocarbon content of the sample. Schematic illustration of the THC gas analyzer operating principle is illustrated in fig. 3.13.

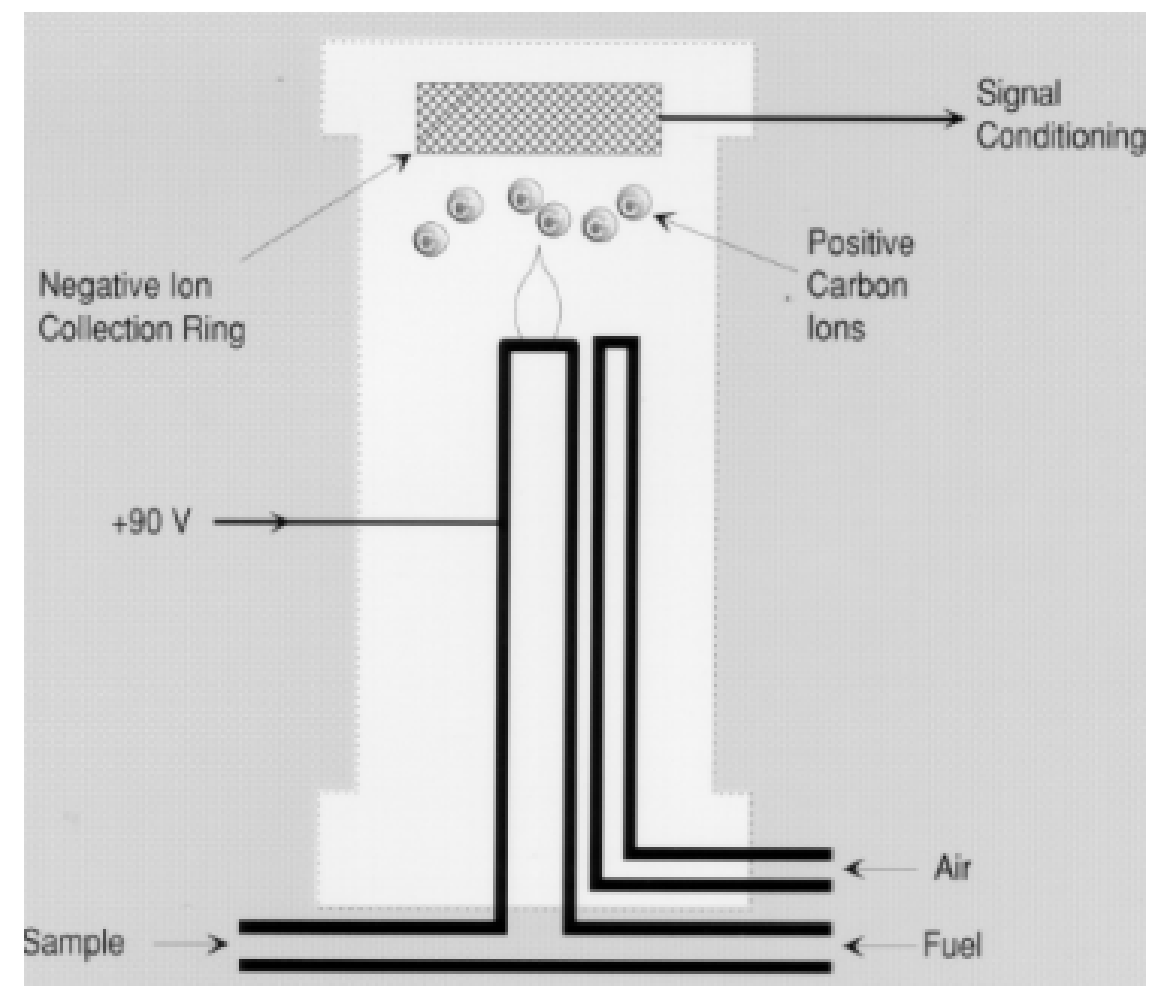

Figure 3.13 Schematic illustration of FID operating principle [85] 


\subsection{4 $\mathrm{NO}_{\mathrm{x}}$ emissions analyzer}

This analyzer works on the principle of chemiluminescence measurement technique. Chemiluminescence is the emission of light as the result of a chemical reaction that does not involve an increase in its temperature. The $\mathrm{NO}_{\mathrm{x}}$ analyzer consists of an ozone generator, $\mathrm{NO}$ converter, reaction chamber, photo electric diode and signal processing electronics. The reaction between ozone and NO leads to the formation of highly excited state $\mathrm{NO}_{2}$ which returns to its ground state by emitting a photon.

$$
\begin{gathered}
\mathrm{NO}+\mathrm{O}_{3} \rightarrow \mathrm{NO}_{2}^{*}+\mathrm{O}_{2} \\
\mathrm{NO}_{2}^{*} \rightarrow \mathrm{NO}_{2}+\text { photons(redlight) }
\end{gathered}
$$

A photodiode measures the intensity of photons emitted and the measurements correlates with the $\mathrm{NO}_{\mathrm{x}}$ concentration of the sample gas. Schematic illustration of the THC gas analyzer operating principle is illustrated in fig. 3.14 .

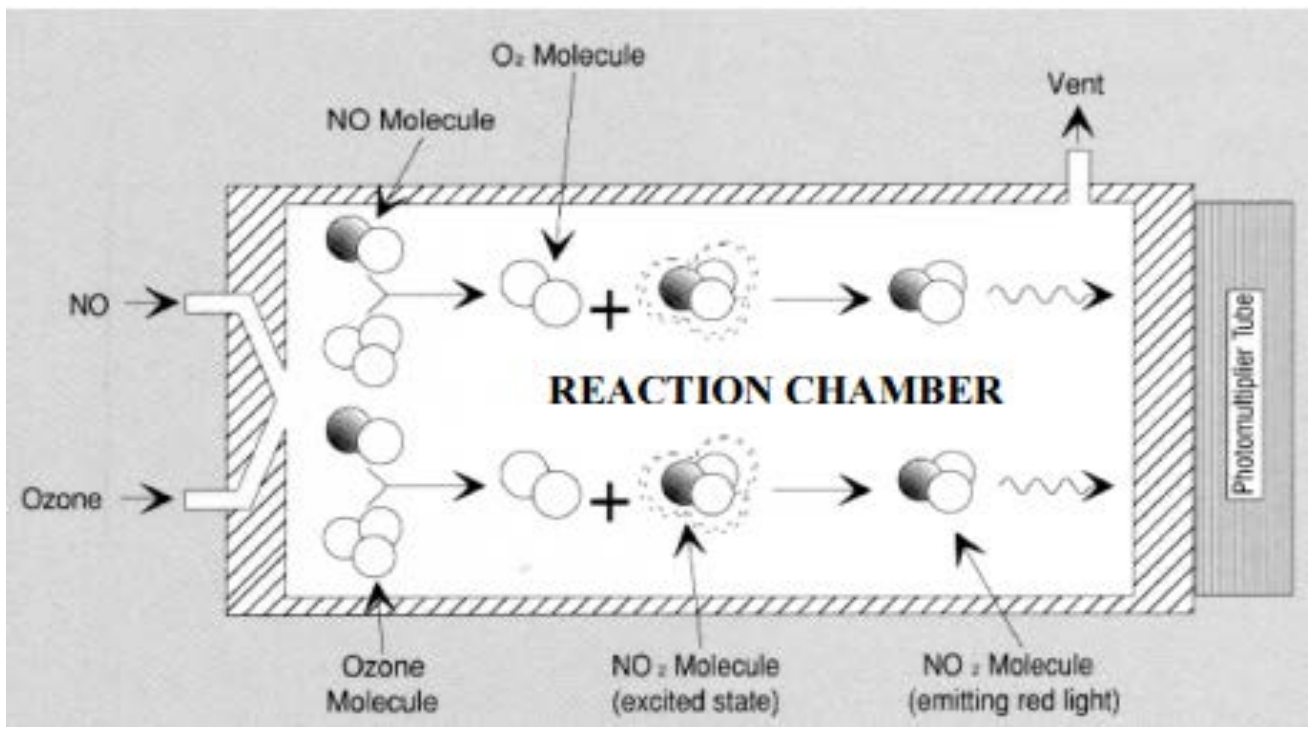

Figure 3.14 Schematic illustration of CLD operating principle [86]

The exhaust gas is sampled through heated probe from a sampling manifold via transfer line. The line is maintained at $240{ }^{\circ} \mathrm{F}\left(115.5{ }^{\circ} \mathrm{C}\right)$ to avoid water condensation. To perform the $\mathrm{NO}_{\mathrm{x}}\left(\mathrm{NO}+\mathrm{NO}_{2}\right)$ measurement, the analyzer employs a converter which converts all the $\mathrm{NO}_{2}$ in the sample to $\mathrm{NO}$ on a heated vitreous carbon bed before passing them through the reaction chamber. This step is bypassed if the analyzer is on NO mode. 


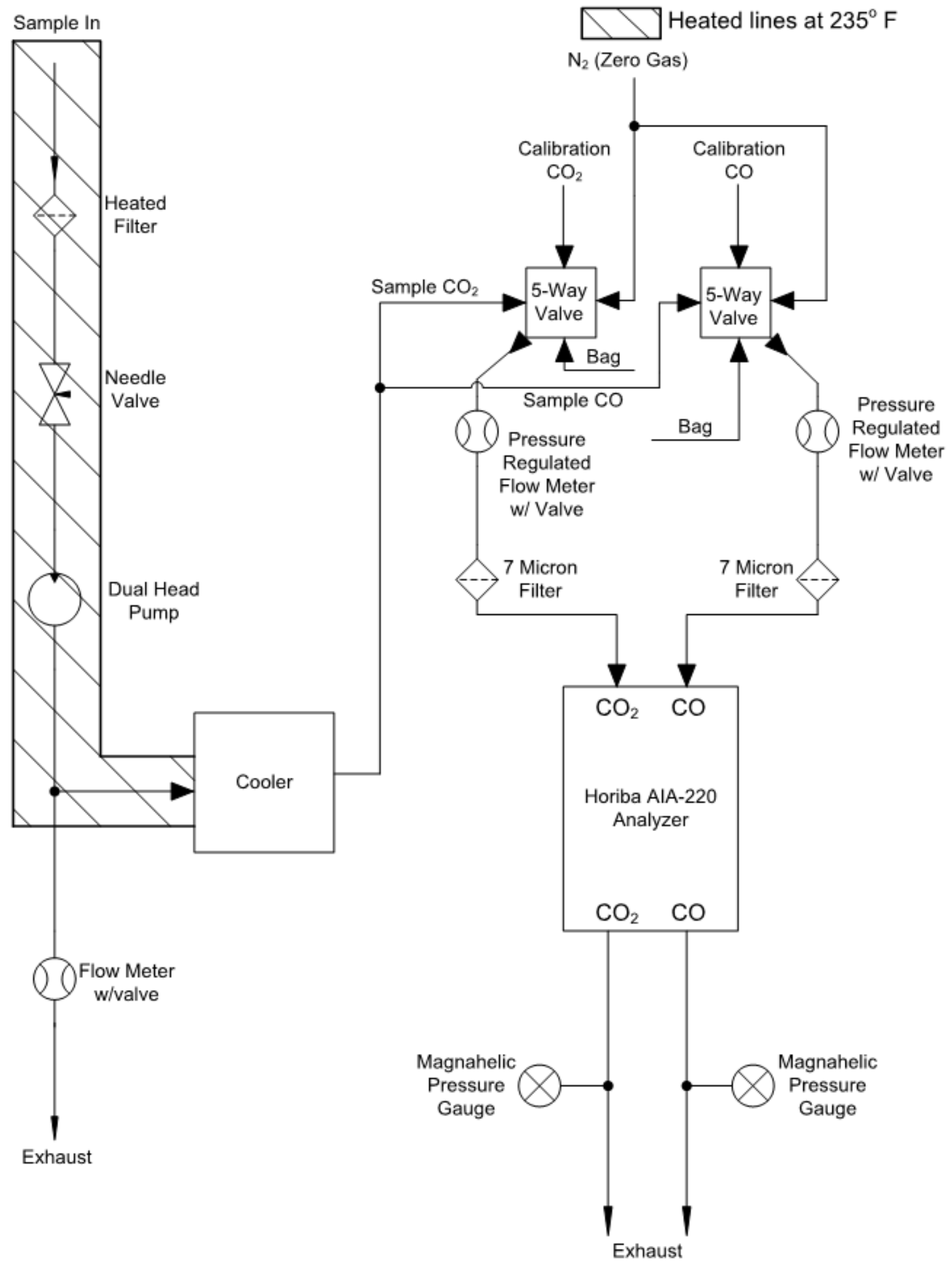

Figure 3.15 Flow schematic for $\mathrm{CO}_{2}$ analyzer box [87] 


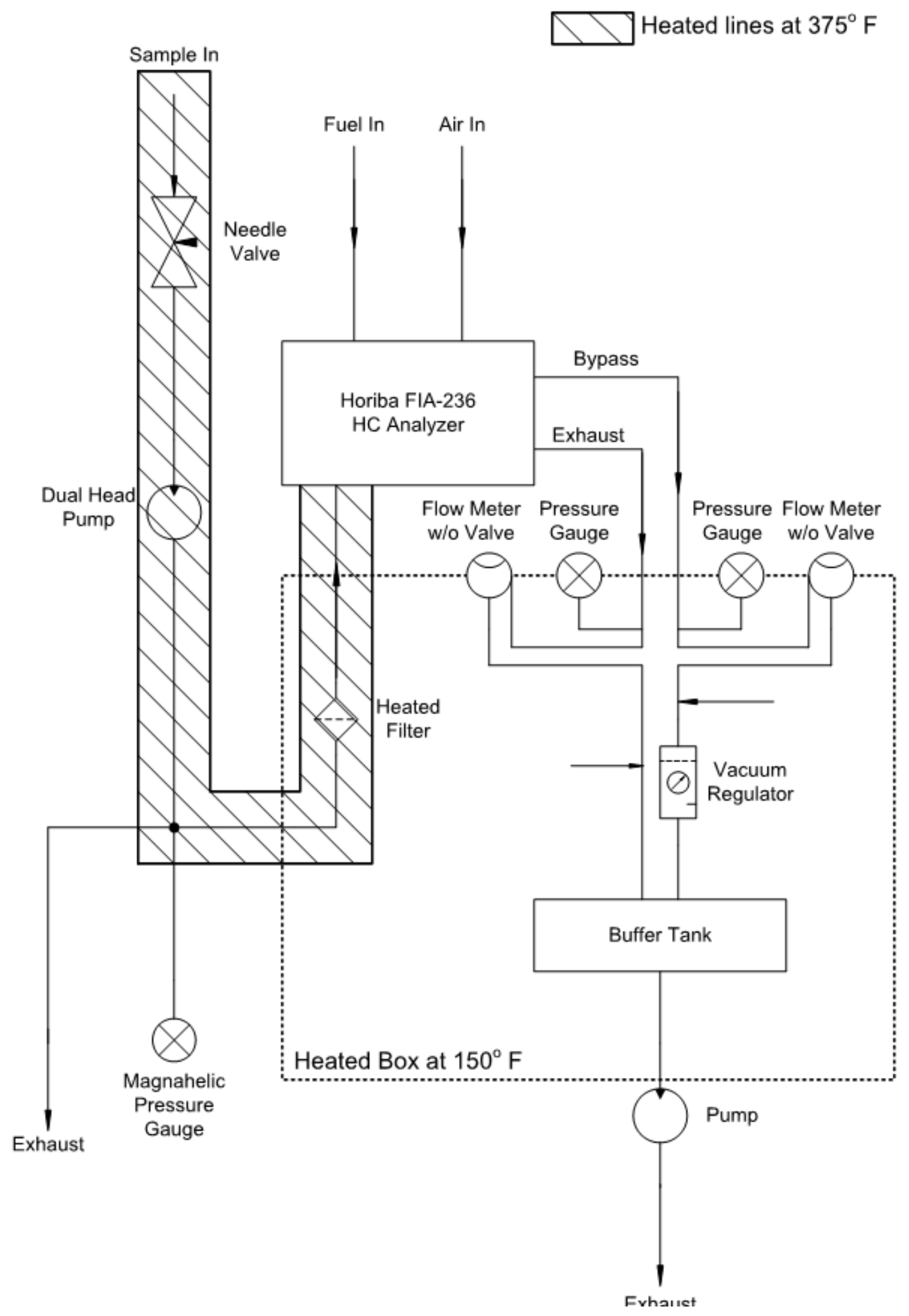

Figure 3.16 Flow schematic for THC analyzer box [87] 


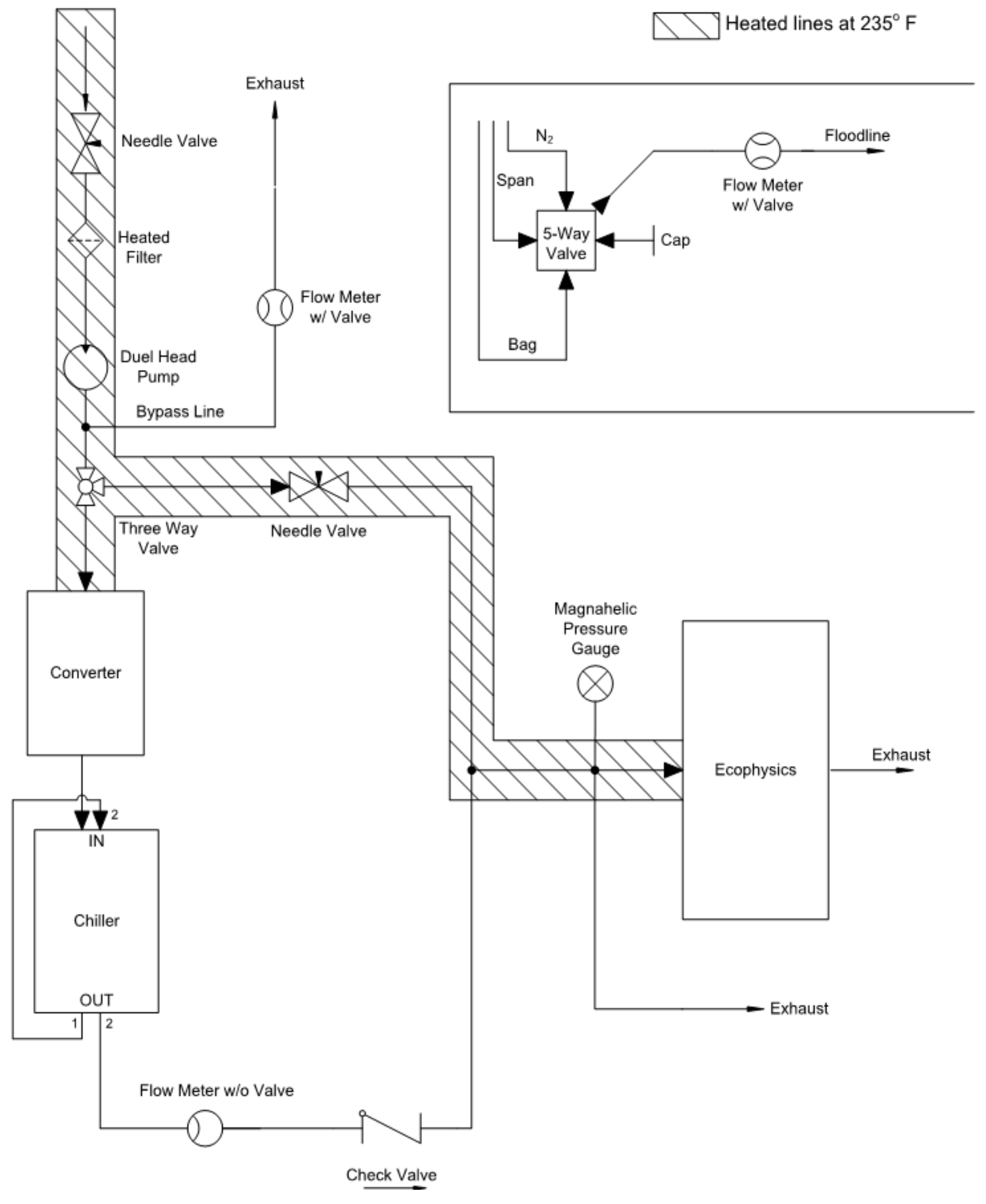

Figure 3.17 Flow schematic for $\mathrm{NO}_{\mathrm{x}}$ analyzer box [87] 


\section{Chapter 4}

\section{Results \& Analysis}

\subsection{In-cylinder pressure analysis}

In-cylinder pressure is used to monitor and analyze the IC engine operation. The pressure analysis is based on the first law of thermodynamics and relies on two parameters: the cylinder volume and the working fluid pressure. Pressure measurements were synchronized with the signal received from the engine encoder, which sends a signal every 0.1 CAD. The cylinder volume is calculated at the corresponding CAD using equations 4.1 and 4.2. Accurate calibration of the absolute crank position is extremely important since it has a very strong influence on IMEP and heat release rate calculations. Determination of TDC aids in such calibration, which carries a significant influence on pressure trace [88].

$$
\begin{gathered}
V=\frac{V_{\mathrm{D}}}{r_{\mathrm{c}}-1}+\frac{\pi B^{2}}{4}(l+a-s) \\
s=a \cos \theta+\sqrt{\left(l^{2}-a^{2} \sin ^{2} \theta\right)}
\end{gathered}
$$

where $V_{D}$ is the cylinder volume at BDC, $r_{c}$ is the compression ratio, $B$ is the bore diameter, $l$ is the connecting rod length and a is the crank radius.

It is necessary to ensure that the value of the dynamic compression ratio is determined correctly to ensure the correct computation of combustion parameters, [89]. The dynamic (compressive/tensile) and thermal loading of the extended piston-liner assembly on the optical engine changes the effective (static) compression ratio specified by the manufacturer. Increased blow-by rates in optical engines further increase the complexity of measuring the crevices volume, therefore motivating to pursue alternate methods for estimating compression ratio [96]. Several methods for estimating the dynamic compression ratio are available in the literature, whether based on in-cylinder pressure traces [90, 91] or measured flow rates [92, 93]. The analysis of motored pressure traces (Figure 4.1) was preferred in this study since it eliminates the uncertainty associated with the evaluation of heat released from combustion [94]. Given that the temperature levels are lower compared to fired operation, the influence of combustion chamber deposits, which could influence heat transfer [95], would also be reduced by such analysis. 
In-cylinder pressure data must be processed by suitable mathematical methods before it could be used for combustion analysis. Piezoelectric transducers used for measuring the pressure of working fluids require referencing their output to the atmospheric pressure (i.e., "pegging”). Literature available for estimating the cylinder pressure pegging may be divided into two main groups: (i) methods which require additional absolute pressure reference and (ii) the methods which utilize the polytropic compression curve [97]. The latter method was used in this study. After referencing the cylinder pressure to an absolute value, the in-cylinder pressure is filtered to minimize the signal noise. The noise in the pressure signal can be due to (i) the conversion of pressure to electrical signal in the sensor (because of thermal effects, lack of linearity in sensor due to ageing, sensor resonance, etc.), (ii) the analog to digital conversion, (iii) signal transmission effects, or (iv) the combustion chamber resonance [98].

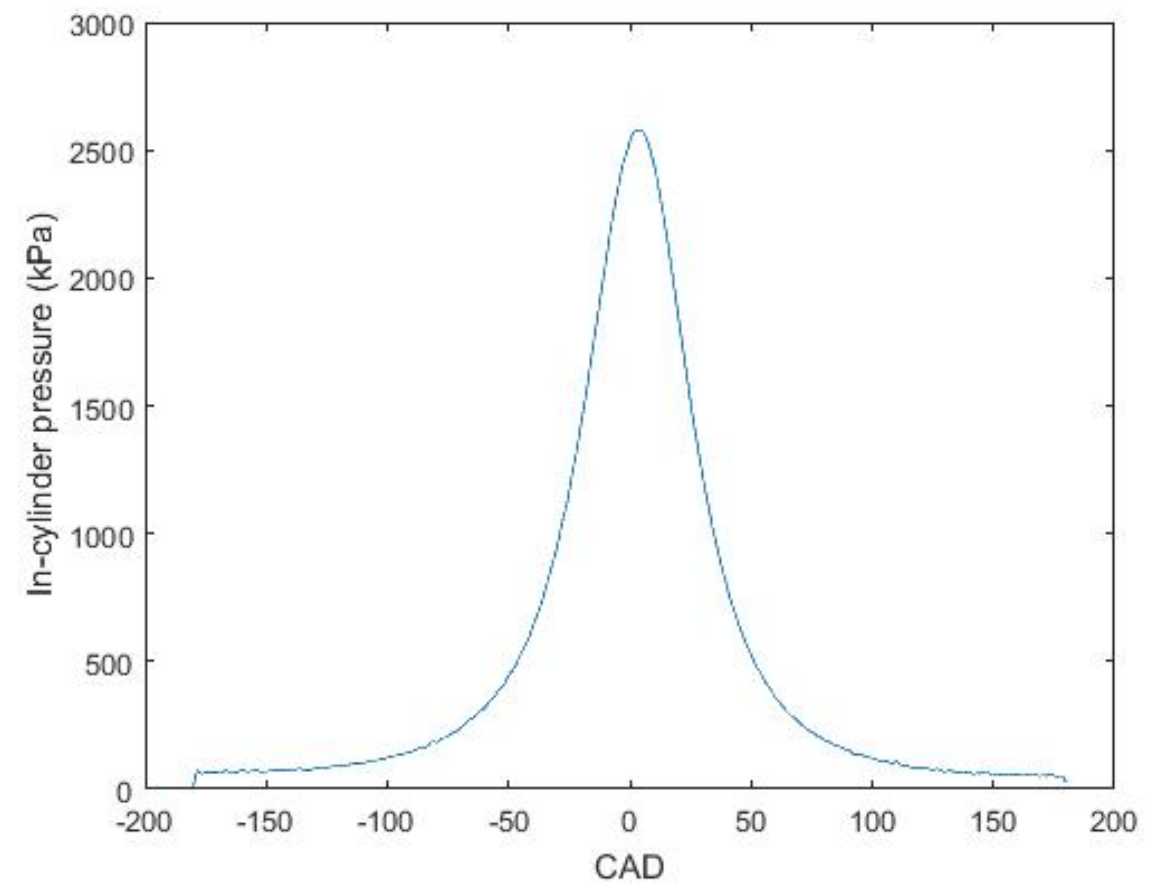

Figure 4.1 Motoring trace after pegging for compression ratio calculation 


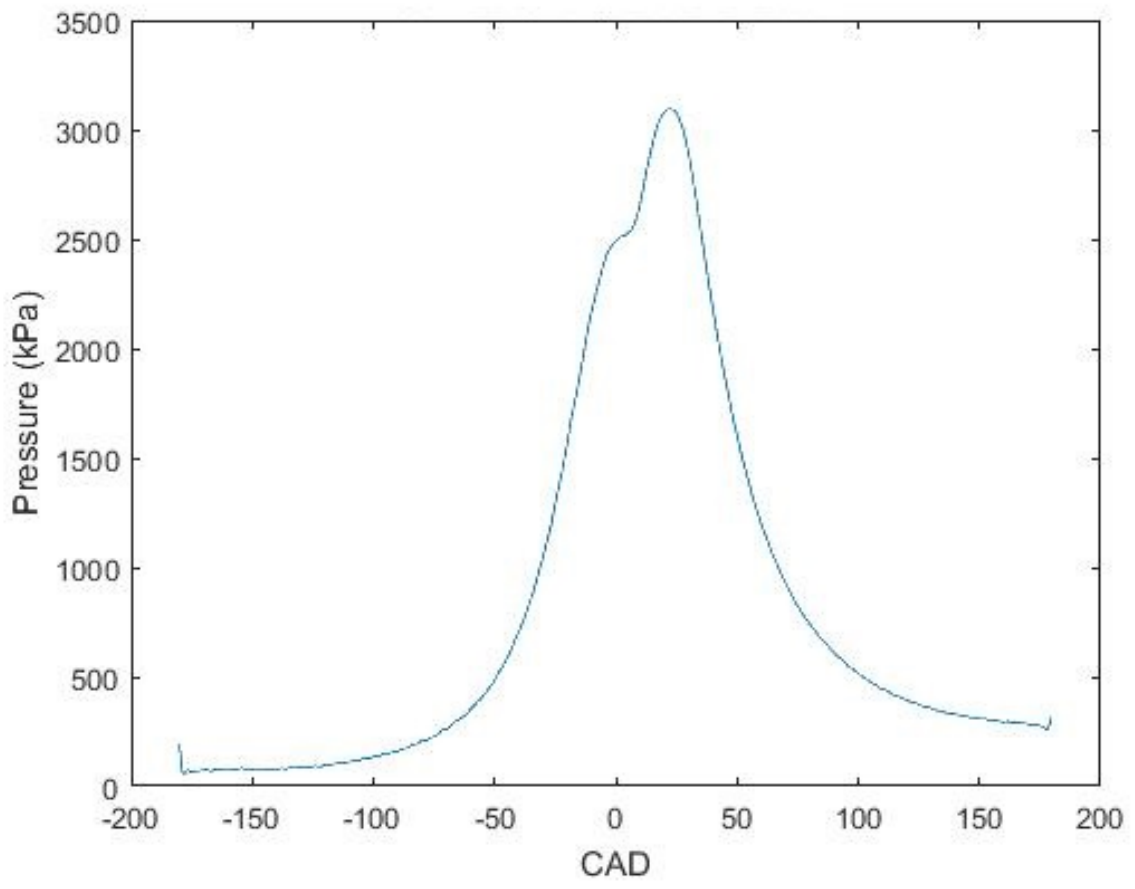

Figure 4.2 Example of a combustion pressure trace for a fired cycle

The compression ratio calculated from the motoring trace was 10.7. The final step in the processing of in-cylinder pressure data is filtering.

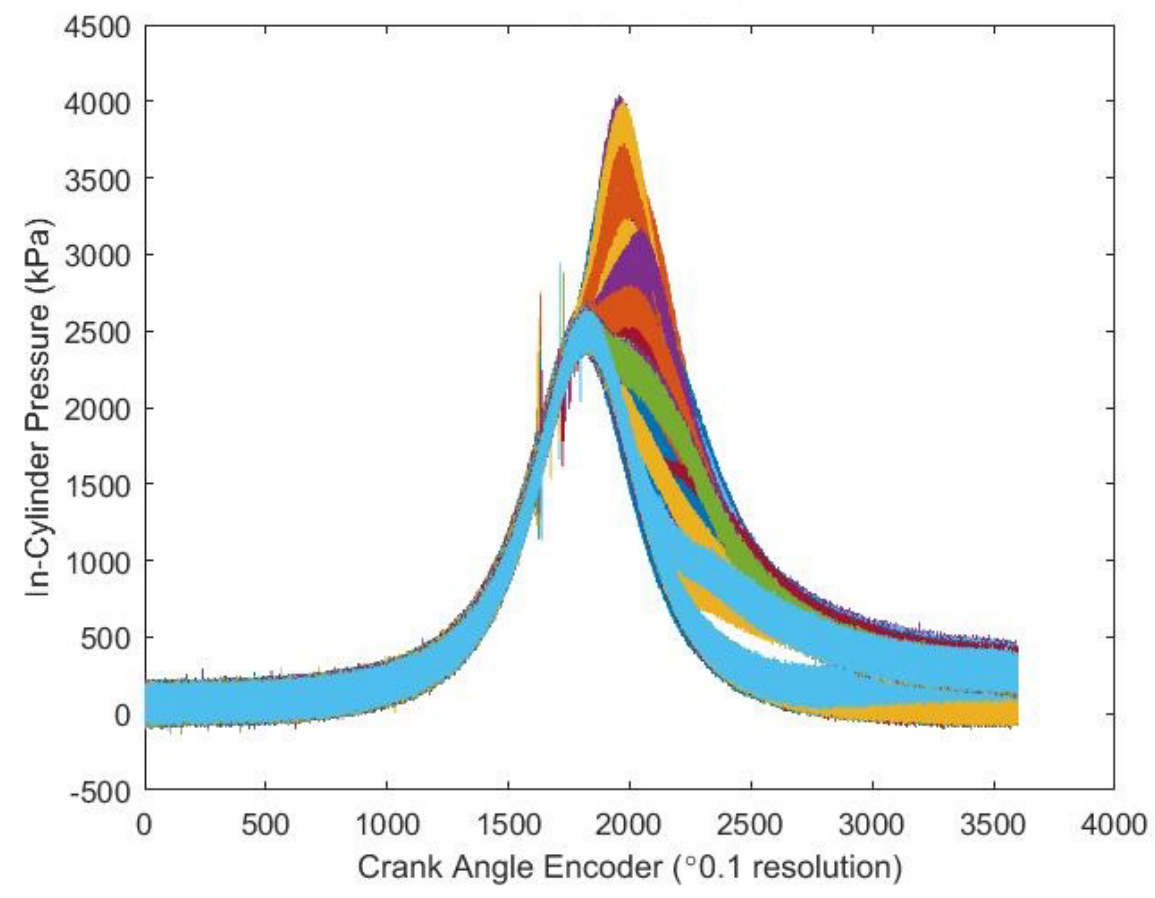

Figure 4.3 In-cylinder pressure raw data (without filter) for combustion trace of 97 engine cycles 


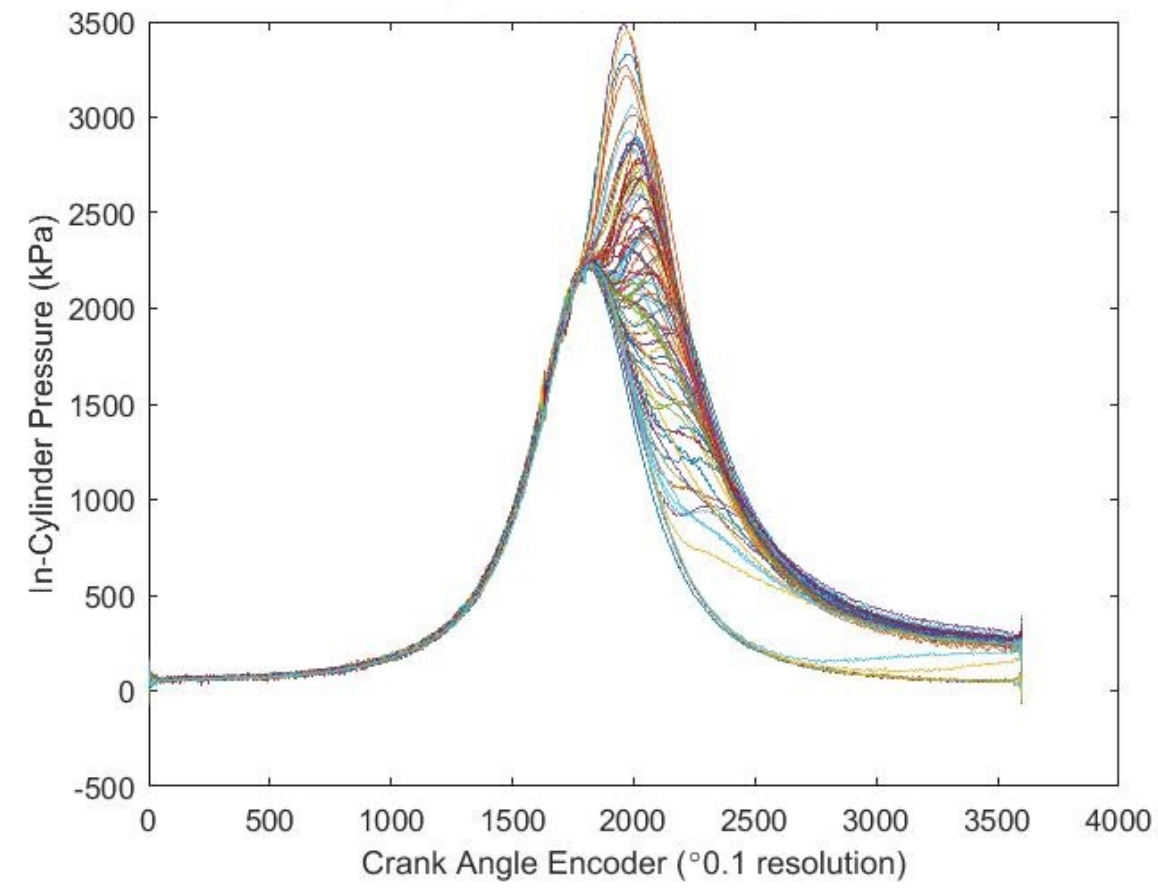

Figure 4.4 Zero phase digital filter for combustion traces of 97 cycles

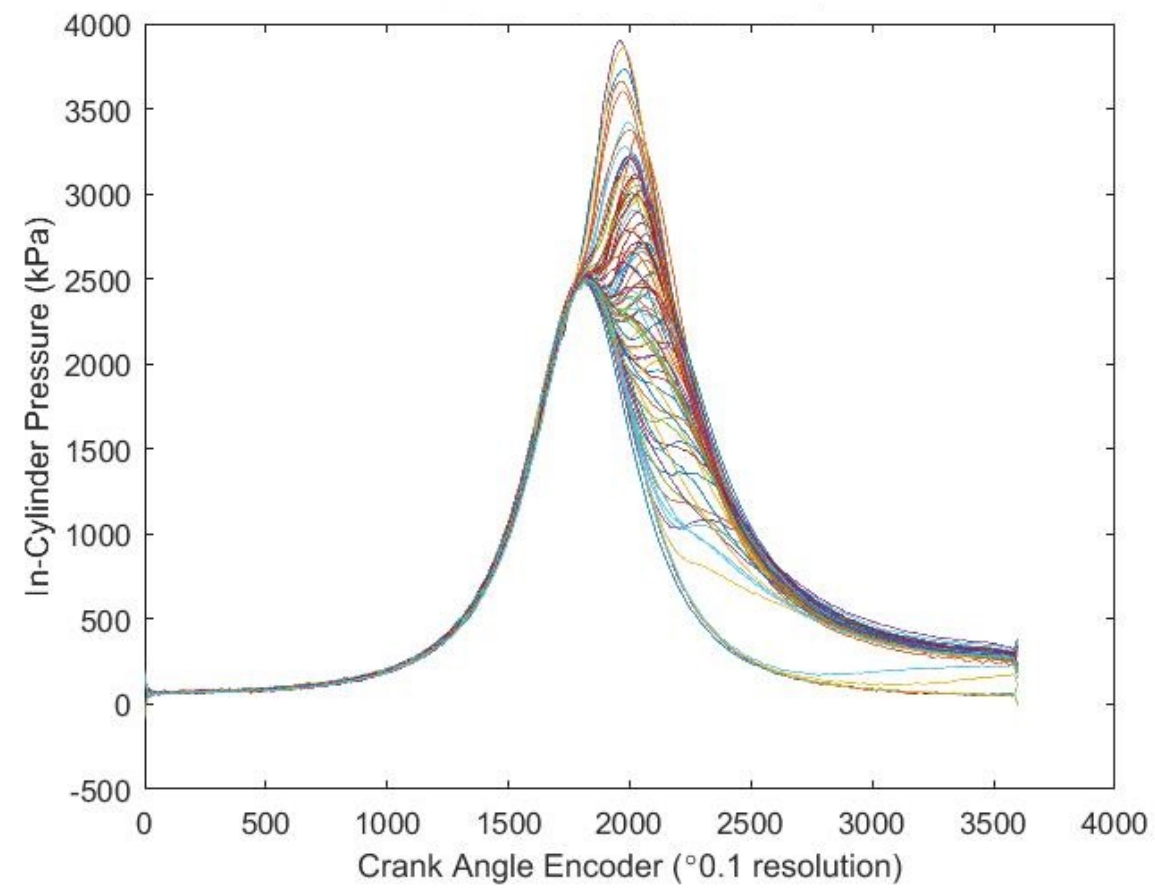

Figure 4.5 Butterworth filter (fourth order) for combustion traces of 97 cycles 
The acquired pressure signal contains point to point variation due to the signal noise. It is therefore necessary to smoothen the pressure trace, to obtain a smooth mean-pressure cycle before carrying out heatrelease calculations and henceforth making any interpretations about the combustion process. Different averaging and filtering techniques can be found in literature for smoothing the signal, thus allowing a precise combustion diagnosis. However, there is not a consensus in the scientific community about the optimal way to proceed [99]. In this study, we have used MATLAB's Butterworth filter and a zero-phase digital filter to analyze the combustion events (Figures 4.4 and 4.5). The zero-phase filter does a forwardbackward filtering, i.e., filter, reverse the signal, and filter again and then reverse again, to reduce phase distortions. On the other hand, a Butterworth filter has the advantages of being smooth and monotonically decreasing frequency response. Once the cut-off frequency of a Butterworth filter is specified, the steepness of the transition is proportional to the filter order. Higher order Butterworth filters approach the ideal lowpass filter response. In the present study, a fourth-order Butterworth filter was chosen. One of the key issues $\mathrm{t}$ during pressure-trace filtering is the selection of the cutoff and stopband edge frequencies. For our analysis, we used 6000 and 0.2 as cut-off and stopband edge frequencies, respectively. This selection was based on the quality of the corresponding heat release rate. Once the higher-frequency noise was removed from pressure signal trace, the remaining physical information was representative of the actual pressure signal. Figs. 4.4 and 4.5 show an example of large cycle-to-cycle variations in the pressure traces, due to cycle-to-cycle fluctuations in the in-cylinder fluid motion, turbulence, equivalence ratio, ignition energy etc. Such variations are the result of poor engine control, hence our motivation to design an accurate control system for our optical engine.

After the pressure data was filtered, it is important to validate the accuracy of cylinder pressure vs crank angle data. Heywood [47] suggests the use of $\log \mathrm{P}$ vs $\log \mathrm{V}$ graph for a motored engine operation to check the quality of cylinder pressure data. On the $\log \mathrm{P}$ vs $\log \mathrm{V}$ graph, the combustion process would be a straight line of slope equal to the ratio of specific heats (gamma). Other parameters like SOC and EOC could be identified from the location of the departure of the curve from the straight line. Since both the compression of unburned gases prior to combustion and the expansion of the burned gases following the end of combustion are close to adiabatic isentropic processes, a behavior close to polytropic relation would be expected $\left(\mathrm{PV}^{\mathrm{n}}=\right.$ constant $)$ [100]. Fig. 4.6 and Fig. 4.8 shows the P-V plot and $\log \mathrm{P}$ vs $\log \mathrm{V}$ plot respectively for the combustion and expansion strokes. The indices of compression and expansion turned out to be 1.29 and 1.31 respectively. These calculated values are lower due to a variety of reasons. Firstly, the engine combustion chamber, by the virtue of its build itself is not ideally adiabatic and comprises of different means of heat losses from the cylinder walls. Also, there might be potential errors in pegging the cylinder pressure data. The combination of all these unaccounted effects could be the reason for the observed deviation in behavior. Fig. 4.7 shows an in-cylinder cut off view of the optical access engine. 


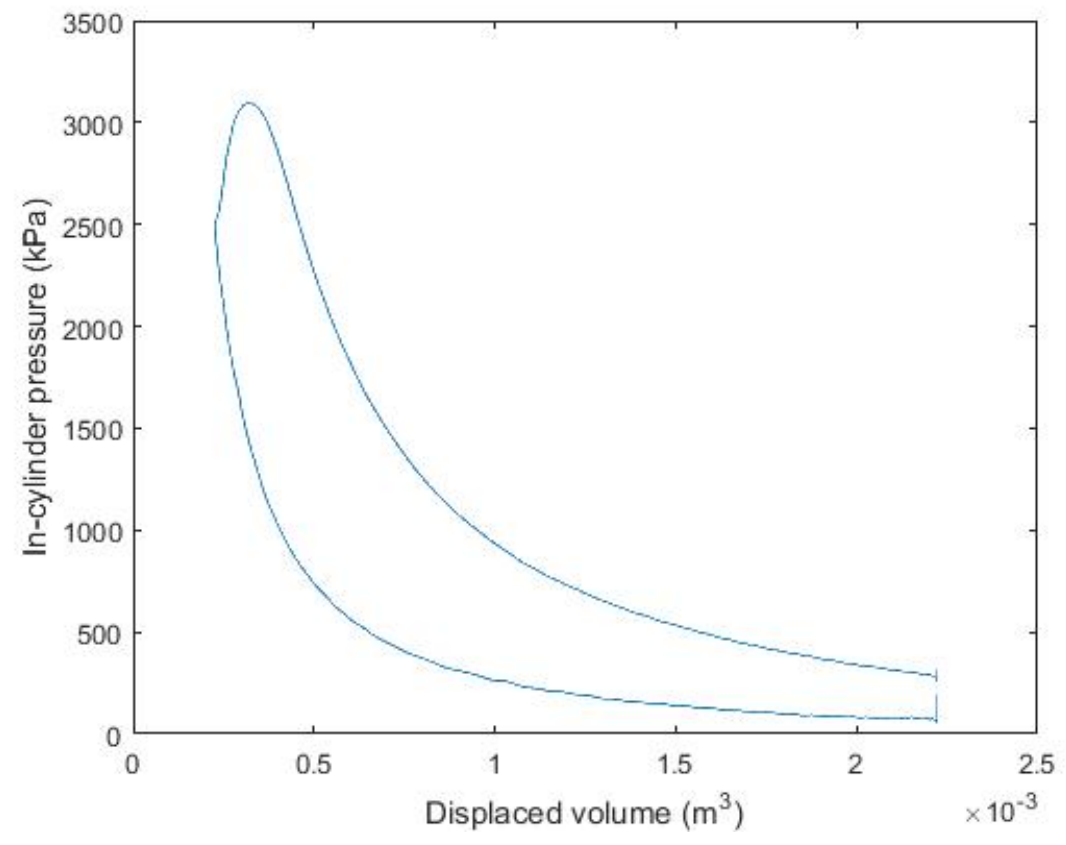

Figure 4.6 P-V diagram of an engine cycle

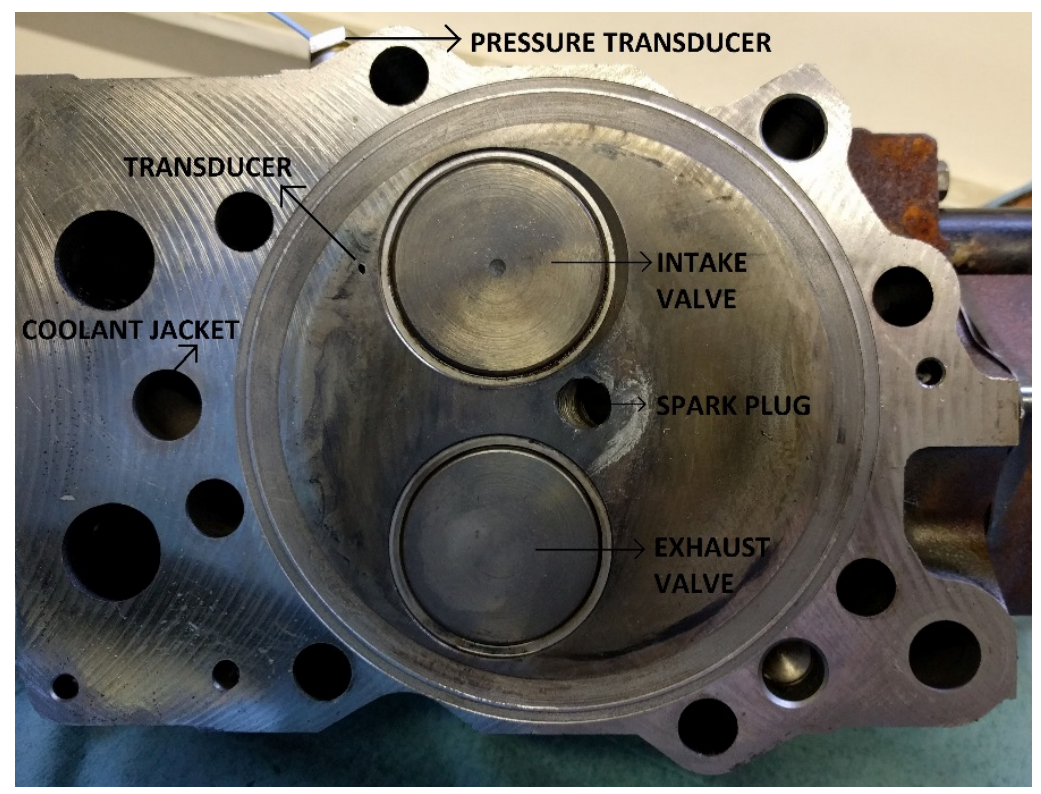

Figure 4.7 In cylinder cut off view of a typical single Cylinder Optically Accessible Engine 


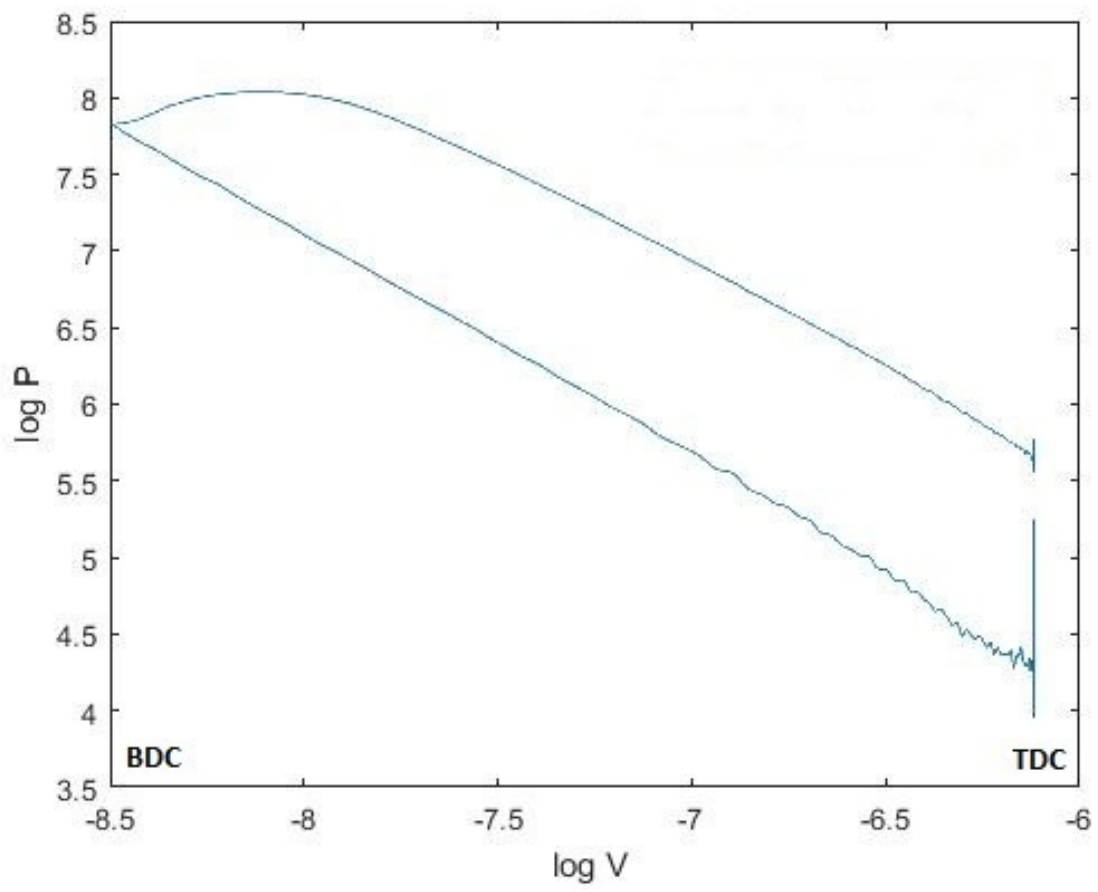

Figure 4.8 Log P vs log P, plot of a combustion cycle

The correlation between pressure rise, burning rate, and flame propagation rate are determined by extracting both the mass fraction of burned gas and the fraction of volume enflamed as functions of crank angle, from the experimental data. The methods used for this purpose and some empirical correlations found, are discussed in this section.

To start with the calculation of parameters determining combustion process, thermodynamic analysis are performed both on a cycle-to-cycle basis and also using data averaged for sets of consecutive cycles. The correlation developed by Woschni [101] was used for calculating the convective heat transfer coefficient.

$$
\mathrm{h}=3.26 \times \mathrm{B}^{-0.2} \times \mathrm{p}^{0.8} \times \mathrm{T}^{-0.53} \mathrm{Xw}^{0.8}
$$

where $h$ is measured in $\mathrm{W} \mathrm{m}^{-2} \mathrm{~K}^{-1}, B$ in $\mathrm{m}, p$ in $\mathrm{kPa}, T$ in $\mathrm{K}_{\text {and }} w$ in $\mathrm{ms}^{-1}$ is dependent on mean piston speed. $w$ is the average gas velocity, $S_{p}$ is the mean piston speed, $V_{d}$ is the displaced volume, $p$ is the in-cylinder pressure, $p_{r}, V_{r}$ and $T_{r}$ are the working fluid pressure, volume and temperature at reference state and $\mathrm{p}_{\mathrm{m}}$ is the motored cylinder pressure. $C_{1}$ and $C_{2}$ are 2.28 and 0 for the compression period \& 2.28 and 3.24 e-3 for expansion period. 


$$
w=C_{1} S_{p}+C_{2} \frac{V_{d} * T_{r}}{p_{r} * V_{r}}\left(p-p_{m}\right)
$$

With the convective heat transfer coefficient values given by the above correlation, the convective heat transfer rate to the combustion chamber walls can be calculated using equations 4.4 and 4.5

$$
\frac{d Q_{w}}{d t}=A^{*} h\left(T_{b}-T_{w}\right)^{8}
$$

where $A$ is the chamber surface area, $T_{b}$ is the burned gas temperature and $T_{w}$ is the cylinder wall temperature. An important advantage of the heat release analysis is that the inaccuracies in cylinder pressure data and heat release calculation could be found out, as it relates the pressure changes to the amount of fuel chemical energy within the cylinder.

$$
\frac{d Q}{d \theta}=\frac{\gamma}{\gamma-1} P \frac{d V}{d \theta}+\frac{1}{\gamma-1} V \frac{d P}{d \theta}+\frac{\partial Q_{w}}{d \theta}
$$

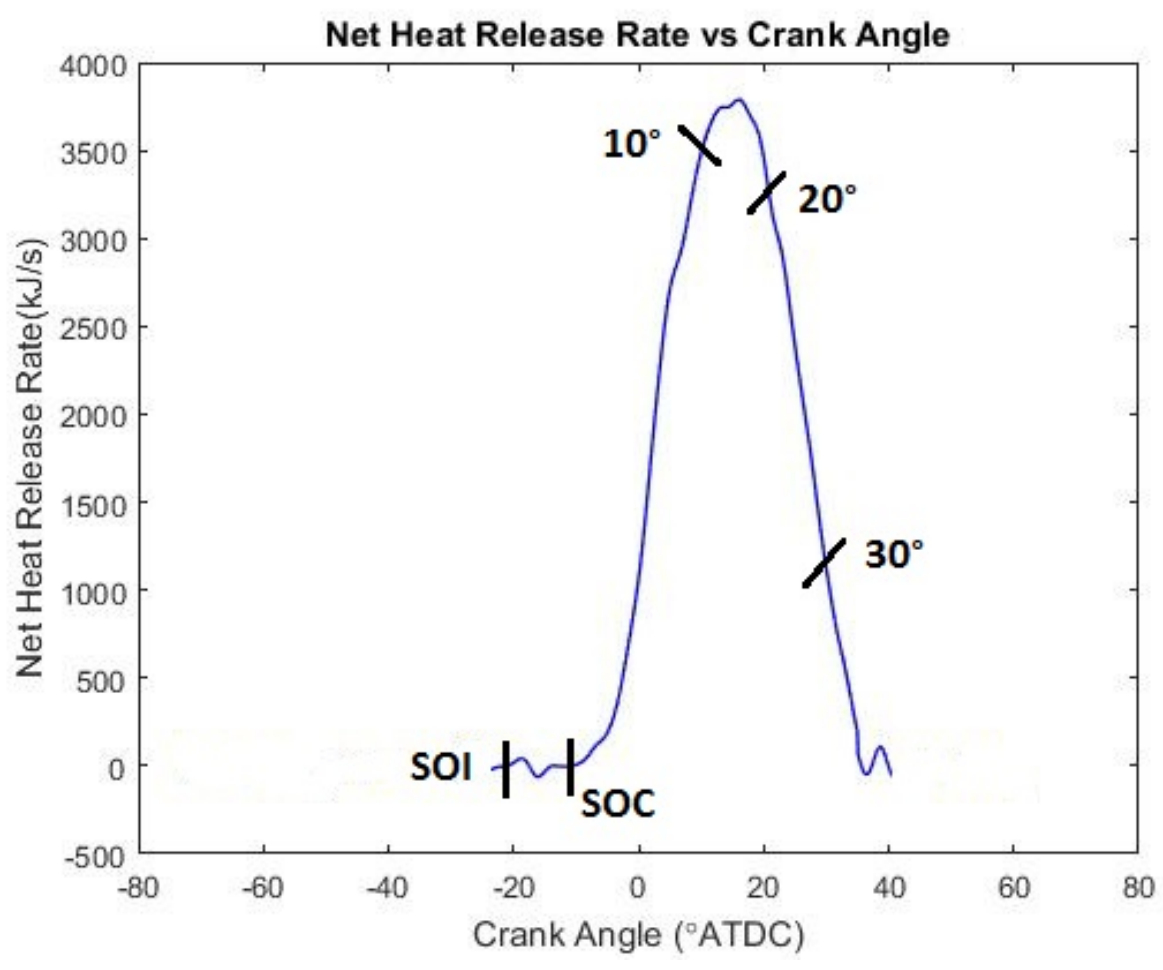

Figure 4.9 The apparent heat release rate for a representative combusting cycle 
An expression used to represent the mass fraction burned versus crank angle curve was given by Wiebe [102] as a function in equation 4.7 .

$$
x_{b}=1-\exp \left[-a\left(\left(\theta-\theta_{o}\right) / \delta \theta\right)^{m+1}\right]
$$

where $\theta$ is the crank angle, $\theta_{o}$ is the start of combustion, $\delta \theta$ is the total combustion duration $\left(\mathrm{x}_{\mathrm{b}}=0\right.$ to $\left.\mathrm{x}_{\mathrm{b}}=1\right)$, and $a=5$ and $m=2$ are chosen adjustable parameters specific to a combustion process. The curve obtained from this plot, has a characteristic S-shape. The rate at which the charge mixture burns, increases from a low value immediately following the spark discharge to a maximum about half way through the burning process and then decreases to close to zero as the combustion process ends. Hence, the s-curve proves convenient to characterize different stages of combustion process by their duration in crank angles.

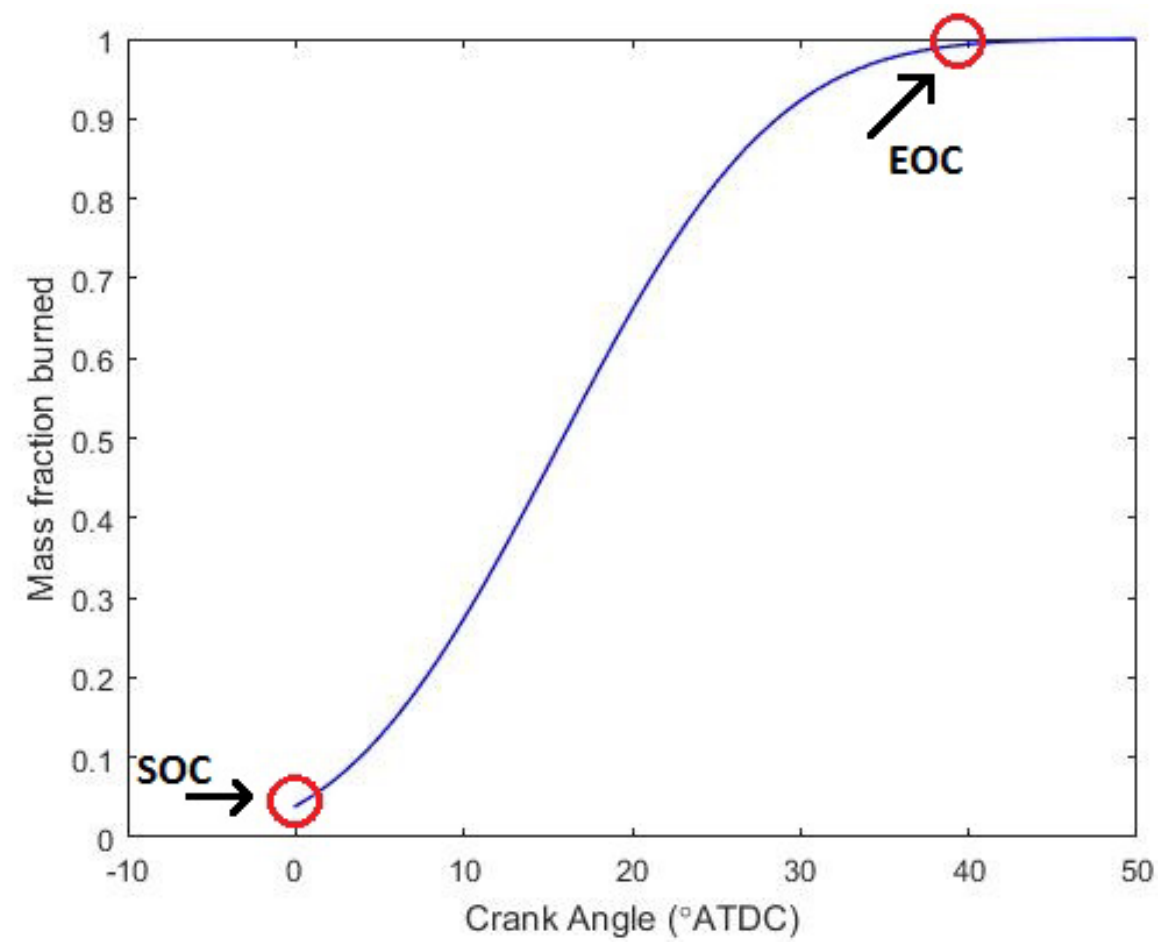

Figure 4.10 Mass fraction burned from -5 deg to 50 deg combustion duration for a representative cycle

Next, the MFB profile calculated according to Rassweiler and Withrow method [reference] is presented in figure 4.11. The Rassweiler and Withrow method is based on the assumption that, during engine combustion, the pressure rise $\Delta p$ consists of two parts: pressure rise due combustion $\left(\Delta p_{c}\right)$ and pressure 
change due to volume change $\left(\Delta p_{v}\right): \Delta p=\Delta p_{c}+\Delta p_{v}$. Assuming that the pressure rise $\Delta \mathrm{p}_{\mathrm{c}}$ is proportional to the heat added to the in-cylinder medium during the crank angle interval, the mass fraction burned at the end of the considered $i$-th interval may be calculated as [47] formulated in equation 4.8:

$$
M F B=\frac{m_{b}(i)}{m_{b}(\text { total })}=\frac{\sum_{0}^{i} \Delta p_{c}}{\sum_{0}^{N} \Delta p_{c}}
$$

where 0 denotes the start of combustion, $N$ - end of combustion ( $\mathrm{N}$ is the total number of crank intervals). For the MFB calculations knowledge of $\Delta p_{c}$ is necessary, and a pressure change due to volume variation is given by:

$$
\Delta p_{v}=p_{i+1}-p_{i}=p_{i}\left[\left(\frac{V_{i+1}}{V_{i}}\right)^{n}-1\right]
$$

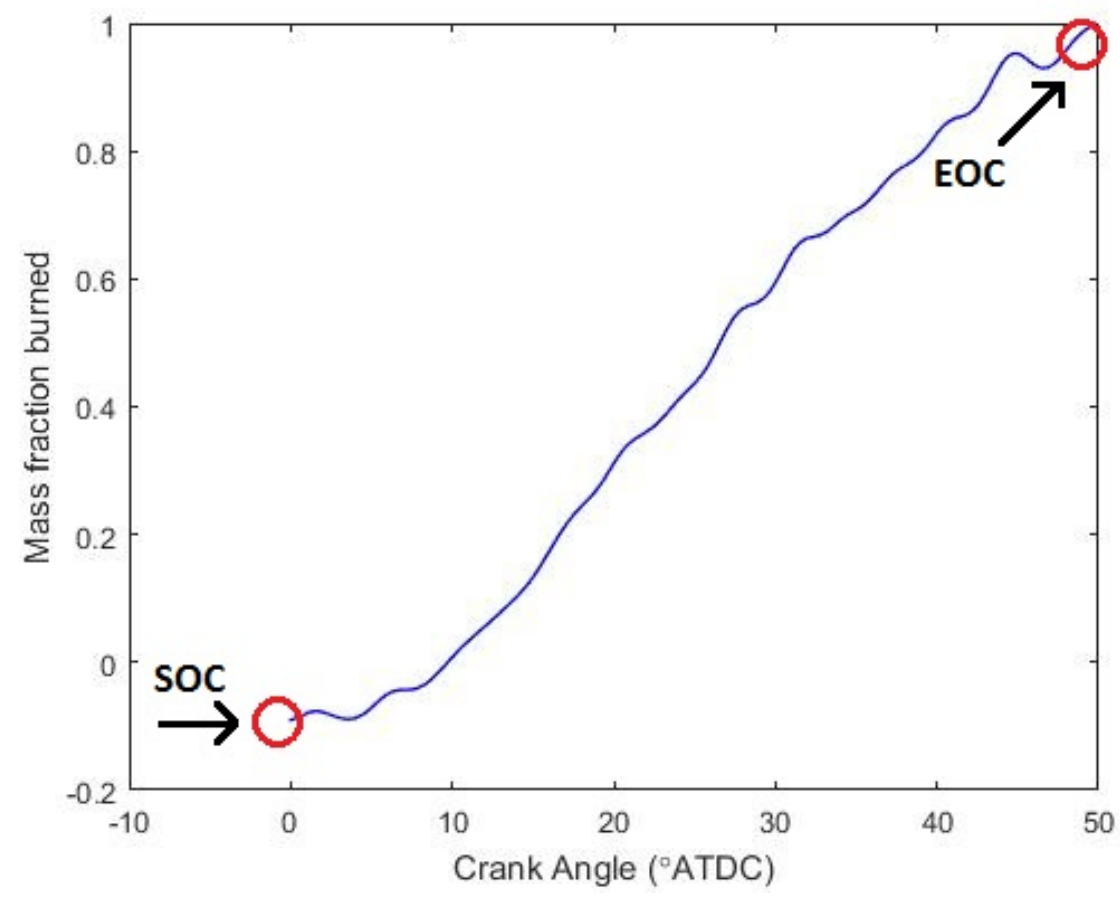

Figure 4.11 Mass fraction burned profile based on Rasswieler \& Withrow method for a representative

$$
\text { cycle }
$$

It is also of interest to measure the cycle-to-cycle variability, derived from pressure data. In terms of available data, it is equal to the coefficient of variation in indicated mean effective pressure (IMEP), expressed statistically as in equation 4.10. It is well documented that vehicle drivability suffers when $C O V_{\text {imep }}$ exceeds about $10 \%$ [47]. Also, the primary metric used to determine engine load is mean effective 
pressure (MEP). The mean effective pressure is defined as work per cycle divided by displaced volume, yielding a value with units of pressure, and is calculated by integrating cylinder pressure versus volume (PV) data. The $C O V_{\text {IMEP }}$ was $6.17 \%$

$$
C O V_{\text {imep }}=\frac{\sigma_{\text {imep }}}{\mu_{\text {imep }}} * 100
$$

\begin{tabular}{|c|c|}
\hline Parameter & Value \\
\hline Engine speed & $900 \mathrm{RPM}$ \\
\hline Gross IMEP & $593 \mathrm{kPa}$ \\
\hline Intake manifold pressure & $98 \mathrm{kPa}$ \\
\hline Intake air temperature & $300 \mathrm{~K}$ \\
\hline Spark timing & $20 \mathrm{BTDC}$ \\
\hline Start of Injection & $372 \mathrm{BTDC}$ \\
\hline Injection pulse-width & $18 \mathrm{~ms}$ \\
\hline Spark duration & $1 \mathrm{~ms}$ \\
\hline Equivalence ratio & 1.1 \\
\hline Fuel injection rate & $3.37 \mathrm{~kg} / \mathrm{h}$ \\
\hline Air mass flow & $52.5 \mathrm{~kg} / \mathrm{h}$ \\
\hline Volumetric efficiency & $79.8 \%$ \\
\hline
\end{tabular}

Table 4.1 Engine operating parameters

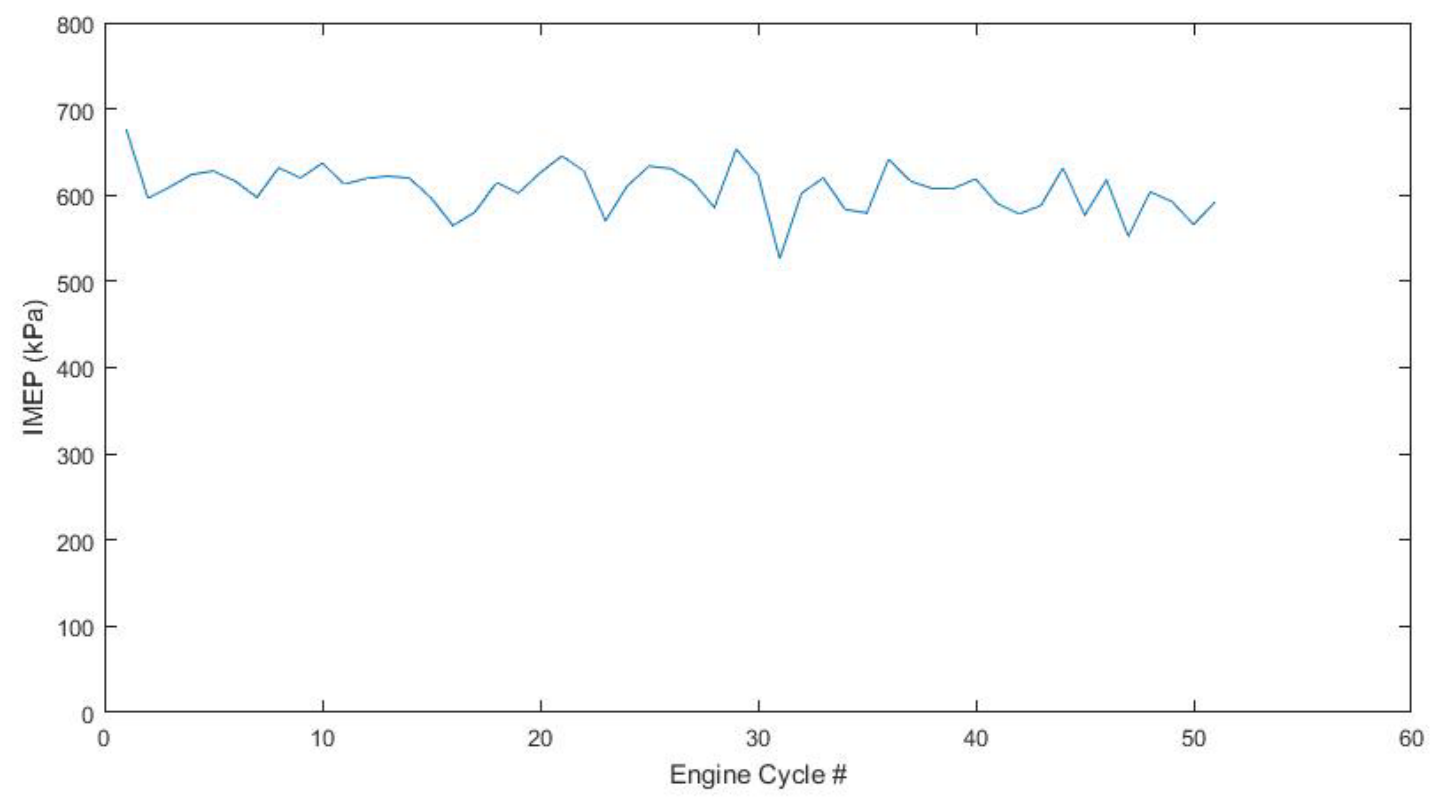

Figure 4.12 IMEP of combusting cycles 
It is to be noted that a 1/5 skip-firing strategy was used for this study. Skip-firing technique is used as a means to allow sufficient cooling of the combustion chamber surfaces. The engine was operated under the following conditions as listed in Table.4.1. Figure 4.13 shows the engine load profile for a single set of 5 skipped injections for every combustion event.

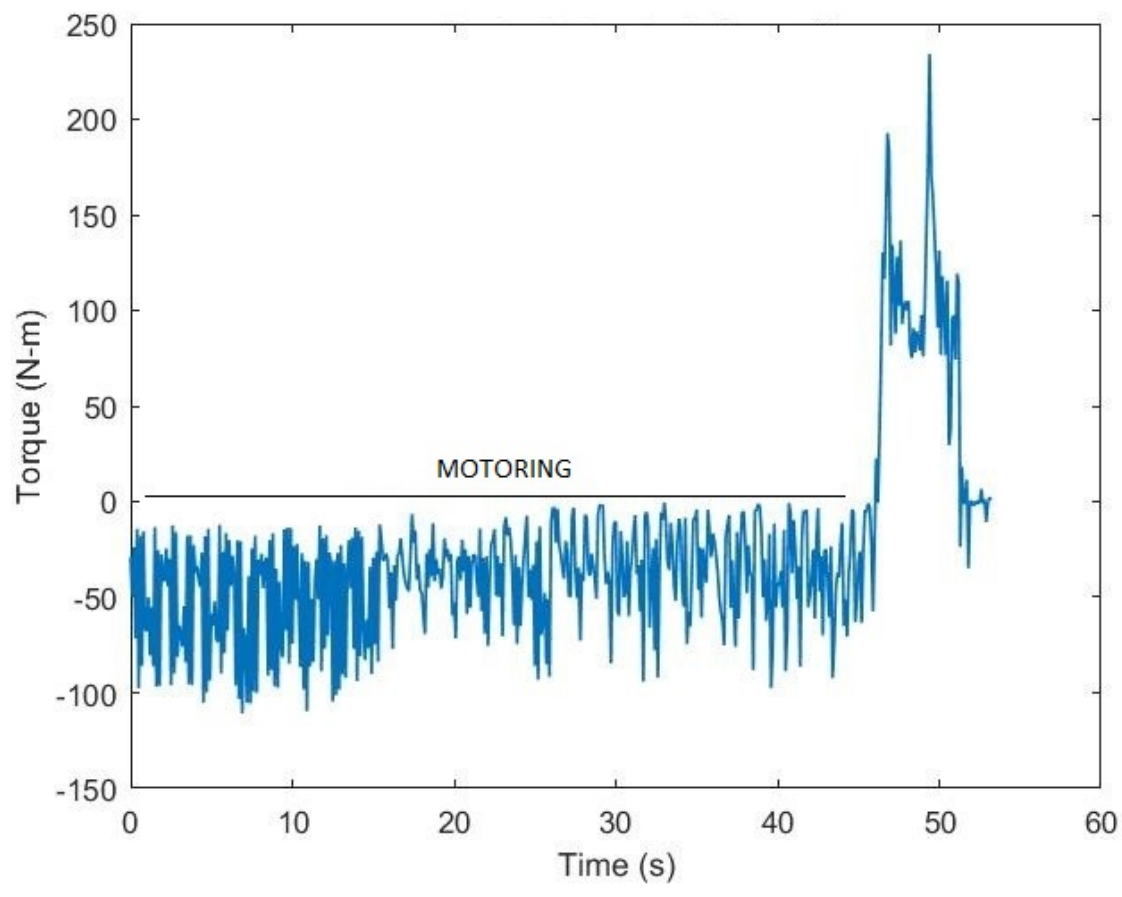

Figure 4.13 Engine load profile for one set of skip fired operation 


\subsubsection{Co-relation of combustion with optical data}

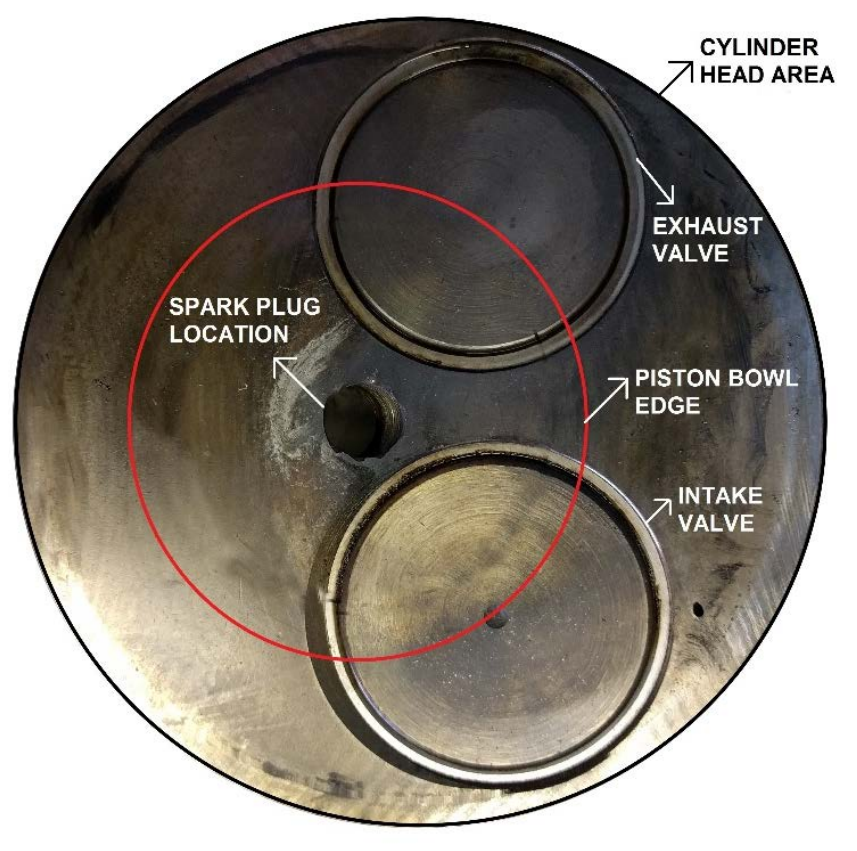

Figure 4.14 Imaged region relative to the total cylinder head area (black circle), spark location, and engine valves. The region is limited by the piston bowl edge (red circle)

In this section, a set of twenty images is used to describe the correlation between the combustion data and flame speed. These images are representative of each of the combustion events marked in figure 4.9. The red circle in Figure 4.14 shows the actual photographed region relative to the total in-cylinder radial area. After ignition, the flame front expanded radially developed from the location of the spark plug across the piston bowl. Due to the high spark luminosity at the spark plug location, the flame kernel luminosity was partially hidden in the first few images acquired after ignition. The flame front propagation in figure 4.15 indicates a wrinkling flame structure. The air/fuel mixture burns in thin, laminar-flame-like layers, which are stretched and wrinkled by turbulence, whereas the principle structure is not changed by turbulence [103]. 


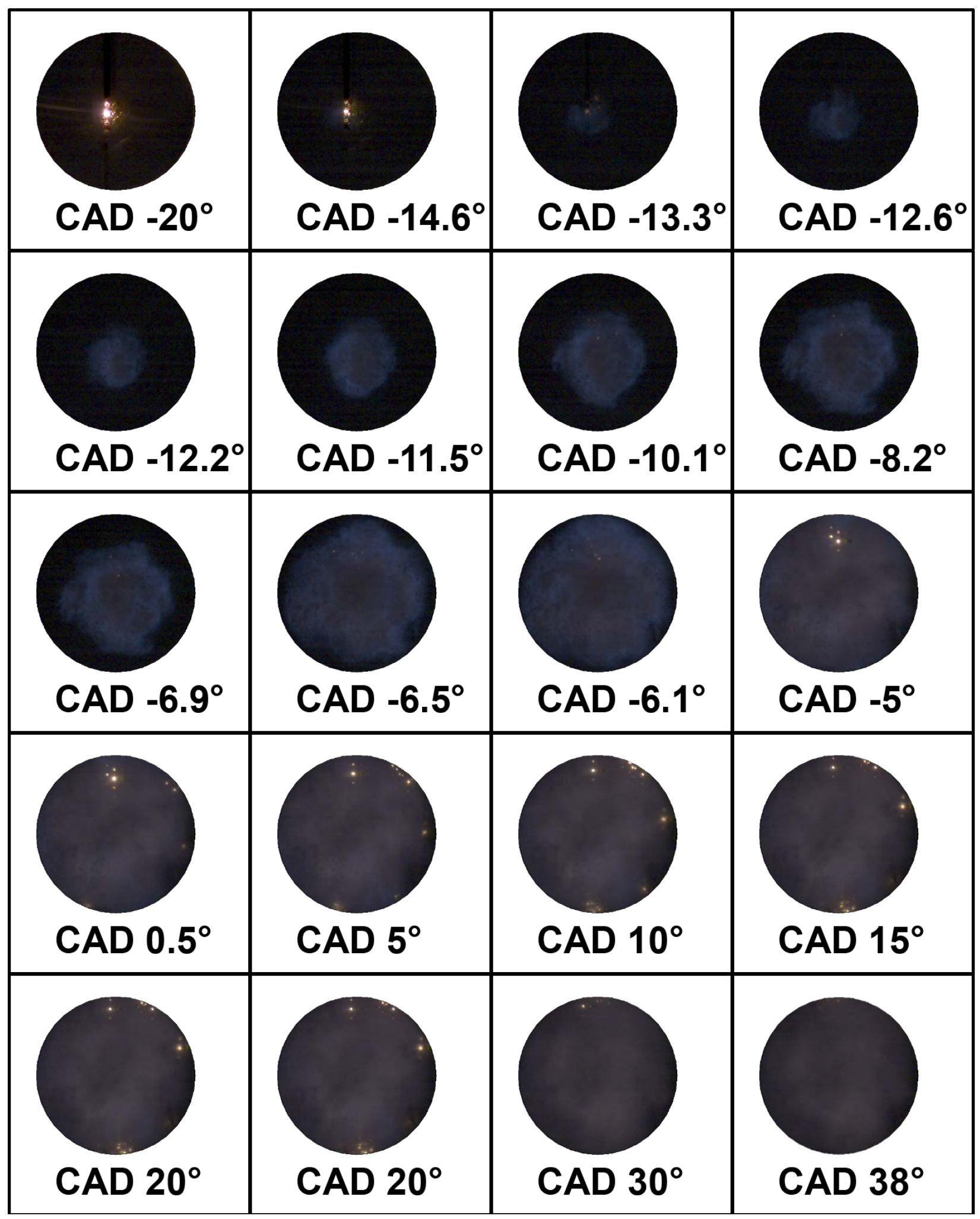

Figure 4.15 Raw flame images representative of combustion events from CAD -10 to CAD 50 


\subsection{Image processing}

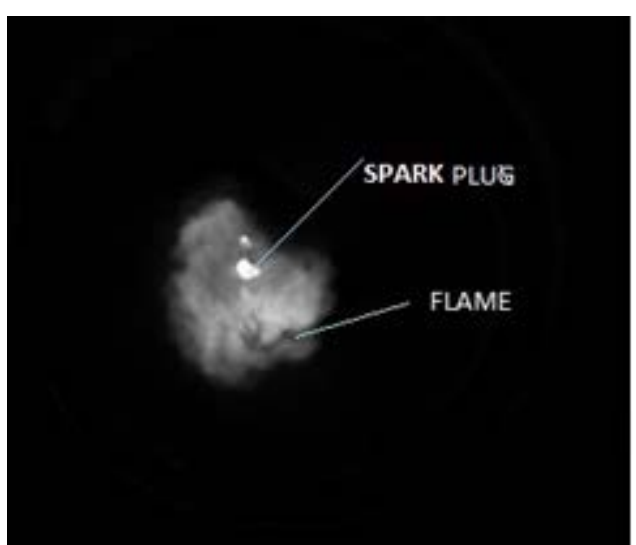

$\mathrm{a}$

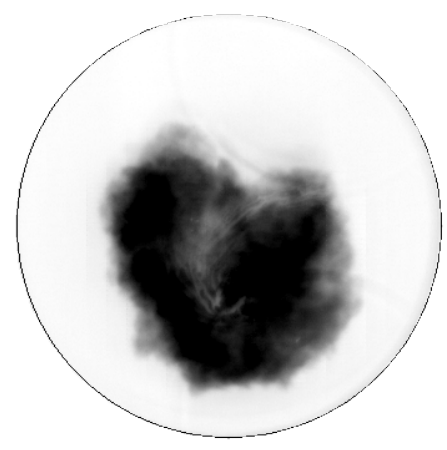

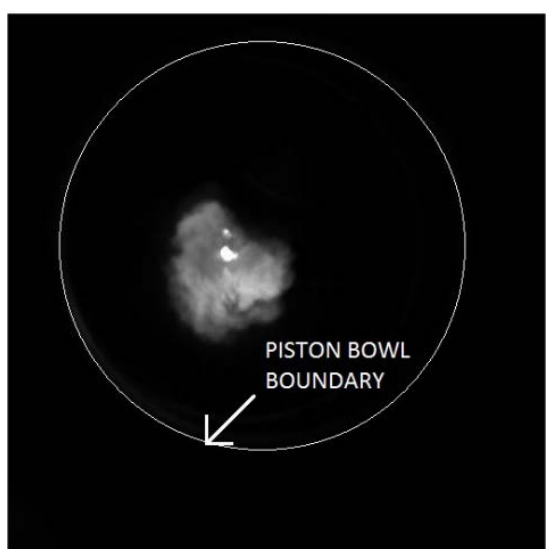

b

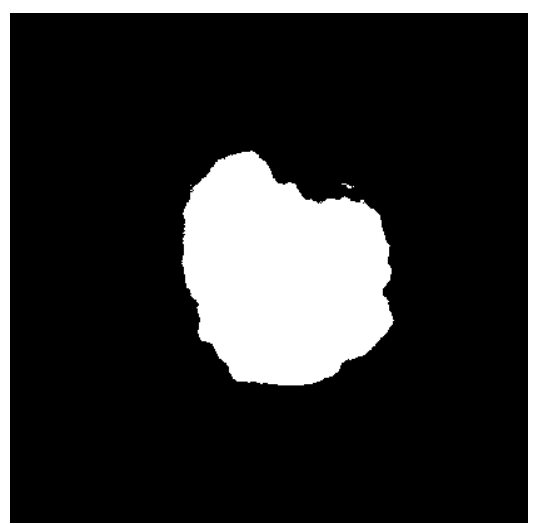

Figure 4.16. Image processing steps: (a) raw image, (b) determination of area of interest, (c) signal thresholding, and (d) binarization

A suitable post processing method was scripted in MATLAB to automatically load and process the images according to the following steps. Figure 4.16.a. shows a typical raw images. The first step in the image processing was to determine the area of interest, which is represented by the combustion bowl boundary (see Fig. 4.16.b). The next step was to identify the flame area using signal thresholding. Specifically, all the values of the pixels in the area of interest that were lower than a certain percentage of the signal intensity in the most bright flame area were considered equal to zero (see Fig. 4.16.c). Finally, the image was binarized with a thresholding of 0.1. A critical and frequent problem in when the image boundaries are not sharply demarcated is the choice of a correct threshold level. For example, the first image when the flame begins. In such a low intensity image, the intensity of grayscale pixels at different points across the dim intensity flame area is determined. The mean intensity of these dim pixels is taken as thresholding value. After the thresholding, morphological transformations were applied to fill holes and 
remove small border objects. In order to decrease noise and smooth the contour, a low pass filter was applied. Further these steps, a circle of dimensions equal to that of the piston bowl edge is masked onto the binarized image. Now, the matrix of masked image is multiplied with the image matrix of the binary image. In doing so, all the white pixels (binary-1) inside the masked circle will be retained and those outside the region of interest will be turned black (binary-0). From the obtained flame images, geometric properties such as area and perimeter are computed using inbuilt MATLAB image processing functions. The above described procedure is iterated in a loop for all the images and thereafter written into a destination folder, after applying the processing steps.

The burning rate can be extracted from the flame area. Assuming a spherical flame, the radii of the burnt gas area and the perimeter, $R_{s}$ and $R_{p}$ respectively, were determined using equation 4.11 :

$$
\begin{aligned}
& R_{s}=\sqrt{\frac{A}{\pi}} \\
& R_{p}=\frac{P}{2 \pi}
\end{aligned}
$$

where $A$ and $P$ are the flame area and perimeter, respectively, deduced from the monochromatic combustion images. The wrinkling ratio $W$ as defined by Renou and Boukhalfa [104] is also calculated according to equation 4.12:

$$
W=\frac{R_{p}{ }^{2}}{R_{s}^{2}}
$$

Fig. 4.17 shows a plot of the computed wrinkling ratio growth with CAD, for a combustion cycle. A flame propagation (turbulent) speed is then derived from $R_{s}$ :

$$
S_{R s}=\frac{d R_{s}}{d t}
$$




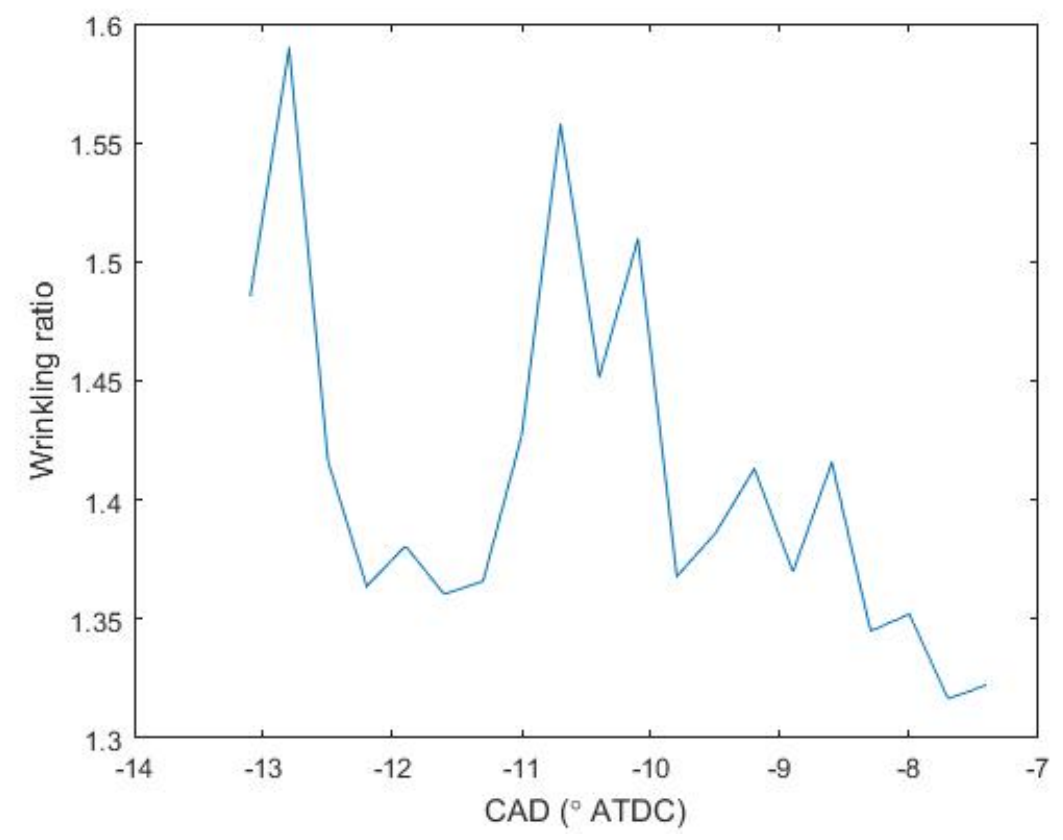

Figure 4.17 Characteristic plot of wrinkling ratio with the flame growth

\subsubsection{Flame radius}

At any given flame radius, the geometry of the combustion chamber and the spark plug location govern the flame front surface area, which is the area corresponding to the leading edge of the flame. Figure 4.18 shows that the flame had already reached the combustion bowl boundary at $-6.5^{\circ}$ ATDC, which limits the number of frames that can be used to calculate the flame area. Further, by deducing the summation of area of pixels, in a fully flame spread spherical surface of the binary image, we can co-relate the pixels area in terms of metric units, given that the diameter of the combustion bowl is $76 \mathrm{~mm}$ and the depth of the window is $31.75 \mathrm{~mm}$. Figure 4.19 shows the calculated growth in flame radius vs CAD. The frequency of acquisition of the images was 15,000 . 


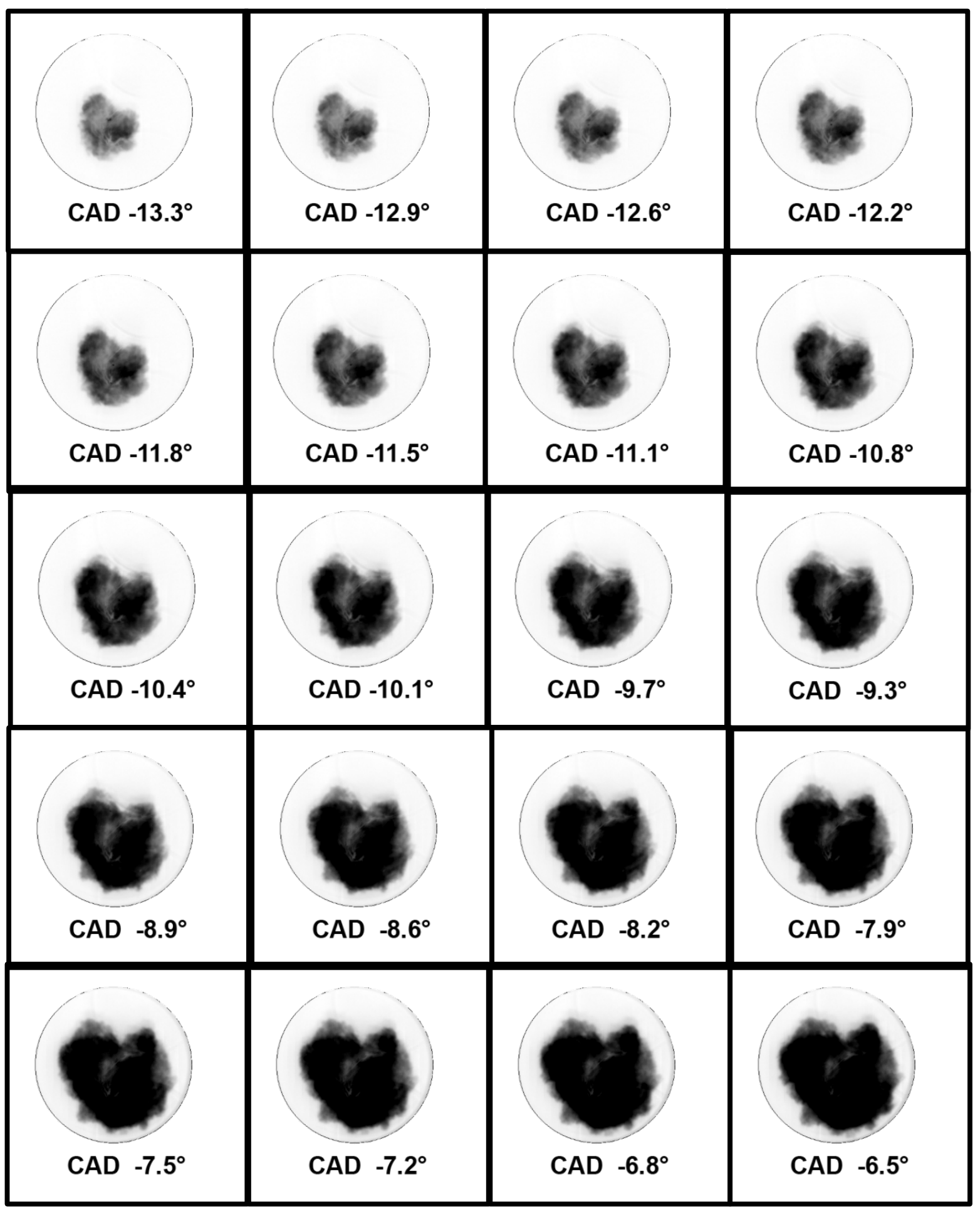

Figure 4.18 Example of flame images used to determine burn rate parameters 


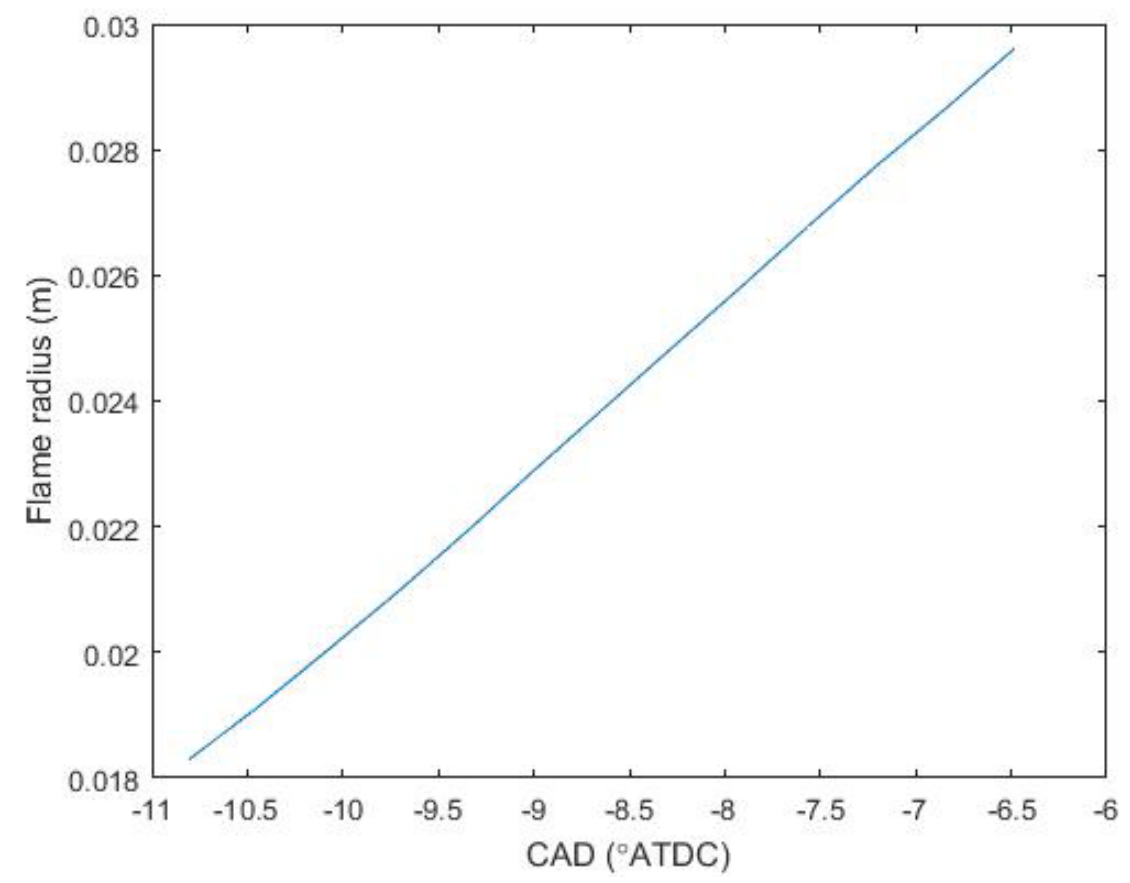

Figure 4.19 The flame radius increase with CAD for a representative combusting cycle

To test the correctness of our experimental setup and, we compared our flame images with images in the literature at similar operating conditions. Figure 4.20b shows the Planar Laser Induced Fluorescence (PLIF) images of methane-air pre-mixed combustion mixture performed by Kaminski et.al [105]. The middle row in Fig 4.20b show a similar degree of wrinkling at similar in-cylinder turbulence.

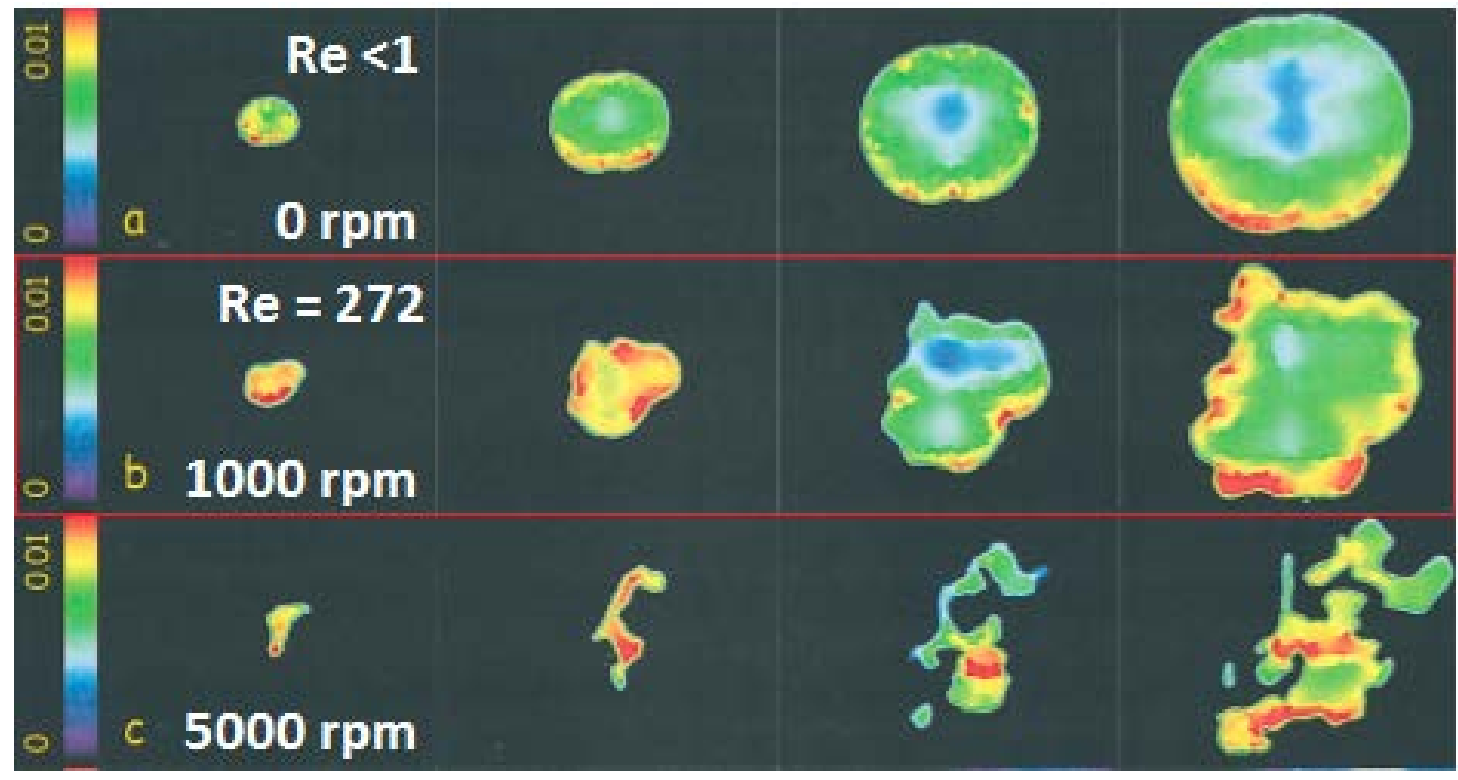

Figure 4.20 a, b, c Evolution of flame front growth studied experimentally using PLIF by [105] 


\subsection{Flame propagation}

The combustion process in spark-ignition engines has been studied extensively in the last five decades. These studies have established that the initial, flame is relatively smooth [106-109]. As it grows, the flame front becomes increasingly influenced by the turbulent flow field through which it is spreading and eventually develops a highly wrinkled and possibly end up like a multiply connected structure [110]. Homogeneous (or pre-mixed) charge combustion in SI engines is an unsteady process in which an ignition flame kernel of size about $1 \mathrm{~mm}$ grows over a time of $1 \mathrm{~ms}$ into a fully developed flame front with a front to back thickness of approximately $10 \mathrm{~mm}$ that propagates through the chamber [111]. In agreement to this conclusion, as the flame developed progressively, it became more wrinkled and thereby increased the flame thickness, surface area and burning rate [112].

There is a wealth of experimental data available at atmospheric conditions, (include flame visualization) that yield information on the rate of entrainment of unburned gas into the flame front [113-115]. However, flame-related data are sparse at the elevated temperatures and pressures encountered in engines. The limited data available have been derived based on thermodynamic analysis of pressure development, with an assumption incorporating thin spherical flame growth, inside constant volume combustion bombs [116118]. The laminar burning velocity, $S_{L}$ is then given by,

$$
S_{L}=\frac{\left(\frac{d m_{b}}{d t}\right)}{\left(A_{f} * \rho_{u}\right)}
$$

where mass burning rate is determined from the rate of pressure rise in the vessel and $A_{f}$ is the flame area. Since the laminar flame thickness under engine conditions is in the order of $0.2 \mathrm{~mm}$ [47] and is much less than the characteristic flame thickness observed in a spherical bomb vessel, the flame can be treated as negligibly thin. Other parameters which do lack to fully account for the physical phenomena taking place inside engines, include rate of flame stretch (a function of flame radius and curvature as well as turbulence) and flame development inside turbulent conditions of flow field, which will be addressed in the forthcoming sections $[119,120]$.

\subsubsection{Flame speed calculation}

Spherically expanding flame method has been one of the methods to determine the laminar flame speed of the burning mixture. This spherical flamelet assumption in SI engines has often been found to be valid for low and midrange engine speeds, which are representative of this study [121]. Turbulent flame velocities have been directly derived from the post processed images. The surface area is calculated as a summation of pixels. The flame propagation speeds were calculated as the time derivative of the surface radius (vide equation 4.13). As observed from Fig. 4.21, the increasing flame wrinkling may have contributed to 
increasing the flame speed. The flame speed thus measured directly from the engine, is a combination of two physical effects occurring in the flame kernel development - viz. flame stretching and flame wrinkling.

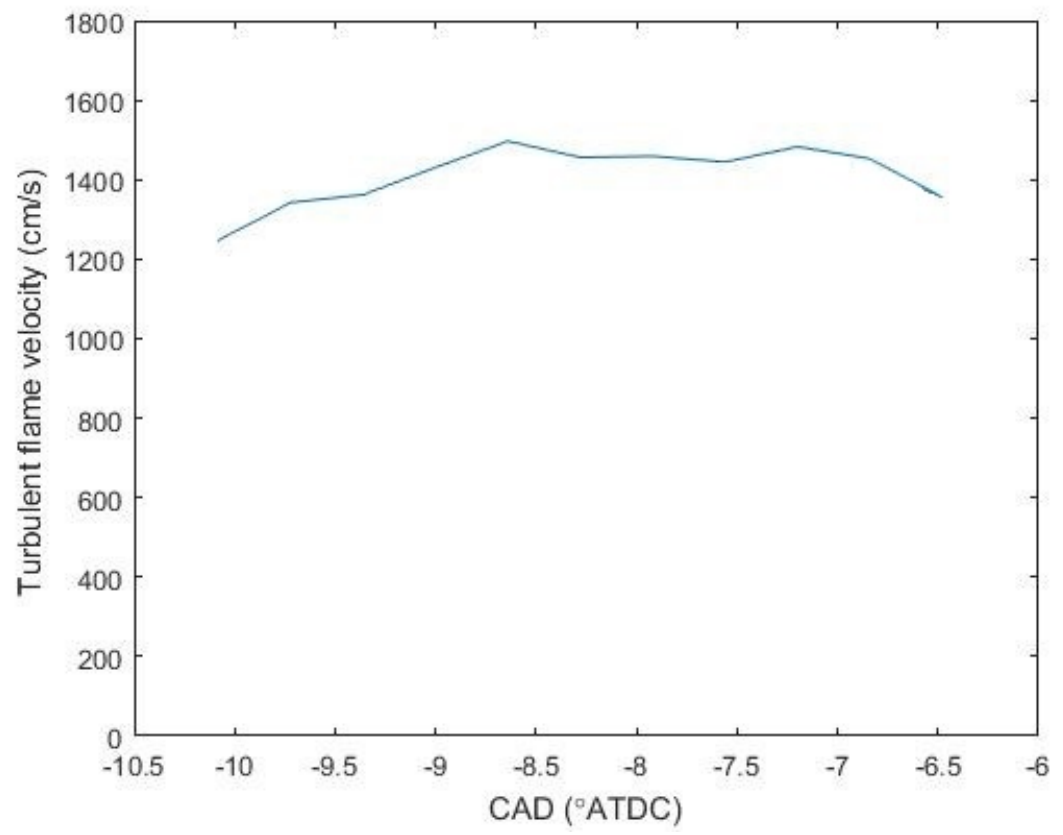

Figure 4.21 Flame velocity for a representative flame images set.

Figure 4.22 shows the cycle-to-cycle variability in turbulent burning velocity. The reason for this behavior in the flame speed can be attributed to the variations in spark energy and in-cylinder flow movement which influenced the growth of the initial flame kernel as well as the fully-developed turbulent flame. There is strong experimental evidence in the literature that the initial flame kernel growth is responsible for up to $50 \%$ of the total cycle-to cycle variations in a gasoline SI engine [142-144]. Since Fig.4.21 and Fig. 4.22 were constructed from the turbulent velocities measured directly from the experiments, the cycle variability in flame speed are a direct indicator of the combustion robustness. It can be seen how each cycle had differemt SOC and flame propagation characteristics. A possible explanation could be the cycle-to-cycle variation in the in-cylinder conditions, or the variability in engine spark/fueling parameters. This aspect needs further investigation for a detailed understanding of the cycle-to-cycle variations in NG SI engines. 


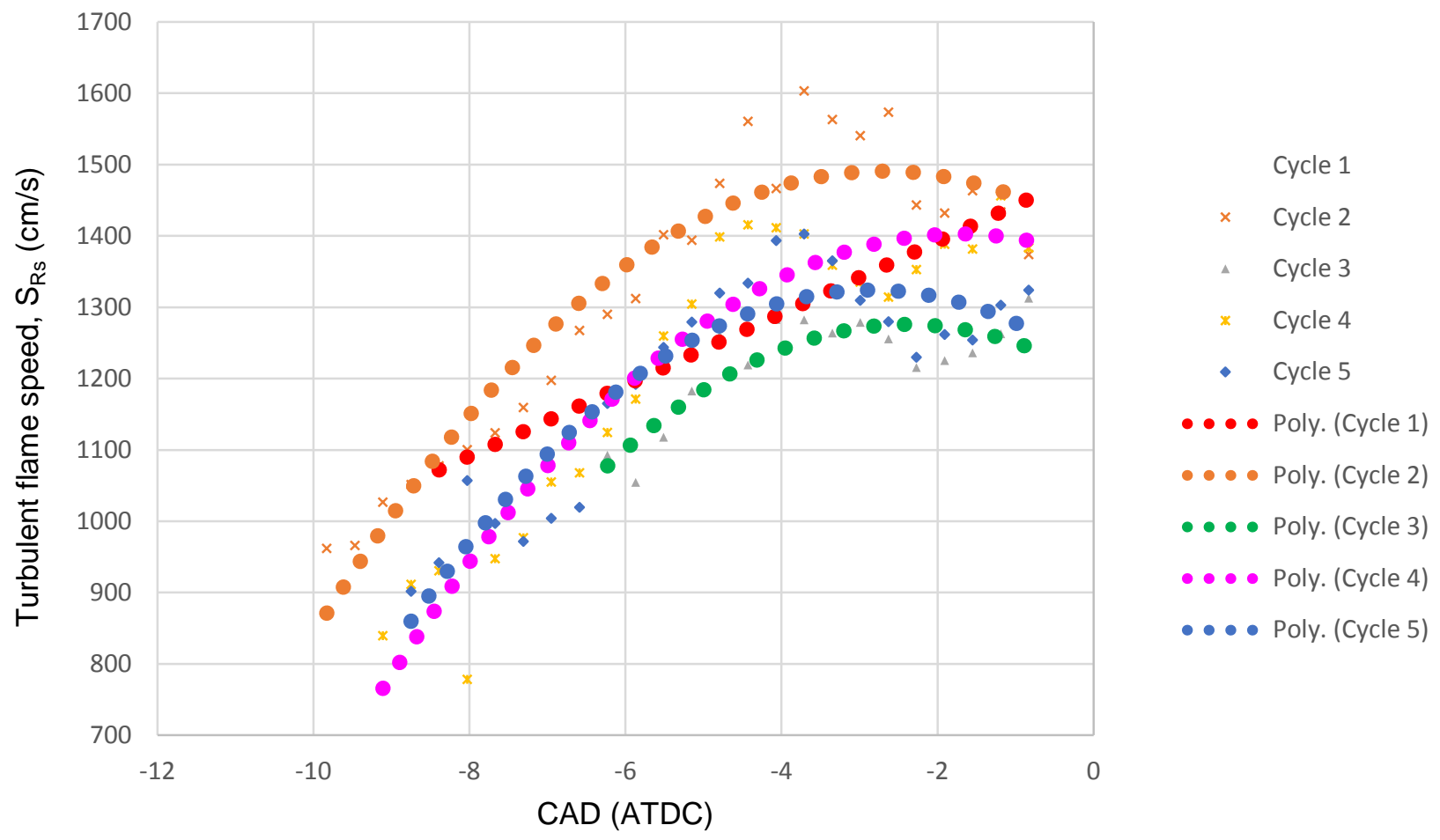

Figure 4.22 Cyclic variability in flame speed vs CAD

\subsection{Intake flow measurement}

An intake surge tank is a solution to reduce pressure fluctuations inside the intake manifold. Figure 4.23, which compares intake flow rate with and without a surge tank arrangement, shows that the intake surge tank reduced up to $83 \%$ the variations in the measured air flow rate.

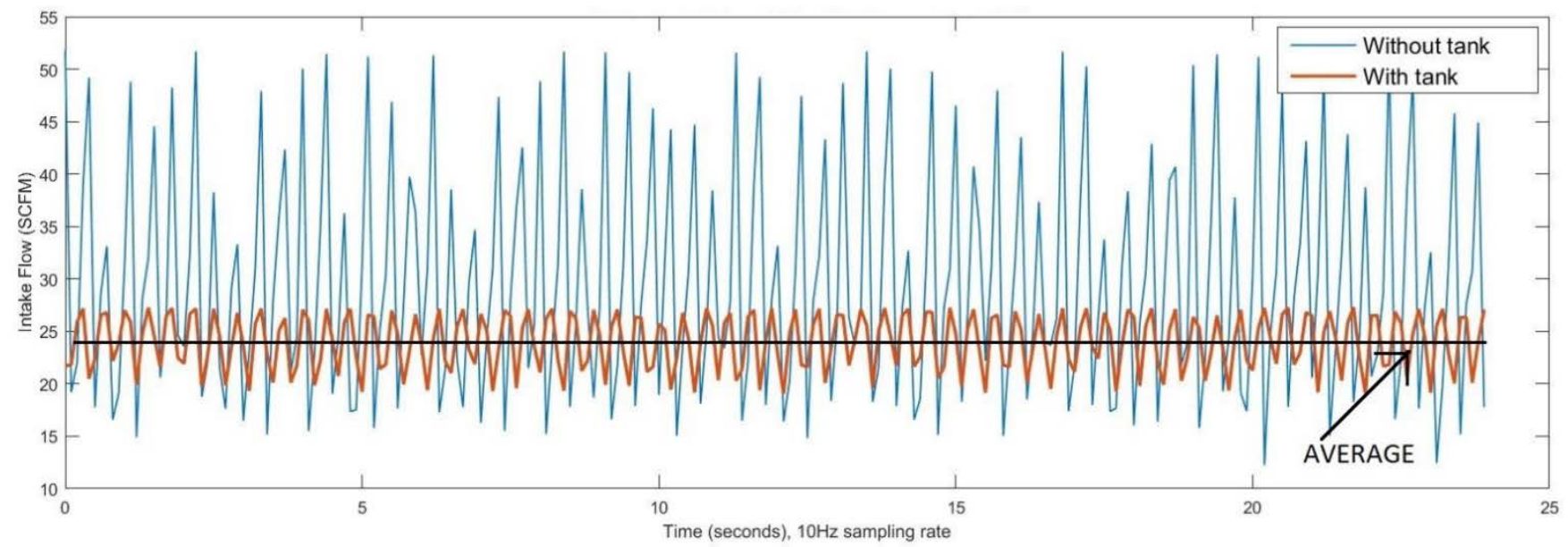

Figure 4.23 Effect of surge tank on intake flow fluctuations with 0.01 ” orifice snubbers 


\subsection{Emission characteristics}

Figure 4.24 shows the trend of observed $\mathrm{CO}_{2}$ emissions versus the engine load. $\mathrm{CO}_{2}$ emissions decreased for the first 20 seconds of the measurement then stabilized. This trend can be explained by the time it takes for the exhaust flow to properly mix inside the collection manifold before reaching the analyzer. Next, figure 4.25 shows HC and CO emissions. The plot shows good agreement of both the trends, which is considered an important parameter to validate the emissions data. The CO emissions are primarily influenced by the air fuel equivalence ratio. Since the engine was operated slightly richer than stoichiometric conditions, the CO emissions were significant, even with the skip fire ratio of 1/5. Hydrocarbon emissions are a direct result of incomplete combustion processes, including crevice effects and partial oxidation of combustion products.

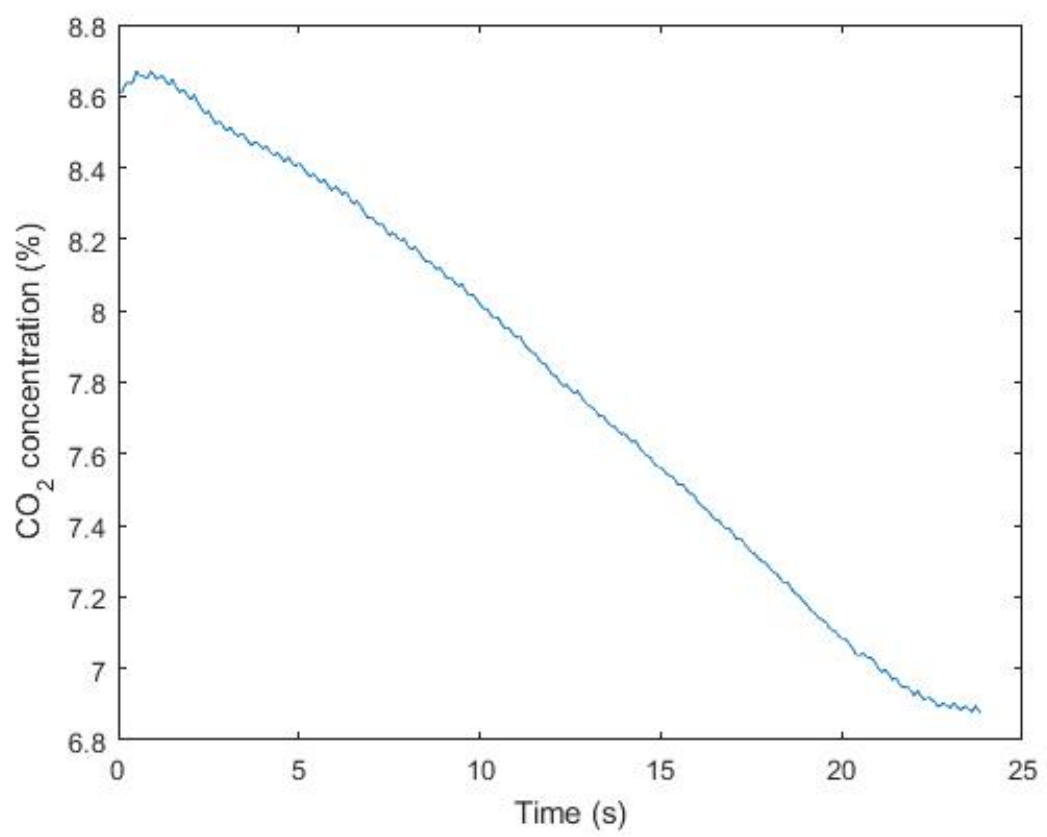

Figure 4.24 Measured emissions level from NDIR gas analyzer for one set of skip fired operation 


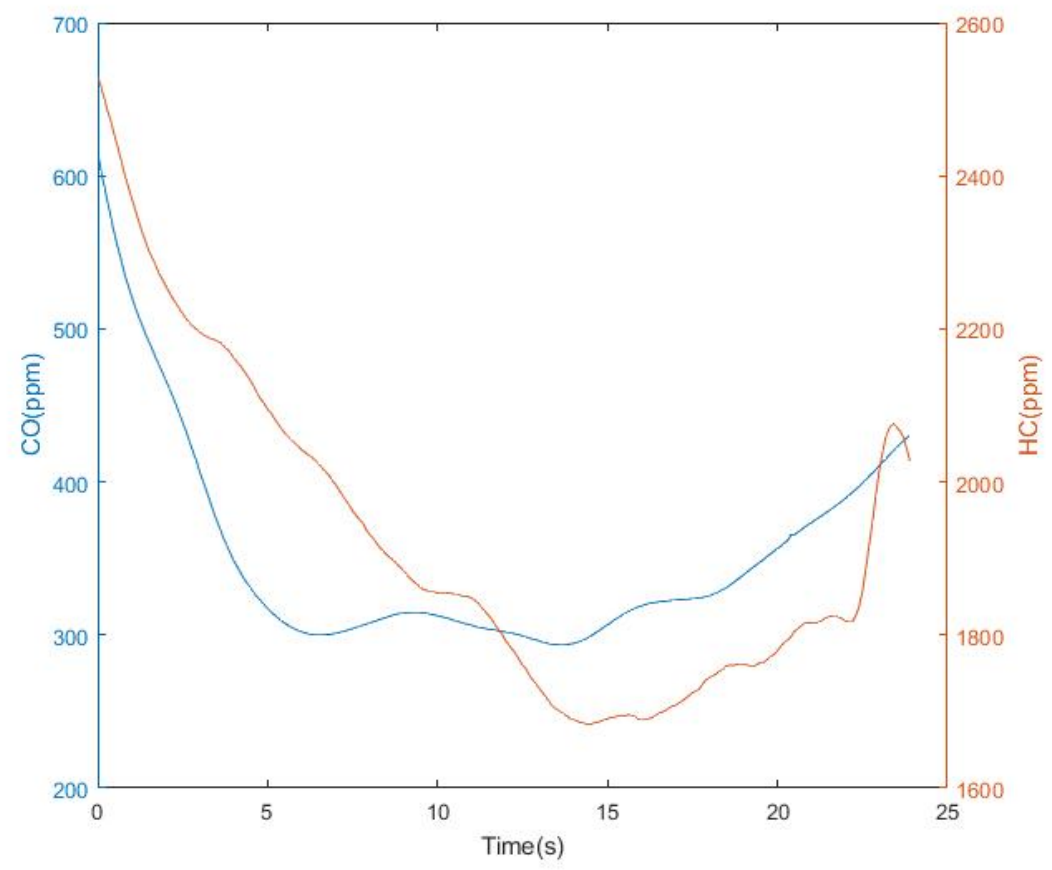

Figure 4.25 Measured emissions level from FID gas analyzer for one set of skip fired operation 


\section{Chapter 5}

\section{Conclusions}

The goal of this study was to develop an experimental platform for optical investigations of engine combustion phenomena based on a single-cylinder heavy-duty spark-ignited engine. The Ricardo Proteus research engine uses a Bowditch piston to provide optical access to the combustion chamber. This optical engine was used for a preliminary investigation of the flame speed in NG combustion. The first part focuses on the setup of a single-cylinder research engine with optical access including the design of its control system and the acquisition of in-cylinder pressure data and high-speed combustion images. The second part focuses on measurements of the turbulent flame speed using the high-speed combustion images.

The optical engine control system can acquire operating parameters (engine speed and torque, air and fuel mass flows, engine fluids temperature), in-cylinder pressure data, combustion images, and engine emissions. The LFE used for intake flow measurements showed large variations in before the installation of pressure snubbers and a surge air tank close to the intake valve.

Two different methods of digital signal processing, i.e., zero phase digital filter and fourth order butterworth filter, eliminated signal artefacts and smoothened the in-cylinder pressure signal for combustion analysis. The Butterworth filter showed superior performance compared to the zero-phase digital filter, indicating it as a method of choice for pressure analysis.

Combustion natural luminosity was used for fundamental combustion analysis in the second part of the study. This visualization technique used a high-speed CMOS camera to acquire time resolved in-cylinder flame images of the burning mixture at $900 \mathrm{rpm}$, at close to stoichiometric conditions. A post processing technique based on the increase of flame area per unit time was developed in MATLAB and use to determine the flame speed. The flame front radius were calculated and reported as a function of the CAD during the first stages of the combustion process (i.e., up to the moment the flame reaches the piston bowl edge), for each of the engine cycle recorded. The turbulent burning velocity was derived from the growth radius. Subsequently, the processing was applied for several engine cycles to discuss the cycle-to-cycle variability with reference to the SOI and SOC.

The following conclusions were drawn from the analysis of the acquired in-cylinder images:

- Image analysis is a helpful tool to explain the results obtained from thermodynamic analysis. 
- $\quad$ The flame edge at the operating conditions investigated in this study was irregular, but roughly spherical, supporting the flamelet assumptions.

- $\quad$ Flame stretch and the turbulent in-cylinder flow strongly affected the calculated flame speed.

\subsection{Future work}

It is recommended that the experiments could be repeated with different blends of natural gas with varying composition and thereby study the effect of fuel compositional changes on flame properties. The study could be extended for investigation of the effect of the equivalence ratio on the turbulent burning velocity of the flame. Flame stretching and curvature as well as Lewis number effects could also be studied over a wide parametric range.

The current framework of skip firing controller based on Arduino are very sensitive to external RF interferences and hence requires proper insulation of the controller from the strong electric fields nearby, such as those coming from the dyno. There is a need for a more robust technique to synchronize both the image acquisition, data acquisition, fueling, and emissions systems simultaneously. One feasible approach could be to tap in to the PCI card for the digital signals of z pulse (1 pulse/ rev) and clock pulse ( 1 pulse/ 0.1 CAD) from the rotary shaft encoder. These signals could be processed and suitably to output TTL signals for camera trigger and digital outputs to open the solid state relay for the injection circuit. Also, this type of master-slave synchronization technique would allow us to corelate the emissions data with the acquired images, to gain an insight in to the formation of pollutants, from an in-cylinder perspective.

The optical portion of the engine limits us in taking experiments for more than a few minutes. The dry lubrication paste and coolant jackets are the only means of reducing the effect of thermal stress. In order to ensure, uniform cooling of the cylinder wall to get accurate representative data, it is recommended to modify the coolant system to allow precise control of raw water supply, during the course of bringing the engine to steady state operating condition. 


\section{Chapter 6}

\section{Bibliography}

1. C.L.Fevre, The prospects for natural gas as a transport fuel in Europe, Oxford Institute for Energy Studies (2014).

2. U.S. Energy Information Administration, Annual Energy Outlook 2016 with projections to 2040, DOE/EIA-0383 (2016). U.S. Energy Information Administration, 2016.

3. Alternative Fuels Data Center, U.S. Natural gas consumption by different end uses in 2014, Retrieved from http://www.afdc.energy.gov/afdc/data/, U.S.Energy Information Administration, 2015.

4. Degaldo, O and Munciref, R. Assessment of heavy duty natural gas vehicle emissions: Implications and policy recommendations. ICCT White paper, 2015.

5. Alternative Fuels Data Center, Trends of alternative fuels consumption in AFVs by fuel type from 1992-2011, Retrieved from http://www.afdc.energy.gov/afdc/data/, U.S.Energy Information Administration, 2014.

6. Merker,G.P., Schwarz,C., Teichmann,R., Combustion Engines Development: Mixture Formation, Combustion. Emissions and Simulation. Springer Publication; 2009

7. Naber JD, Siebers DL, Di.Julio SS, Westbrook CK. Effects of natural gas composition on ignition delay under diesel conditions. Combustion and Flame Vol 99 (1994): 192-200.

8. El-Sherif AS. Effects of natural gas composition on the nitrogen oxide, flame structure and burning velocity under laminar premixed flame conditions. Fuel Vol.77 (1998): 1539-47

9. Rosen J. Running on methane. Mech Eng.Vol.112 (1990): 66-71

10. IEO. Natural gas trends. 〈http://www.eia.doe/iea/overview.html〉, May 2003.

11. Hesterberg TW, Lapin CA, Bunn WB. A comparison of emissions from vehicles fueled with diesel or compressed natural gas. Environ Sci Technol Vol.42 (2008): 6437-45.

12. Fontaras G, Martini G, Manfredi U, Marotta A, Krasenbrink A, Maffioletti F, et al. Assessment of on-road emissions of four Euro V diesel and CNG waste collection trucks for supporting air-quality improvement initiatives in the City of Milan. Sci Total Environ (2012): 65-72.

13. Walkowicz K, Proc K, Wayne S, Nine R, Campbell K, Wiedemeier G. Chassis dynamometer emission measurements from refuse trucks using dual-fuel natural gas engines. SAE Technical Paper 2003-01-3366; 2003. 
14. Einewall P, Tunestål P, Johansson B. Lean burn natural gas operation vs. stoichiometric operation with EGR and a three way catalyst. SAE Technical Paper 2005-01-0250; 2005.

15. Yoon S, Collins J, Thiruvengadam A, Gautam M, Herner J, Ayala A. Criteria pollutant and greenhouse gas emissions from CNG transit buses equipped with three-way catalysts compared to lean-burn engines and oxidation catalyst technologies. J Air Waste Manage Assoc Vol.63 (2013): 926-33.

16. McTaggart-Cowan GP, Reynolds CCO, Bushe WK. Natural gas fuelling for heavy-duty onroad use: current trends and future direction. Int J Environ Stud Vol. 63 (2006): 421-40.

17. Gutierrez JH, Saldivar AR, Mora JR. LNG research study - phase 1. Testing of a natural gas compressor engine. Report by the Southern California gas Company, October 2003.

18. Karavalakis G, Durbin TD, Villela M, Miller JW. Air pollutant emissions of light duty vehicles operating on various natural gas compositions. J Nat Gas Sci Eng Vol 4 (2012): 816.

19. Graboski MS, McCormick RL, Newlin AW, Dunnuck DL, Kamel MM, Ingle WD. Effect of fuel composition and altitude on regulated emissions from a leanburn, closed loop controlled natural gas engine. SAE Technical Paper 971707; 1997.

20. McTaggart-Cowan GP, Rogak SN, Munshi SR, Hill PG, Bushe WK. The influence of fuel composition on a heavy-duty, natural-gas direct-injection engine. Fuel Vol.89 (2010):752-9.

21. Karavalakis G, Hajbabaei M, Durbin TD, Johnson KC, Zheng Z, Miller WJ. The effect of natural gas composition on the regulated emissions, gaseous toxic pollutants, and ultrafine particle number emissions from a refuse hauler vehicle. Energy Vol.50 (2013): 280-91.

22. Hajbabaei M, Karavalakis G, Johnson KC, Lee L, Durbin TD. Impact of natural gas fuel composition on criteria, toxic, and particle emissions from transit buses equipped with lean burn and stoichiometric engines. Energy Vol.62 (2013): 425-34.

23. Feist MD, Landau M, Harte E. The effect of fuel composition on performance and emissions of a variety of natural gas engines. SAE Technical Paper 2010- 01-1476; 2010.

24. G.Karavalakis, et.al. Regulated, greenhouse gas, and particulate emissions from lean burn and stoichiometric natural gas heavy duty vehicles on different fuel compositions. J.Fuel Vol.175 (2016): 146-156

25. A.Kakaee, A.Paykani, M.Ghajar, "The influence of fuel composition on the combustion and emission characteristics of natural gas fueled engines”, Renewable and Sustainable Energy Reviews, Vol.38 (2014): 64-78. 
26. United States Climate Action Report 2014. First biennial report of the United States of America, sixth national communication of the United States of America, under the united nations framework convention on climate change; 2014.

27. Feist MD. Fuel Composition Testing using Cummins, John Deere, and Detroit Diesel natural gas engines. Final report prepared by Southwest Research Institute for the Southern California Gas Company, Report No. 03.13721, April 2009.

28. Hajbabaeia M, Karavalakisa G, Johnsona K, Lee L, Durbina T. Impact of natural gas fuel composition on criteria, toxic, and particle emissions from transit buses equipped with lean burn and stoichiometric engines. Energy Vol.62 (2013): 425-34.

29. Karavalakisa G, Hajbabaeia M, Durbina T, Johnsona K, Zheng Zh, Miller W. The effect of natural gas composition on the regulated emissions, gaseous toxic pollutants, and ultrafine particle number emissions from a refuse hauler vehicle. Energy Vol.50 (2013): 28-91.

30. McTaggart-Cowan, G.P., Rogak, S.N., Munshi, S.R., Hill, P.G., Reynolds, Bushe, W.K., The influence of fuel composition on a heavy-duty, natural-gas directinjection engine. Fuel Vol.89 (2010): 752-759.

31. Economides, M.J., Wood, D.A. The state of natural gas. J. Nat. Gas. Sci. Eng. Vol.1 (2009): 1-13.

32. Korakianitis, T., Namasivayam, A.M., Crookes, R.J. Natural-gas fueled spark ignition (SI) and compression-ignition (CI) engine performance and emissions. Prog. Energy Combust. Sci. Vol.37 (2011): 89-112.

33. Farzaneh-Gord M, Rahbari HR, Nikofard H. The effect of important parameters on the natural gas vehicles driving range. Pol J Chem Technol Vol.14 (2012): 61-8.

34. Farzaneh-Gord M, Rahbari HR, Bajelan M, Pilehvari L. Investigation of hydrate formation in natural gas flow through underground transmission pipeline. J Nat Gas Sci Eng Vol.15 (2013) $: 27-37$

35. Jahanian, O., Jazayeri, S.A. A comprehensive numerical study on effects of natural gas composition on the operation of an HCCI engine. Oil Gas Sci. Tech. Vol. 67 (2012): 503515.

36. Kakaee, A.H., Paykani, A., Ghajar, M. The influence of fuel composition on the combustion and emission characteristics of natural gas fueled engines. Renew. Sust. Energy Rev. Vol. 38 (2014): 64-78.

37. Malenshek, M., Olsen, D.B. Methane number testing of alternative gaseous fuels. Fuel Vol.88 (2009), 650-56 
38. Kim, K., Kim, H., Kim, B., Lee, K., Lee, K. Effect of natural gas composition on the performance of a CNG engine. Oil Gas Sci. Tech. Vol.64 (2009): 199-206.

39. Elder ST, Jones K, Taine RR. Effects of varying fuel composition on the performance of CNG and LPG fueled vehicles. Trans Inst Prof Eng N Z: Electr/Mech/Chem Eng Sect Vol.12 (1985):161-72.

40. King S. The impact of natural gas composition on fuel metering and engine operational characteristics. SAE Technical 920593; 1992.

41. Thiagarajan S, Midkiff KC, Bell SR, Green MN. Investigation of fuel composition effects on a natural gas fueled spark-ignited engine. In: Proceedings of the ASME internal combustion engine division spring meeting; Marietta, OH, USA; 1995

42. Kado N, Okomoto RA, Kuzmicky P, Kobayashi R, Ayala A. Emissions of toxic pollutants from compressed natural gas and low sulfur diesel-fueled heavyduty transit buses tested over multiple driving cycles. Environ Sci Technol Vol.29 (2005) :7638-49

43. Ayala A, Gebel ME, Okamoto RA, Rieger PL, Kado NY, Cotter C, et al. Oxidation catalyst effect on CNG transit bus emissions. SAE Technical Paper 2003-01-1900; 2003.

44. Okomoto RA, Kado N, Kuzmicky P, Ayala A. Unregulated emissions from compressed natural gas (CNG) transit buses configured with and without oxidation catalyst. Environ Sci Technol Vol.40 (2006): 332-341.

45. Turrio-Baldassarri L, Battistelli C, Conti L, Crebelli R, De Berardis B, Iamiceli A, et al. Evaluation of emission toxicity of urban bus engines: compressed natural gas and comparison with liquid fuels. Sci Total Environ Vol.355 (2006): 64e-77.

46. M.Sjeric, et.al., Modelling of early flame kernel growth towards a better understanding of cyclic combustion variability in SI engines, Energy conversion and Management, Vol. 103 (2015) :895-909

47. Heywood, J.B. Internal Combustion Engine Fundamentals. McGraw Hill. New York, USA, 1988.

48. N. Ozdor, M. Dulger, E. Sher, Cyclic variability in spark ignition engines: a literature survey. SAE Technical Paper No. 940987; 1994.

49. C.R. Stone, A.G. Brown, P. Beckwith, Cycle-by-cycle variations in spark ignition engine combustion - Part II: Modelling of flame kernel displacements as a cause of cycle-by-cycle variations, SAE Paper no. 960613; 1996.

50. Galloni, Enzo. Analyses about parameters that affect cyclic variation in a spark ignition engine. J.Applied Thermal Engineering. Vol.29 (2009): 1131-1137. 
51. Reyes M, Tinaut FV, Gimenez B, Perez A. Characterization of cycle-to-cycle variations in a natural gas spark ignition engine, 2015.

52. Kaleli Aliriza, et.al. Controlling spark timing for consecutive cycles to reduce the cyclic variations of SI engines. J.Applied Thermal Engineering, Vol.87 (2015): 624-632.

53. Ji Shaobo., et.al. Cyclic variation of large-bore multi point injection engine fuelled by natural gas with different types of injection systems. J. Applied Thermal Engineering Vol.102 (2016) :1241-1249.

54. Ma F, Ding S, Wang Y, Wang Y, Wang J, Zhao S. Study on combustion behaviors and cycleby-cycle variations in a turbocharged lean burn natural gas S.I. engine with hydrogen enrichment. Int J Hydrogen Energy, 2008.

55. Wang J, Chen H, Liu B, Huang Z. Study of cycle-by-cycle variations of a spark ignition engine fueled with natural gas hydrogen blends. Int J Hydrogen Energy Vol. 33 (2008): 487683.

56. Huang B, Hu E, Huang Z, Zheng J, Liu B, Jiang D. Cycle-by cycle variations in a spark ignition engine fueled with natural gas hydrogen blends combined with EGR. Int J Hydrogen Energy, 2009

57. B. Johansson, Cycle to cycle variations in SI engines - the effects of fluid flow and gas composition in the vicinity of the spark plug on early combustion, SAE Paper no. 962084; 1996.

58. N. Ozdor, M. Dulger, E. Sher, Cyclic variability in spark ignition engines. a literature survey, SAE Paper no. 940987; 1994.

59. T.A. Baritaud, Optical and numerical diagnostic for SI engine combustion studies, Proceedings of International Symposium COMODIA, 1994.

60. N. Ozdor, M. Dulger, E. Sher, Cyclic Variability in Spark Ignition Engines a Literature Survey, SAE Technical Paper, 1994

61. F. Matekunas, Modes and Measures of Cyclic Combustion Variability, 1983

62. B. Johansson, Cycle to cycle variations in SI engines - the effects of fluid flow and gas composition in the vicinity of the spark plug on early combustion, SAE Paper no. 962084; 1996.

63. P.G. Hill, Cyclic variation and turbulence structure in spark-ignition engines, Combustion and Flame Vol. 72 (1988) :73-89

64. M.B. Young, Cyclic dispersion in the homogeneous-charge spark-ignition - a literature survey, SAE Paper no. 810020; 1981. 
65. N. Nedunchezhian, S. Dhandapani, Experimental investigation of cyclic variation and combustion phases in a lean-burn, two-stroke SI engine, SAE Paper no. 2001-28-0059; 2001.

66. K. Kampanis, C. Arcoumanis, R. Kato, S. Kometani, Flow, combustion and emissions in a five-valve research engine, SAE Paper no. 2001-01-3556; 2001.,

67. Pischinger.S and Heywood, J.B. How Heat Losses to the Spark Plug Electrodes Affect Flame Kernel Development in an SI-Engine. SAE Publication J.Engines; 1990.

68. Miles, C.Paul .The history and evolution of optically accessible research engines and their impact on our understanding of engine combustion. Proceedings of the ASME 2014 IC Engine Division Fall Technical Conference, (2014) IN, USA.

69. Bowditch, F.W. Cylinder and Piston Assembly.US Patent App 2,919,688.

70. Bowditch F.W. A New Tool for Combustion Research a Quartz Piston Engine. SAE Technical paper 610002; 1961.

71. Withrow, L. and Rassweiler,G.M., Absorption Spectra of Gaseous Charges in a Gasoline Engine. Industrial and Engineering Chemistry Vol.23 (7): 923-931.

72. Nakanishi,K, et.al. The effects of charge dilution on combustion and its improvement- flame photograph study. SAE Technical paper 750054; 1975.

73. Heywood, J.B. and Gatokowski, J.A. Flame Photographs in a Spark Ignition Engine. Combustion and Flame, Vol 56 (1984): 71-81.

74. Namazian.M., Hansen.S., Lyford-Oike,E., Sanchez-Barsse,J., Heywood,J., and Rifle, J. SAE Transation Paper 800044 , Vol 89 (1980).

75. Miles, P.C., Green, R.M., and Witze, P.O. In-cylinder gas velocity measurements comparing crankcase and blower scavenging in a fired two-stroke cycle engine. SAE Technical Paper $940401 ; 1994$.

76. Steeper, R.R. and Stevens, E.J. Characterization of Combustion, Piston Temperature, Fuel Sprays and Fuel Air Mixing in a DISI optical engine. SAE Technical paper 2000-01-2900; 2000.

77. Bates, S.C. A Transparent Engine for Flow and Combustion Visualization Studies. SAE Technical paper 880520; 1988.

78. Allen, J., Simms, A., et.al. An advanced optically accessed single cylinder research and development engine for fuel/air mixing and combustion diagnostics. Proceedings of the $15^{\text {th }}$ Internal Combustion Engine Smposium, No.9936102 (1999): 595-600.

79. Fuyoto,T., Matsumoto, T., et.al. A new generation of optically accessible single cylinder engines for high speed and high load combustion analysis. SAE Int. J.Fuels Lubricants Vol.5 (2011): 307-315. 
80. Proteus single cylinder research engine No.102. Instruction and Operating Manual. 1986.

81. Photron Fastcam SA5, Hardware Manual, Revision 1.00E (US/EU), Photron Limited. May 2009

82. Justham,T. Cyclic variation in the flow field behavior within a direct injection spark ignition engine: a high speed digital particle image velocimetry study. Doctoral thesis, Loghborough University (2010).

83. U.S.E.PA. Electronic Code of Federal Regulations Title 40 Part 1065. Retrieved from http://www.ecfr.gov/cgi-bin/text-idx?tpl=/ecfrbrowse/Title40/40cfr1065_main_02.tpl [Accessed on July 10, 2016].

84. Non-dispersive Infrared analyzer (NDIR) module, Horiba Limited, 1999.

85. FID Hydrocarbon analyzer module, Rosemount Analytical. 2006

86. CLD NO/NO analyzer module, Rosemount Analytical, 2006.

87. Center for Alternative Fuels, Engines and Emissions (2010). Raw emissions analyzer box plumbing schematic, West Virginia University, Morgantown.

88. E. Pipitone and A.Beccari. Determination of TDC in internal combustion engines by a newly developed thermodynamic approach. Appl. Therm. Eng. 30 (2010): 1914-1926.

89. M.Klein and L.Eriksson. Methods for cylinder pressure based compression ratio estimation. SAE Tech Paper 2006-01-0185; 2006.

90. M.Klein, L.Eriksson, J.Aslund. Compression ratio estimation based on cylinder pressure data. Control Eng. Pract Vol.14 (2006): 197-211.

91. V.T.Lamaris and D.T.Hountalas. Validation of a diagnostic method for estimating the compression condition of direct injection diesel engines. Proc. Inst. Mech. Eng. A.J. Power Energy Vol.224 (2010).

92. K.Sticker, L.Koecher, D.Vanalstine, G.M. Shaver. Estimation of effective compression ratio for engine utilizing flexible intake valve actuation”, Proc. Inst. Mech. Eng. D.J. Automob Eng. Vol.226 (2012).

93. K.Sticker, L.Kocher, E.Koeberlein, D.Vanalstine, G.M. Shaver. Input observer convergence and robustnesss: application to compression ratio estimation. Control Eng. Pract. Vol.21 (2012) :565-582

94. A.Irimescu, C.Tornatore, L.Marchitto and S.Merola. Compression ratio and blow by rates estimation based on motored pressure trace analysis for an optical spark ignition engine. Appl.Therm. Eng. Vol.61 (2013): 101-109.

95. M.Cerit and H.S. Soyhan. Thermal analysis of a combustion chamber surrounded by deposits in an HCCI engine. Appl. Therm. Eng. Vol.50 (2013): 81-88. 
96. K. Lee, M. Yoon, M. Sunwoo. A study on pegging methods for noisy cylinder pressure signal, Control Engineering Practice Vol.16 (2008): 922-929.

97. F. Payri, A. Broatch, B. Tormos, V. Marant. New methodology for in-cylinder pressure analysis in direct injection diesel engines - application to combustion noise, Measurement Science and Technology Vol.16 (2005): 540-547.

98. F. Payri, J.M. Lujan, J. Martin, A. Abbad. Digital signal processing of in-cylinder pressure for combustion diagnosis of internal combustion engines, Mechanical Systems and Signal Processing Vol.24 (2010): 1767-1784.

99. R.K.Maurya, D.D.Pal and A.K.Agarwal. Digital signal processing of cylinder pressure data for combustion diagnostics of HCCI engine, Mechanical Systems and Signal Processing Vol.36 (2013): 95-109.

100. T.Thurnheer and P.Soltic. The polytropic volume method to detect engine events based on the measured cylinder pressure. Control Eng. Pract Vol.20 (2012): 293-99.

101. G.Woschini. A universally applicable equation for the instantaneous heat transfer coefficient in the internal combustion engine” SAE Tech Paper 670931 ;1967.

102. Heywood,J.B., Higgins,J.M., Watts, P.A., and Tabaczynski, R.J. Development and use of a cycle simulation to predict SI engine efficiency and NOx emissions. SAE paper 710159 ;1979.

103. Dreizler,A., Lindenmaeir,S., Maas,U., Hult,J., et.al. Characterisation of a spark ignition system by planar laser-induced fluorescence of $\mathrm{OH}$ at high repitition rates and comparison with chemical kinetics calculations. Vol. 70 (2000) :287-294.

104. B. Renou and A. Boukhalfa. An experimental study of freely propagating premixed flames at various Lewis numbers, Combust. Sci. Technol. Vol. 162 (2001) :347-370.

105. Kaminski, F.C., Hult, J., Alden,M., et.al. Spark ignition of turbulent methane/air mixtures revealed by time resolved planar laser-induced fluorescence and direct numerical simulations. Proceedings of the Combustion Institute. Vol.28 (2000) :399-405.

106. Gautam.T.Khalgatgi. Early Flame Development in a Spark Ignition Engine, Combustion and Flame Vol.60 (1985) :299-308.

107. Curry, S. A three dimensional study of flame propagation in spark ignition engine. SAE Transactions Vol. 71(1963) :628-650.

108. Harrow, G. A., Orman, P. L., and Toft, G. B., J. Inst. Petroleum (1975) :49-204.

109. Lancaster, D. R., Krieger, R. B., Sorenson, S. C., and Hull, W. L., SAE Paper No. 760160; 1976. 
110. De Soete, G. C. Propagation behavior of spark ignited flames in the early stages. Proc. Int. Conf. Combustion and Engineering, I. Mech. E. 1983.

111. Abraham,J., Forman,A. and Bracco, F.V. A discussion of turbulent flame structure in Premixed charges. SAE Paper No. 850354; 1985.

112. L.Gillespie, et.al. Aspects of Laminar and Turbulent Burning Velocity Relevant to SI Engines. SAE Technical Paper 2000-01-0192; 2000.

113. Bradley, D., Hicks, R.A., Lawes, M., Sheppard, C.G.W. and Woolley, R. The measurement of laminar burning velocities and Markstein numbers for isooctane-air and iso-octane-nheptane-air mixtures at elevated temperatures and pressures in an explosion bomb. Combustion and Flame. Vol.115 (1998): 126-144.

114. Kwon, S., Tseng, L.-K, and Faeth, G.M. Laminar burning velocities and transition to unstable flames in $\mathrm{H}_{2} / \mathrm{O}_{2} / \mathrm{N}_{2}$ and $\mathrm{C}_{3} \mathrm{H}_{8} / \mathrm{O}_{2} / \mathrm{N}_{2}$ mixtures. Combustion and Flame. Vol.90 (1992): 230-246.

115. Palm-Leis, A. and Strehlow, R.A. On the propagation of turbulent flames, Combustion and Flame, Vol.13 (1969): 111-129.

116. Metghalchi, M. and Keck, J.C. Laminar burning velocity of propane-air mixtures at high temperature and pressure. Combustion and Flame Vol.38 (1980): 143-154.

117. Lewis, B. and Von Elbe, G. Combustion, flames and explosions of gases, 3rd Ed. Academic Press Inc. London, 1984.

118. Karpov, V.P. and Severin, E.S. Combustion Explosion \& Shock Waves, (1980): 16-41.

119. Lancaster, D.R., Krieger, R.B., Sorenson, S.C. and Hull, W.L. Effects of turbulence on spark ignition engine combustion, SAE paper $760160 ; 1976$.

120. Lipatnikov, A. and Chomiak, J. Effects of turbulence length scale on flame speed: a modelling study, Engineering Turbulence Modelling and Experiments $4^{\text {th }}$ Ed. Elsevier, 1999.

121. Becker, H., Arnold, A., Suntz, R., Monkhouse, P.,Wolfrum, J., Maly, R., and Pfister, W., Appl. Phys. B Vol.50 (1990): 473-78.

122. C.Xiouris, T.Ye, J.Jayachandran, F.N.Egolfopoulos. Laminar flame speeds under enginerelevant conditions: Uncertainity quantification and minimization in spherically expanding flame experiments. Combustion and Flame Vol. 163 (2016): 270-283.

123. Bradley D, Lau AKC, Lawes M. Flame stretch rate as a determinant of turbulent burning velocity. Philosophical Transactions R. Soc. Lond. A: Physical Sciences and Engineering. Vol. 338 (1992): 359-387. 
124. J. Vancoillie, J. Demuynck, L. Sileghem, M. Van De Ginste, S. Verhelst , L. Brabant et al. The potential of methanol as a fuel for flex-fuel and dedicated spark-ignition engines. Appl. Energy Vol.102 (2013): 140-149.

125. X. Wu , Q. Li , J. Fu , C. Tang, Z. Huang, R. Daniel, et al. Laminar burning characteristics of 2,5-dimethylfuran and iso-octane blend at elevated temperatures and pressures. J.Fuel Vol.95 (2012): 234-240.

126. X. Wu , Z. Huang, X. Wang, C. Jin , C. Tang, L. Wei , et al. Laminar burning velocities and flame instabilities of 2,5-dimethylfurane-air mixtures at elevated pressures. Combustion and Flame Vol.158 (2011): 539-546.

127. P. Brequigny, G. Dayma, F. Halter , C. Mounaïm-Rousselle , T. Dubois , P. Dagaut. Laminar burning velocities of premixed nitromethane/air flames: an experimental and kinetic modeling study, Proc. Combust. Inst. Vol.35 (2014): 703-710.

128. P. Brequigny, F.Halter, et.al. Fuel performances in Spark Ignition (SI) engines: Impact of flame stretch, J. Combustion and Flame Vol.166 (2016): 98-112.

129. S.M. Candel, T.J. Poinsot. Flame stretch and the balance equation for the flame area, Combust. Sci. Technol. Vol.70 (1990): 1-15.

130. Aung, K. T., Tseng, L.K., Ismail, M.A. and Faeth G.M. Response to Comment by S. C. Taylor and D.B. Smith on Laminar Burning Velocities and Markstein Numbers of Hydrocarbon/Air Flames. Combustion \& Flame, Vol.109 (1995): 526-530.

131.F.A. Williams. A review of some theoretical considerations of turbulent flame structure, Agard Conference Procedings Vol.164 (1975).

132. B. Karlovitz, D.W. Denniston, D.H. Knapschaefer , F.E. Wells. Studies on turbulent flames, Symp. (Int.) Combust. Vol.4 (1953): 613-620.

133. G.H. Markstein. Non-steady flame propagation, Pergamon Press, 1964.

134. A.Bilgili (2015). Acceleration of Non-Equidiffusive Flames in Channels: Computational Simulations and Analytical Studies, West Virginia University, Morgantown, USA.

135. Akkerman and V. Bychkov, Turbulent flame and Darrieus-Landau instability in a three dimensional flow. Combust. Theory Modeling, 7 (2003): 767-794.

136. Davis, S.G., Quinard, J. and Searby, G. Combustion and Flame, Vol.130 (2002): 123-136.

137. V.Akkerman and V.Bychkov. Velocity of weakly turbulent flames of finite thickness, Combustion Theory and Modelling. Vol.9 (2005): 323-351.

138. Bradley, D., Gaskell, P.H. and Gu, X.J. Burning velocities, Markstein lengths and flame quenching for spherical methane-air flames: a computational study. Combustion and Flame Vol. 104 (1996): 176-198. 
139. Rallis, C.J. and Garforth, A.M. The determination of laminar burning velocity’, Proc. Energy Combust. Sci. Vol.6 (1980): 303-329.

140. Clavin, P. Dynamic Behaviour of Premixed Flame Fronts in Laminar and Turbulent Flows. Progress in Energy \& Combustion Science Vol. 11 (1985): 1-59.

141. Bradley, D. and Harper, C.M. The development of instabilities in laminar explosion flames', Combustion and. Flame Vol.99 (1994): 562-572.

142. Holmström K, Denbratt I. Cyclic variation in an SI engine due to the random motion of flame kernel. SAE technical paper 961152; 1996.

143. Stone CR, Brown AG, Beckwith P. Cycle-by-cycle variations in spark ignition engine combustion - Part II: modeling of flame kernel displacements as a cause of cycle-by-cycle variations. SAE technical paper 960613; 1996.

144. Chen H, Xu M, Hung DLS, Zhuang H. Cycle-to-cycle variation analysis of early flame propagation in engine cylinder using proper orthogonal decomposition. Exp Thermal Fluid Sci Vol. 58(2014) :48-55. 